\title{
The role of smooth muscle cells in calcification of atherosclerotic plaques
}

Citation for published version (APA):

Seime, T. (2021). The role of smooth muscle cells in calcification of atherosclerotic plaques. [Doctoral Thesis, Maastricht University, Karolinska Institutet, Stockholm]. Karolinska Institutet. https://doi.org/10.26481/dis.20211207ts

Document status and date:

Published: 01/01/2021

DOI:

$10.26481 /$ dis.20211207ts

Document Version:

Publisher's PDF, also known as Version of record

\section{Please check the document version of this publication:}

- A submitted manuscript is the version of the article upon submission and before peer-review. There can be important differences between the submitted version and the official published version of record.

People interested in the research are advised to contact the author for the final version of the publication, or visit the DOI to the publisher's website.

- The final author version and the galley proof are versions of the publication after peer review.

- The final published version features the final layout of the paper including the volume, issue and page numbers.

Link to publication

\footnotetext{
General rights rights.

- You may freely distribute the URL identifying the publication in the public portal. please follow below link for the End User Agreement:

www.umlib.nl/taverne-license

Take down policy

If you believe that this document breaches copyright please contact us at:

repository@maastrichtuniversity.nl

providing details and we will investigate your claim.
}

Copyright and moral rights for the publications made accessible in the public portal are retained by the authors and/or other copyright owners and it is a condition of accessing publications that users recognise and abide by the legal requirements associated with these

- Users may download and print one copy of any publication from the public portal for the purpose of private study or research.

- You may not further distribute the material or use it for any profit-making activity or commercial gain

If the publication is distributed under the terms of Article $25 \mathrm{fa}$ of the Dutch Copyright Act, indicated by the "Taverne" license above, 


\title{
VASCULAR SURGERY DIVISION, DEPARTMENT OF MOLECULAR MEDICINE AND SURGERY \\ Karolinska Institutet, Stockholm, Sweden
}

$\&$

CARDIOVASCULAR RESEARCH INSTITUTE MAASTRICHT, DEPARTMENT OF BIOCHEMISTRY Maastricht University, Maastricht, The Netherlands

\section{THE ROLE OF SMOOTH MUSCLE CELLS IN CALCIFICATION OF ATHEROSCLEROTIC PLAQUES}

\author{
Till Seime
}



All previously published papers were reproduced with permission from the publisher.

Published by Karolinska Institutet.

Printed by Universitetsservice US-AB, 2021

(C) Till Seime, 2021

ISBN 978-91-8016-409-2

Cover illustration: Immunofluorescent analysis of an advanced human carotid lesion revealed a sleepy baby dragon. 



\section{THE ROLE OF SMOOTH MUSCLE CELLS IN CALCIFICATION OF ATHEROSCLEROTIC PLAQUES THESIS FOR DOCTORAL DEGREE (Ph.D.)}

By

\section{Till Seime}

The thesis will be defended in public at Maastricht University, Maastricht, The Netherlands, December $7^{\text {th }} 2021$ at 10:00.

\section{Promotors:}

Prof. Leon J. Schurgers, PhD

Maastricht University

Department of Biochemistry

Cardiovascular Research Institute Maastricht

Prof. Ulf Hedin, MD, PhD

Karolinska Institutet

Department of Molecular Medicine and Surgery

Division of Vascular Surgery

Assoc. Prof. Ljubica Perisic Matic, PhD

Karolinska Institutet

Department of Molecular Medicine and Surgery

Division of Vascular Surgery
Assessment Committee:

Prof. Casper G. Schalkwijk, PhD

Maastricht University Medical Center

Department of Health, Medicine and Life Sciences

Prof. Paula da Costa Martins, PhD

Maastricht University

Department of Molecular Genetics

Assoc. Prof. Lars-Arne Haldosén, PhD

Karolinska Institutet

Department of Biosciences and Nutrition

Assoc. Prof. Sebastian Lewandowski, PhD

Karolinska Institutet

Department of Clinical Neuroscience

Prof. Anders Malmström, PhD

Lund University

Department of Experimental Medical Science

Prof. Anna Hultgårdh-Nilsson, $\mathrm{PhD}$

Lund University

Department of Experimental Medical Science

The research presented in this dissertation was funded with a grant from European Union's Horizon 2020 research and innovation program under the Marie Skłodowska-Curie grant (agreement No 722609), INTRICARE 


\section{THE ROLE OF SMOOTH MUSCLE CELLS IN CALCIFICATION OF ATHEROSCLEROTIC PLAQUES THESIS FOR DOCTORAL DEGREE (Ph.D.)}

By

\section{Till Seime}

The thesis will be defended in public at Rolf Luft centrum L1:00, Anna Steckséns Gata 53, Karolinska Universitetssjukhuset, Solna. December 9 ${ }^{\text {th }}, 2021$ at 09:00.

Principal Supervisor:

Prof. Ulf Hedin, MD, PhD

Karolinska Institutet

Department of Molecular Medicine and Surgery

Division of Vascular Surgery

Co-supervisor:

Assoc. Prof. Ljubica Perisic Matic, PhD

Karolinska Institutet

Department of Molecular Medicine and Surgery

Division of Vascular Surgery

Co-supervisor:

Prof. Leon J. Schurgers, PhD

Maastricht University

Department of Biochemistry

Cardiovascular Research Institute Maastricht

Co-supervisor:

Prof. Chris Reutelingsperger, $\mathrm{PhD}$

Maastricht University

Department of Biochemistry

Cardiovascular Research Institute Maastricht
Opponent:

Assoc. Prof. Jordan D. Miller, PhD

Mayo Clinic

Department of Surgery, Physiology \& BME

Division of Cardiovascular Surgery

Examination Board:

Assoc. Prof. Lars-Arne Haldosén, PhD

Karolinska Institutet

Department of Biosciences and Nutrition

Prof. Anders Malmström, PhD

Lund University

Department of Experimental Medical Science

Assoc. Prof. Sebastian Lewandowski, PhD

Karolinska Institutet

Department of Clinical Neuroscience

Chair:

Assoc. Prof. Joy Roy, MD, PhD

Karolinska Institutet

Department of Molecular Medicine and Surgery

Division of Vascular Surgery

The research presented in this dissertation was funded with a grant from European Union's Horizon 2020 research and innovation program under the Marie Skłodowska-Curie grant (agreement No 722609), INTRICARE 
"Jede wirkliche Geschichte ist eine unendliche Geschichte." "Every real story is a never ending story." — Michael Ende, Die unendliche Geschichte 
"C'est le temps que tu as perdu pour ta rose qui fait ta rose si importante."

"It is the time you have wasted for your rose that makes your rose so important."

— Antoine de Saint-Exupéry, Le Petit Prince 


\section{ABSTRACT}

Calcification (CALC) is a predominant feature of late-stage cardiovascular disease (CVD) but responsible mechanisms and its contribution to the risk of clinical events remain unclear. Formation of highly mineralized extracellular matrix (ECM) leads to progressive aortic valve stenosis (AVS) and has been identified as a surrogate marker for atherosclerotic disease burden. However, we previously found enrichment of genes associated with CALC in atherosclerotic carotid lesions from asymptomatic patients and in patients on statin therapy. This thesis aimed to investigate how CALC correlates with gene expression profiles in human specimens of carotid plaques as well as AVS and functionally characterize the underlying mechanisms associated to osteogenic phenotypic transformation of structural cells.

Study I explored gene expression profiles and biological pathways related to macro-CALC in human carotid lesions, estimated by computed tomography (CT). Microarray profiling, bioinformatic analysis and histological validation based on high- $v s$ low-CALC plaques revealed upregulation of smooth muscle cell (SMC) markers in high-CALC plaques, whereas macrophage markers were downregulated. The most enriched processes in high-CALC plaques were related to SMC differentiation and ECM organization, while inflammation, lipid transport and chemokine signaling were repressed. Proteoglycan 4 (PRG4) was identified as the most upregulated gene in association with plaque CALC and found in the ECM overlapping with SMA, CD68 and tartrate-resistant acid phosphatase (TRAP) positive cells.

Study II characterized PRG4 in the context of AVS and aortic valve CALC. Transcriptomic, histological and immunohistochemical (IHC) analysis of human aortic valves from patients undergoing aortic valve replacement showed significant upregulation of PRG4 in thickened and CALC regions of aortic valves compared with healthy regions. In addition, $P R G 4$ positively associated with mRNA expression of proteins involved in cardiovascular CALC. Treatment of human valve interstitial cells (VICs) with recombinant human PRG4 (rhPRG4) enhanced phosphate (Pi) induced CALC and increased bone morphogenetic protein 2 (BMP2) expression.

Study III analyzed the role of PRG4 in vascular remodeling and intimal CALC. PRG4, detected by IHC, localized to SMCs in early human intimal thickening, while in advanced lesions it was found in the ECM, surrounding macro-CALC. In vivo mouse and rat models showed increased Prg4 expression in SMCs during intimal hyperplasia, correlating with osteogenic markers and transforming growth factor $\beta(T g f \beta)$. Moreover, PRG4 was enriched around intimal plaque CALC in apolipoprotein $\mathrm{E}$ deficient mice $\left(\mathrm{ApoE}^{-/}\right)$on warfarin. In vitro, $P R G 4$ was induced in primary human vascular SMCs by TGF $\beta$ and calcifying conditions, while SMC markers were repressed. Silencing experiments showed that $P R G 4$ expression was driven by transcription factors mothers against decapentaplegic homolog 3 (SMAD3) and SRY-box transcription factor 9 (SOX9). The addition of rhPRG4 increased ectopic SMC calcification, while arresting cell migration, proliferation and osteogenic transformation.

Study IV assessed the influence of biomechanical forces, related to atherosclerotic carotid macro-CALC, on SMC phenotype and plaque stability. Finite element modeling (FEM), based on preoperative $\mathrm{CT}$ images, identified that biomechanical stretch was significantly reduced in close proximity to macro-CALC, while pathologically increased levels were observed within distant soft tissues. In vitro modeling of these conditions revealed upregulation of markers for SMC differentiation and contractility under low stretch but also impeded SMC alignment and increased osteogenic transdifferentiation. In contrast, high-stretch in combination with calcifying conditions induced rapid SMC apoptosis, suggesting a contribution to atherosclerotic plaque stabilization by the load-bearing capacities of macro-CALC.

Overall, this thesis demonstrates that vascular disease pathology related to CALC can be comprehensively described by linking clinical diagnostics and underlying biological processes via in silico analysis, thereby contributing to the basic understanding of disease progression and patient specific phenotypic variability. 


\section{LIST OF SCIENTIFIC PAPERS}

I. Karlöf E, Seime T, Dias N, Lengquist M, Witasp A, Almqvist H, Kronqvist M, Gådin JR, Odeberg J, Maegdefessel L, Stenvinkel P, Matic LP, Hedin U. Correlation of computed tomography with carotid plaque transcriptomes associates calcification with lesion-stabilization. Atherosclerosis. 2019 Sep;288:175-185.

II. Artiach $\mathrm{G}^{*}$, Carracedo $\mathrm{M}^{*}$, Seime T, Plunde O, Laguna-Fernandez A, Matic L, Franco-Cereceda A, Bäck M. Proteoglycan 4 is Increased in Human Calcified Aortic Valves and Enhances Valvular Interstitial Cell Calcification. Cells. 2020 Mar 11;9(3):684.

III. Seime T, Akbulut AC, Liljeqvist ML, Siika A, Jin H, Winski G, van Gorp RH, Karlöf E, Lengquist M, Buckler AJ, Kronqvist M, Waring OJ, Lindeman JHN, Biessen EAL, Maegdefessel L, Razuvaev A, Schurgers LJ, Hedin U, Matic L. Proteoglycan 4 Modulates Osteogenic Smooth Muscle Cell Differentiation during Vascular Remodeling and Intimal Calcification. Cells. 2021 May 21;10(6):1276.

IV. Seime T, van Wanrooji M, Karlöf E, Johansson S, Matic L, Gasser T.C, Hedin U. Biomechanical assessment of macro-calcification in human carotid atherosclerosis and its impact on smooth muscle cell phenotype. Manuscript.

* authors contributed equally 


\section{OTHER RELATED PUBLICATIONS}

I. Röhl S, Suur BE, Lengquist M, Seime T, Caidahl K, Hedin U, Arner A, Matic L, Razuvaev A. Lack of PCSK6 Increases Flow-Mediated Outward Arterial Remodeling in Mice. Cells. 2020 Apr 18;9(4):1009.

II. Röhl S*, Rykaczewska U*, Seime T*, Suur B.E, GonzalezDiez M, Gådin J.R, Gainullina A, Sergushichev A.A, Wirka R, Lengquist M, Kronqvist M, Bergman O, Odeberg J, Lindeman J.H.N, Quertermous T, Hamsten A, Eriksson P, Hedin U, Razuvaev A, Perisic Matic L. Transcriptomic profiling of experimental arterial injury reveals new mechanisms and temporal dynamics in vascular healing response. J Vasc Surg-Vasc Sci 2020, 10.1016/j.jvssci.2020.01.001.

* authors contributed equally 



\section{CONTENTS}

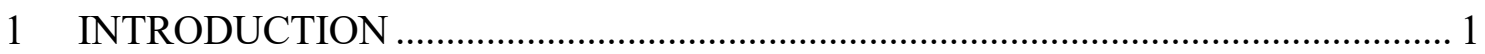

1.1 Cardiovascular disease - biggest killer worldwide ....................................

1.1.1 Epidemiology and risk factors........................................................2

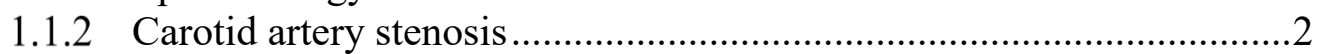

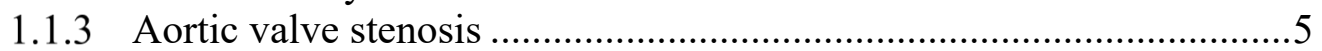

1.1.4 Current clinical praxis .............................................................. 6

1.2 VSMC and VIC plasticity - vascular chamaeleons ...................................10

1.3 Vascular calcification - bones in arteries and valves ...................................12

1.3.1 Molecular mechanisms of vascular calcification .............................12

1.3.2 Lessons learned from bone biology .................................................13

1.3.3 Proteoglycan 4 and other important proteoglycans ..........................15

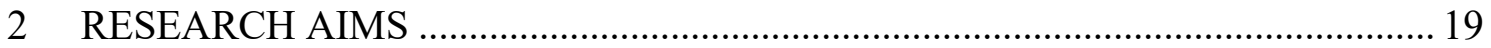

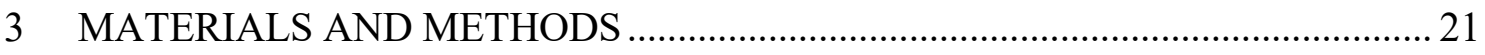

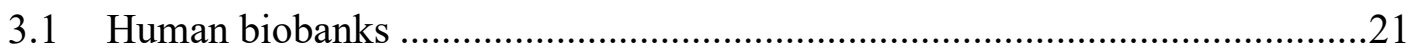

3.2 In silico CTA image analysis and biomechanical modeling..........................22

3.3 In vivo models of osteogenic transformation and calcification......................23

3.4 In vitro models of osteogenic transformation and calcification.....................25

3.5 In vitro models of tissue stretch ..................................................................26

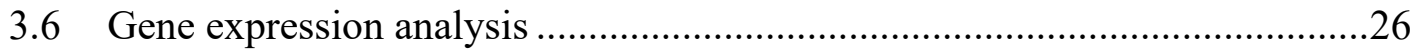

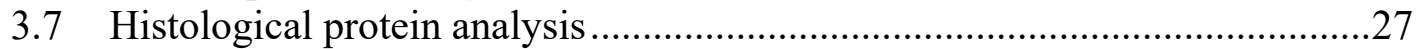

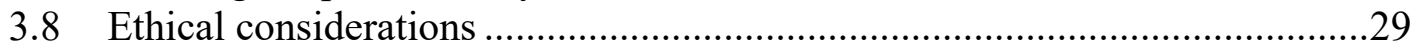

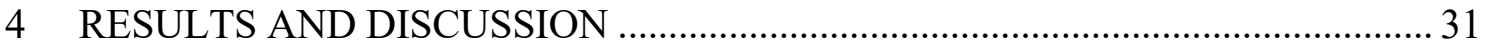

4.1 Macro-calcification relates to stabilizing biological pathways in late-stage carotid lesions

4.2 Formation of intimal and valvular macro-calcification is marked by

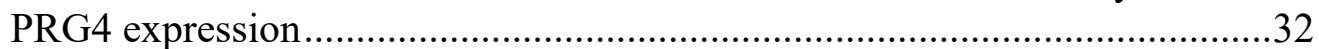

4.3 PRG4 expression is dependant on SMC and VIC osteogenic phenotypic

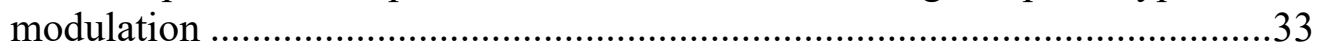

4.4 Extracellular PRG4 counteracts SMC migration and dedifferentiation...........34

4.5 Macro-calcification exerts load-bearing capacities in human carotid

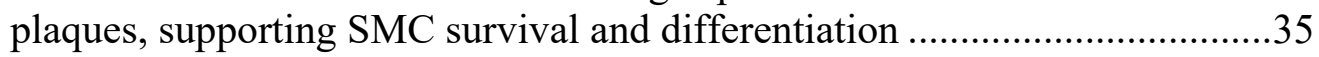

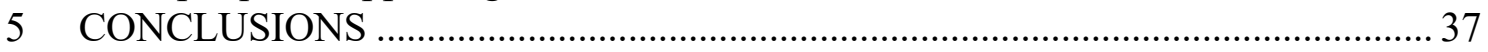

6 SOCIETAL IMPACT AND RESEARCH PERSPECTIVE …..................................... 39

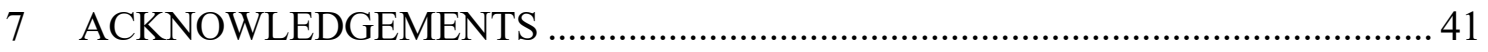

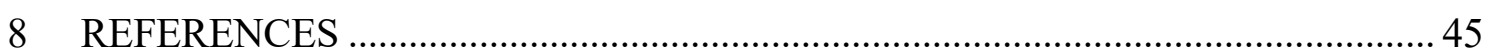

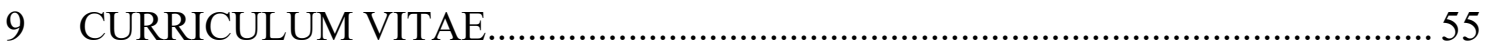




\section{LIST OF ABBREVIATIONS}

\begin{tabular}{|c|c|}
\hline ACAN & Aggrecan \\
\hline ACTA2 & Actin \\
\hline ApoE & Apolipoprotein E \\
\hline $\mathrm{ApoE}^{-/-}$ & Apolipoprotein E deficient mouse \\
\hline AVA & Aortic valve area \\
\hline AVS & Aortic valve stenosis \\
\hline BAV & Bicuspid aortic valve \\
\hline $\mathrm{BiKE}$ & Biobank of Karolinska endarterectomies \\
\hline BMP & Bone morphogenic protein \\
\hline BMPR2 & Bone morphogenic protein receptor type 2 \\
\hline $\mathrm{Ca}$ & Calcium \\
\hline $\mathrm{CaPi}$ & Calcium-phosphate \\
\hline CAC & Coronary artery calcification \\
\hline CALC & Calcification \\
\hline CASP3 & Caspase 3 \\
\hline CEA & Carotid endarterectomy \\
\hline CKD & Chronic kidney disease \\
\hline $\mathrm{CNN}$ & Calponin \\
\hline $\mathrm{CT}$ & Computed tomography \\
\hline $\mathrm{Ct}$ & Cycle threshold \\
\hline CTA & Computed tomography angiography \\
\hline CVD & Cardiovascular disease \\
\hline DMP1 & Dentin matrix acidic phosphoprotein 1 \\
\hline $\mathrm{EC}$ & Endothelial cell \\
\hline $\mathrm{ECM}$ & Extracellular matrix \\
\hline ECST & European carotid surgery trial \\
\hline EV & Extracellular matrix vesicle \\
\hline FEM & Finite element modeling \\
\hline FGF & Fibroblast growth factor \\
\hline $\mathrm{FH}$ & Familial hypercholesterolemia \\
\hline GAG & Glycosaminoglycan \\
\hline GH & Growth hormone \\
\hline GWAS & Genome wide association studies \\
\hline HDL & High-density lipoprotein \\
\hline HPRT & Hypoxanthine phosphoribosyltransferase 1 \\
\hline
\end{tabular}


Hounsfield unit

IBSP

Integrin binding sialoprotein

ICAM-1

Intracellular cell adhesion molecule 1

IF

Immunofluorescence

IGF

Insulin-like growth factor

IHC

Immunohistochemistry

$\mathrm{IHH}$

Indian hedgehog

HSPG2

Perlecan

IL

Interleukin

IPH

Intraplaque hemorrhage

ITGAM

Integrin subunit alpha $\mathrm{M}$

LDL

Low-density lipoprotein

$\mathrm{Ldlr}^{-/-}$

Low-density lipoprotein receptor deficient mouse

LMOD1

Leiomodin 1

LRNC

Lipid rich necrotic core

MATX

Matrix component

MGP

Matrix gla protein

MI

Myocardial infarction

MMP

Matrix metalloproteinase

MRI

Magnetic resonance imaging

MYH11

Myosin heavy chain 11

MYOCD

Myocardin

NASCET

North American symptomatic carotid endarterectomy trial

OPG

Osteoprotegrin

OPN

Osteopontin

OSX

Osterix

oxLDL

Oxidized low-density lipoprotein

PCR

Polymerase chain reaction

PCSK9

Proprotein convertase subtilisin/kexin type 9

PDLIM7

PDZ and LIM domain protein 7

PG

Proteoglycan

Pi

Phosphate

PTH

Parathyroid hormone

qPCR

Quantitative real-time polymerase chain reaction

RANKL

Receptor activator af nuclear factor kappa B ligand

rhPRG4

Full length recombinant human PRG4 
ROS

RPLP0

RUNX2

SM22 $\alpha$

SMA

SMAD3

SMC

SNP

SMTN

SOX9

T3

TGF $\beta$

TIA

TLR

$\mathrm{TNF} \alpha$

TRAP / ACP5

US

$\mathrm{VC}$

VCAM-1

VEC

VIC

WT
Reactive oxygen species

Ribosomal Protein Lateral Stalk Subunit P0

Runt-related transcription factor 2

Smooth muscle cell protein $22 \alpha$

Smooth muscle alpha actin

Mothers against decapentaplegic homolog 3

Smooth muscle cell

Single nucleotide polymorphism

Smoothelin

SRY-box transcription factor 9

Tri-iodothyronine

Transforming growth factor $\beta$

Transitory ischemic attacks

Toll-like receptor

Tumor necrosis factor $\alpha$

Tartrate-resistant acid phosphatase

Ultrasound

Vascular calcification

Vascular cell adhesion molecule 1

Valvular endothelial cell

Valvular interstitial cell

Wild-type 


\section{LIST OF ILLUSTRATIONS}
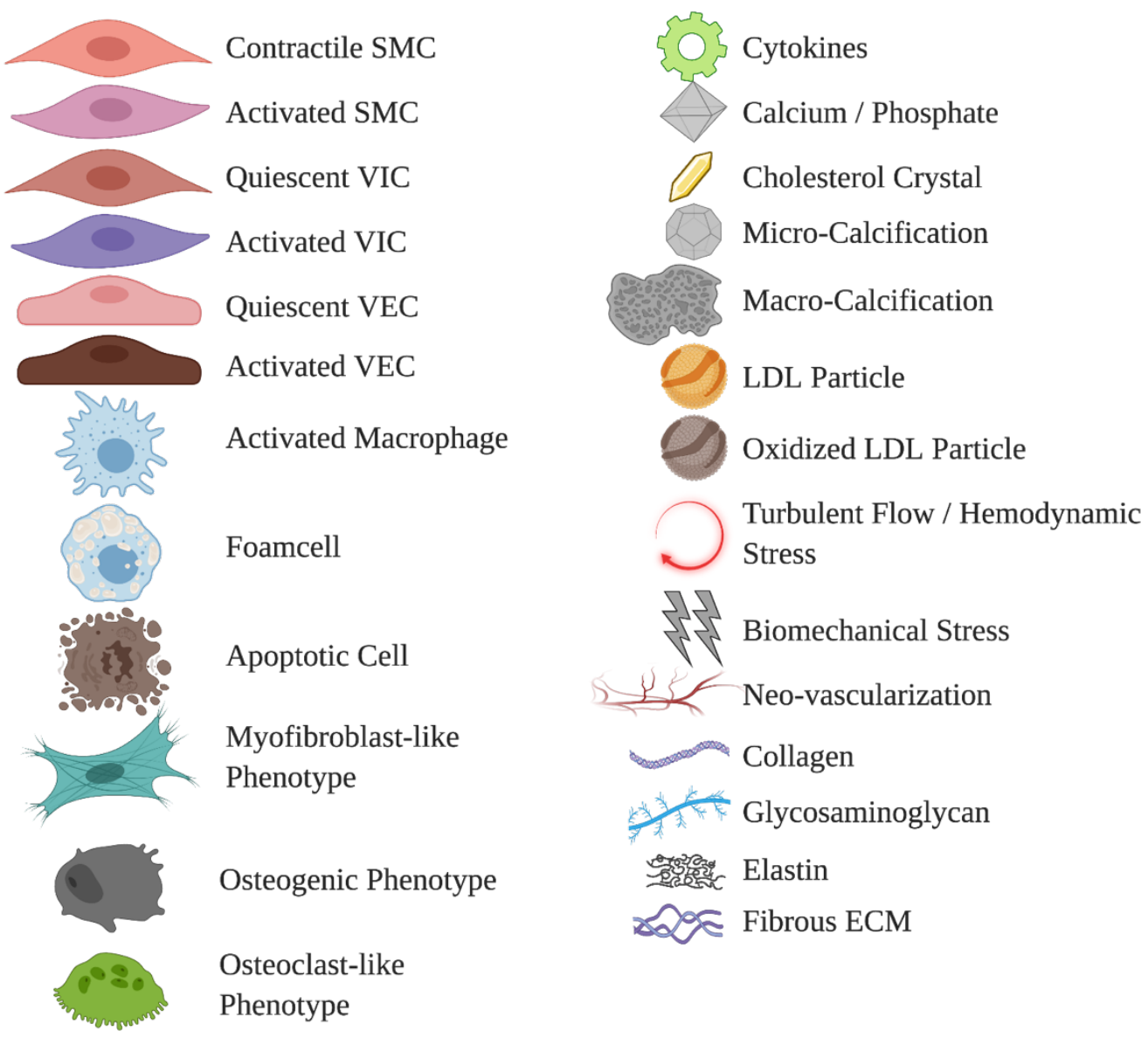



\section{INTRODUCTION}

\subsection{CARDIOVASCULAR DISEASE - BIGGEST KILLER WORLDWIDE}

The term CVD describes a variety of conditions affecting the heart and blood vessels, such as rheumatic and congenital heart disease, coronary and peripheral artery disease, cerebrovascular disease (e.g. carotid artery stenosis), AVS and aortic aneurysm (Figure 1A). However, population-based studies could attribute many of these medical conditions to one major underlying pathology, atherosclerosis ${ }^{2}$.

Atherosclerosis is a systemic disease of large and medium sized arteries that manifests itself in the form of vessel wall thickening (stenosis) with increasing accumulation of lipids and fibrous tissue $^{3}$ (Figure 1B). Maladaptation of the immune system response, normally required to reestablish vascular homeostasis, generates chronic cardiovascular inflammation further contributing to disease progression ${ }^{4}$. Early atherosclerotic lesions have been discovered to form already during teenage years ${ }^{5}$ but often remain asymptomatic for a long time making complications caused by occlusion, plaque rupture and consequential thrombus formation increasingly prevalent among the elderly ${ }^{6-8}$.

A

B

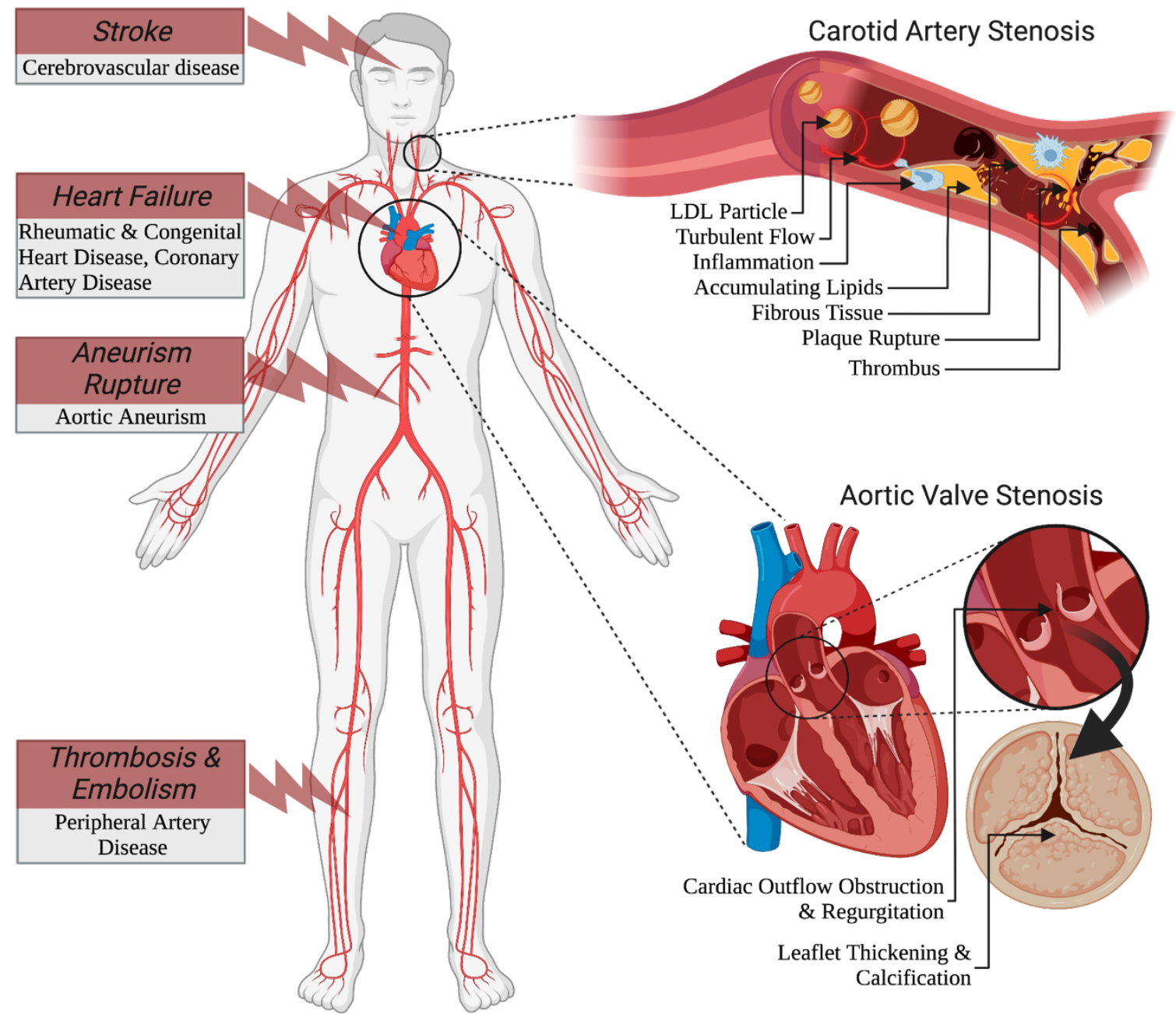

Figure 1: Systemic impact of CVD. (A) CVD pathologies affect the whole human body and are a major cause of multiple fatal complications, such as stroke, heart failure and aneurysm rupture. (B) Two common manifestations are atherosclerotic carotid artery stenosis and aortic valve stenosis. 


\subsubsection{Epidemiology and risk factors}

To date, CVD poses the foremost cause of global mortality accounting for more than $30 \%$ of all deaths worldwide, 4 million in Europe alone every year ${ }^{9-12}$. Symptomatic carotid artery stenosis causes an estimated $8-20 \%$ of all strokes ${ }^{10}$, affecting approximately $75 \%$ men and $62 \%$ women at 65 years and older ${ }^{6}$. Up to $7 \%$ of the same age group suffer from AVS, reaching a one-year mortality rate above $50 \%$ due to cardiac outflow obstruction in severe cases ${ }^{7,13}$.

Although knowledge of major risk factors like high blood pressure, cholesterol levels, smoking, physical inactivity, overweight, genetic predisposition and congenital disorders is increasing 9,14-16, lethal complications such as heart failure, stroke and aortic aneurysm rupture remain high. Moreover, prevalence of CVD is rising in developing countries due to population growth and increasing life span ${ }^{17}$.

An important factor inducing vascular remodeling and increasing risk of disease initiation are detrimental fluid mechanics in certain areas of the cardiovascular system. Narrow curvatures or branch points, e.g. at the coronary arteries, carotid bifurcations or aortic valve leaflets, create turbulent flow conditions causing constant biomechanical stress on the vessel wall over time 18,19. While increased biomechanical stress is compensated by vascular remodeling in young healthy individuals, it can lead to pathological hyperplasia when amplified by high blood pressure, physical inactivity and other risk factors.

In addition, a fatty "western-type" diet is considered to be one of the most common risk factors for CVD. Apolipoproteins (ApoA, ApoB, ApoC, ApoE) facilitate the formation of plasma lipoprotein particles within the bloodstream to transport lipids ${ }^{20}$. Many lipoprotein particles rich in ApoB (VLDL, IDL, LDL) are main drivers of CVD progression. Especially cholesterol-rich low-density lipoprotein particles (LDL) are associated with decreased nitric-oxide-synthase activity and consecutive endothelial dysfunction, preceding their entry and accumulation within the vessel wall ${ }^{21}$. However, lipids do not always exhibit the same atherogenic effects. High-density lipoproteins (HDL) mainly containing ApoA, have previously been attributed anti-oxidative and cholesterol-clearing properties, which lead to overall atheroprotective effects ${ }^{22,23}$.

Hereditary genetic disorders can cause major predisposition to develop CVD at young age. Extensive studies on patients with familial hypercholesterolemia $(\mathrm{FH})$ constitute the basis for our present understanding of the cholesterol metabolism as well as congenital malfunctions in LDL handling. Michael S. Brown and Joseph L. Goldstein received the Nobel prize in 1985 for their analysis of $\mathrm{FH}$ as a monogenic dominant trait. They found individuals who carried a homozygote mutation to have severely increased cholesterol levels (up to five times), while patients with a heterozygote genetic defect still showed elevated cholesterol levels (two to three times higher) compared to the normal population ${ }^{24}$. As a consequence, $\mathrm{FH}$ can cause severe atherosclerosis and coronary infarction already in adolescence. They further described that these clinical impacts were induced on a molecular level by a lack of functional LDL-receptors, severely impairing metabolism of circulating lipids ${ }^{25-28}$. The recent emergence of genome-wide association studies (GWAS) allowed for a more detailed comparison of genetic variants and revealed that single nucleotide polymorphisms (SNPs) and other mutations account for 30 to $60 \%$ of CVD susceptibility variation ${ }^{29,30}$. To date the majority of variants are implicated in lipid metabolism and inflammation, but several have been identified to also affect phenotypic changes of structural cells, like SMCs, regarding their contractility, migration and proliferation 31-33. These findings raised the hypothesis that SMCs together with disrupted lipid metabolism and chronic inflammation are causal drivers of CVD initiation.

\subsubsection{Carotid artery stenosis}

\subsubsection{The arterial wall under physiological conditions}

Healthy arteries are composed of three main layers: i) tunica intima directly exposed to the blood flow, ii) tunica media and iii) tunica adventitia ${ }^{34}$ (Figure 2). The luminal lining of the vessel wall (intima) is formed by a mono-layer of endothelial cells (ECs) adhering to a 
basement membrane mainly composed of collagen type IV, laminin and perlecan (HSPG2) ${ }^{35}$. ECs together with the basement membrane composition have been shown to support homeostasis by secreting factors inhibiting excessive SMC proliferation in the media, inflammatory infiltration and coagulation ${ }^{36,37}$. Mechanosensing ion channels, integrins and extensive glycocalyx make ECs highly flow responsive. Under laminar conditions they adapt an organized elongated pattern in flow direction, forming a tight non-thrombogenic surface to the blood circulation, only selectively permeable to cells and macro-molecules ${ }^{38}$. In contrast, turbulent flow, oscillatory shear stress and local hypoxia lead to poor "cobble-stone"-like alignment and secretion of pro-inflammatory and pro-migratory factors like vascular cell adhesion molecule 1 (VCAM-1), interleukin (IL) 8, platelet derived growth factor B (PDGF), TGF $\beta$ and other cytokines inducing vascular remodeling ${ }^{39,40}$. This activation of endothelial cells and further signaling, driving the vascular adaptation to changed shear conditions, is fundamentally controlled by nitric oxide (NO) generation 41,42 , previously known as endothelium-derived relaxing factor (EDRF). Robert F. Furchgott, Louis J. Ignarro and Ferid Murad were jointly awarded the Nobel Prize in 1998 for the description of this pathway in vasodilation. In addition to their role in regulating vascular tone, ECs have been suggested to contribute to inner elastic lamina formation by elastin secretion ${ }^{43}$. The inner elastic lamina separates intima from media, the dominating layer of muscular arteries like the common carotid. This layer is mainly formed by a circumferentially orientated, tightly linked network of contractile SMCs. Contractile SMCs display a differentiated state, expressing typical cytoskeletal markers such as smooth muscle alpha actin (SMA), myosin heavy chain 11 (MYH11) and smoothelin (SMTN) to actively distribute strain within the arterial wall and maintain the contractile tone. They establish a basement membrane network of similar composition and function as the intimal counterpart ${ }^{35}$. Nevertheless, SMCs retain the capacity of de-differentiating to a "synthetic" phenotype, characterized by proliferation, migration and expression of structural proteins and matrix degrading enzymes, relevant for ECM remodeling 44. This feature is crucial to adapt vessel compliance and regain homeostasis after vascular injury. Equally important for maintaining elasticity and providing general tissue strength is the medial ECM. However, while certain key components like collagens and proteoglycans show a higher turnover rate, being remodeled by SMCs and inflammatory cells, organized elastin fibers are generally considered to only be formed during development ${ }^{45}$. The outer elastic lamina marks the border between tunica media and adventitia. This collagen-rich surrounding layer mainly provides tensile strength to prevent overstretching of the vessel wall. However, large numbers of residing progenitor cells ${ }^{46,47}$, fibroblasts and immune cells as well as connection to the lymphatic and nervous system allow response to insults by fibrosis and inflammation ${ }^{48}$. In large vessels or cases of severe or chronic remodeling the adventitia can develop a substantial vasa vasorum $^{49}$.

\subsubsection{Initiation of carotid artery stenosis}

Despite rigorous scientific efforts to define key events causing pathological remodeling of the carotid artery, the sequence of disease initiation remains heavily debated. Nevertheless, three main factors were identified to interact, causing vessel wall destabilization and activation of other players involved during disease progression: hemodynamic shear stress, lipids and genetic predisposition. An interplay of EC activation by turbulent flow conditions, subsequent permeability for lipids and minerals as well as resulting proliferation and migration of SMCs causes adaptive intimal thickening ${ }^{50}$, one of the earliest indicators of atherosclerotic lesion formation ${ }^{41,51}$. Clinically, this vascular adaptation is measured by $\mathrm{B}$ mode ultrasound and widely adopted as a surrogate for the rate of CVD progression, called carotid intimal/medial thickness. Perhaps the most important limitation of this assessment arises from the general measurement acquisition in the common carotid artery, whereas advanced atherosclerotic disease occurs predominantly within the internal carotid. Moreover, the primary drivers of intimal/medial thickening appear to be of biomechanical nature, defined by age and hypertension, which do not necessarily reflect the full atherosclerotic process 52 . In atherosclerosis, prevailing disruption of the endothelial homeostasis causes permeability to LDL particles, that aggregate to intimal proteoglycans ${ }^{53-55}$. LDL particles trapped within the 
subintimal ECM have been shown to be oxidized by resident vascular cells ${ }^{56}$ and induce leukocyte adhesion on the endothelium as well as macrophage activation within the sub-intima 57. Oxidized LDL (oxLDL) particle overload leads to an accumulation of lipid-filled macrophages or so-called foam cells forming early manifestations of a lipid-rich core. These lesions are commonly referred to as xanthomas ${ }^{3,58,59}$ (Figure 2). Pro-inflammatory cytokine secretion and release of reactive oxygen species (ROS) by activated macrophages promote further LDL retention and activation of matrix metalloproteinases (MMPs), weakening the vessel wall matrix ${ }^{60,61}$. Studies on familial hypercholesterolemia confirmed the adverse effects of sustained high LDL plasma levels, provoking atherosclerotic lesion formation in form of lipid depositions within the subendothelial layers already at a young age ${ }^{62}$.

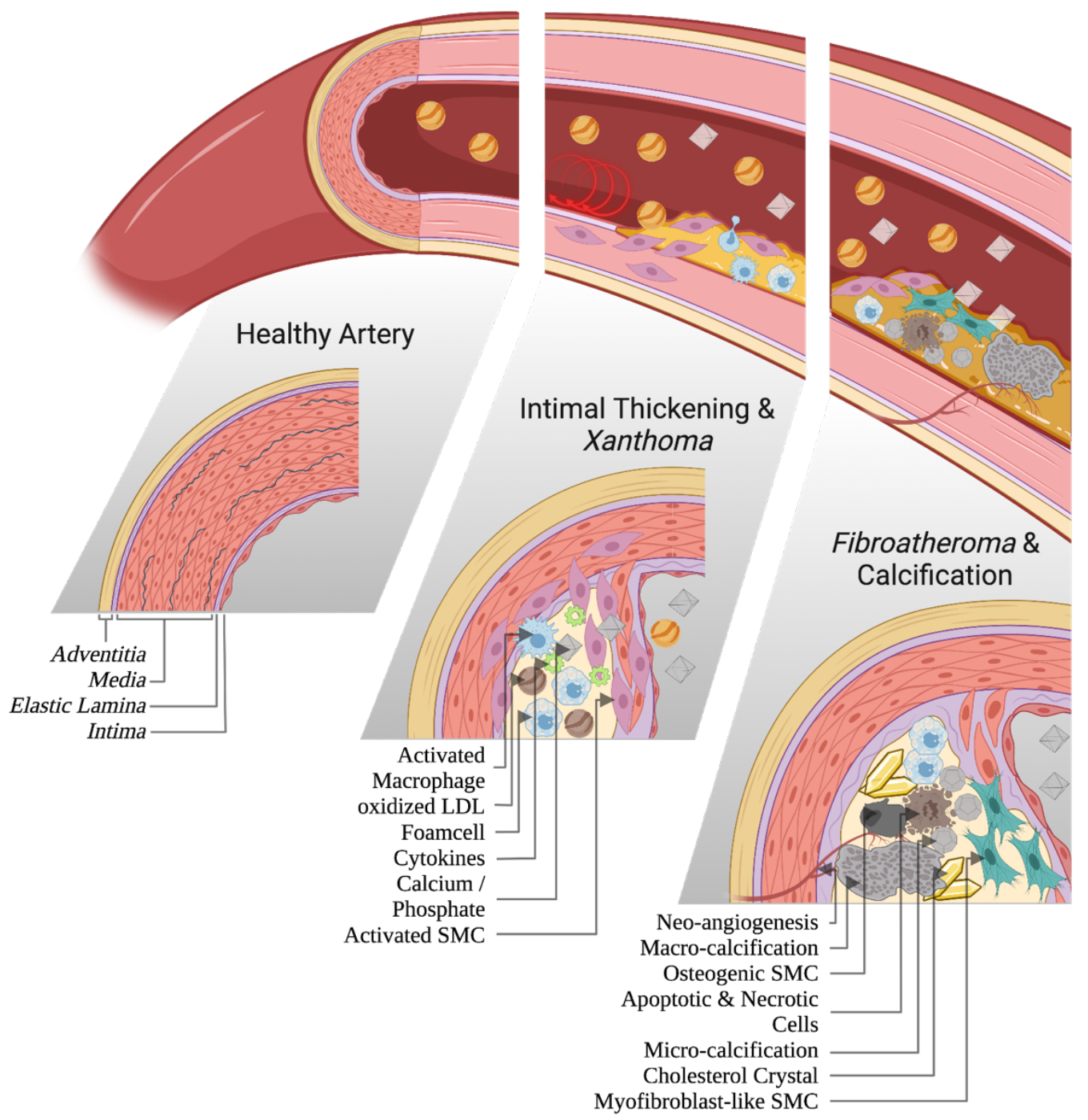

Figure 2: Schematic illustration of the healthy artery wall and atherosclerotic lesion progression. Early intimal thickening is mainly characterized by infiltration of the subendothelial layer by lipid particles and inflammatory cells, leading to SMC proliferation and migration. During later stages of plaque development, pro-fibrotic and osteogenic mechanisms lead to ECM remodeling and formation of calcification.

\subsubsection{Atherosclerotic carotid lesion progression}

While processes leading up to disease initiation remain contested, the overall biological pathways driving lesion progression seem to be more clear. Although early xanthomas formed via LDL infiltration and aggregation as well as immune activation might still be completely reversible ${ }^{5}$, chronic influx of lipids and inflammatory cells will lead to excessive SMC activation and loss of their contractile features ${ }^{63}$. This dedifferentiation is orchestrated by a rapidly changing extracellular milieu including various atherogenic molecules like pro-inflammatory cytokines (e.g. IL $1 \beta$ and 6, tumor necrosis factor $\alpha$ (TNF $\alpha$ ) and interferon $\gamma$ $(\mathrm{IFN} \gamma)$ ), growth factors (e.g. PDGFB and TGF $\beta$ ) as well as inorganic calcium (Ca) and $\mathrm{Pi}^{64-68}$. 
Synthetic SMCs proceed to migrate towards luminal parts of the lesion, contributing to intimal hyperplasia by extensive proliferation and ECM secretion ${ }^{37}$. This stage of lesion development is called pathological intimal thickening. Interestingly, SMCs have also been reported to show lipid clearing capacities, forming CD68 positive foam-like cells in the process ${ }^{69}$. Together with macrophage activation this may aid initial lipid clearance from the vessel wall but in turn results in enhanced foam-cell accumulation. The strongly pro-inflammatory and pro-apoptotic plaque environment finally leads to expansive caspase 3 (CASP3) -dependent apoptosis and necrosis of macrophages and SMCs ${ }^{70-72}$. Furthermore, impaired phagocytic clearance results in deposition of apoptotic debris and inorganic cholesterol crystals underneath a layer of foamcells, forming a continuous lipid-rich necrotic core ${ }^{73,74}$. This irreversible disruption of the intima is referred to as fibroatheroma (Figure 2).

Pathological examination of human atherosclerotic plaques often reveals very advanced lesions that remain asymptomatic for decades due to a protective fibrous cap established by migrating SMCs and subsequent fibrous ECM formation, separating the lesion from the lumen ${ }^{75,76}$. Although clinical research is starting to recognize the importance of patient specific plaque heterogeneity, the majority of advanced lesions are considered to be characterized by: i) extensive intimal thickening, ii) structural disorganization of the vessel wall and iii) significant aggregation of lipids and fibrotic ECM ${ }^{77}$. Perpetual apoptosis and failing response mechanisms to clear the accumulating debris lead to secondary necrosis and necrotic core stiffening ${ }^{72}$. This biomechanical wall stiffening as well as the narrowing lumen are currently considered to be the major risk factors for a potential plaque rupture. While SMCs are considered to strengthen the fibrous cap integrity by secreting ECM components such as collagen and elastin ${ }^{78}$, inflammatory cells (macrophages and T-lymphocytes) within the same area release MMPs and cytokines that induce ECM degradation ${ }^{79}$. Therefore late stage plaque stability is partially dependent on a fragile balance between SMCs and active inflammation ${ }^{4,80}$. Insufficient tissue oxygenation within the necrotic core and hypoxic macrophages trigger neo-angiogenesis originating from the vasa vasorum ${ }^{81-83}$. While actively enhancing inflammatory cell recruitment and affecting ECM remodeling via oxygenation ${ }^{84}$, these immature capillaries lack supporting pericytes, which causes their leakiness and fragility ${ }^{85}$. Hence, intraplaque hemorrhages (IPH) are common sources of increased inflammation and destabilization in advanced atherosclerotic plaques ${ }^{86-88}$. Intimal macro-CALC $(>2 \mathrm{~mm})$ is mostly a feature of late-stage atherosclerotic lesions ${ }^{3}$. However, micro-CALC $(<15 \mu \mathrm{m})$ can already be present in early intimal thickening and the necrotic core ${ }^{89}$. Detailed mechanisms of CALC formation and its impact on plaque stability are subject of section 1.3.

\subsubsection{Aortic valve stenosis}

\subsubsection{The aortic valve under physiological conditions}

The aortic valve is an avascular tissue surrounding the orifice of the aorta with the crucial function of preventing blood-backflow into the left ventricle under diastole. It is formed from three leaflets or cusps which attach to the aortic root forming the sinus of Valsalva, origin of the coronary arteries ${ }^{34}$. The valve closes under diastole due to the aortic backpressure on the cusps and opens under systole when this pressure is equalized by the blood flow from the heart. This constant movement is maintained by a refined composition of valvular endothelial cells (VECs), valvular interstitial cells (VICs) and ECM components ${ }^{90}$. Similar to ECs forming the luminal layer of arteries, VECs line the outer leaflet-layer in direct contact to the blood stream, capable of sensing and adapting to hemodynamic changes. In contrast to ECs, VECs align perpendicular to shear inflicted by blood flow ${ }^{91}$. Below the VEC monolayer, three distinct layers of VICs and different matrix components form the structural part of each leaflet. On the aortic side, tightly connected VICs and collagen fibers form the fibrosa, providing necessary load bearing capacities ${ }^{92}$. The middle layer, called spongiosa, is composed of VICs and glycosaminoglycans (GAGs) with inherent cushioning and shear absorbing properties ${ }^{93}$. The final layer on the ventricular side is called ventricularis and consists of elastin fibers and VICs, generating tissue compliance and elasticity ${ }^{94}$ (Figure 3 ). 


\subsubsection{Initiation of AVS}

Similar to arterial pathologies, it is not possible to define a single factor responsible for the initiation of leaflet inflammation, thickening, fibrosis and CALC, finally leading to disturbed functionality and clinical symptoms. However, it is likely that low-shear and high tensile biomechanical stresses, mostly exhibited on the aortic side, induce local VEC dysfunction making the endothelial layer permeable for lipoproteins ${ }^{95,96}$. Additionally, activated VECs express increased levels of adhesion molecules (VCAM-1 and intracellular cell adhesion molecule 1 (ICAM-1)) triggering inflammatory cell infiltration into the subendothelial layers 97,98. Another common factor for AVS initiation and CVD in general is increased oxidative stress, causing oxLDL formation, tissue inflammation, VIC apoptosis and early CALC ${ }^{99-101}$. In accordance to xanthoma formation, accumulation of lipid-filled activated macrophages enhances secretion of pro-inflammatory cytokines and ECM degradation, finally resulting in valve thickening and early mechanical deficiencies ${ }^{102}$.

Healthy Aortic Valve Cusp

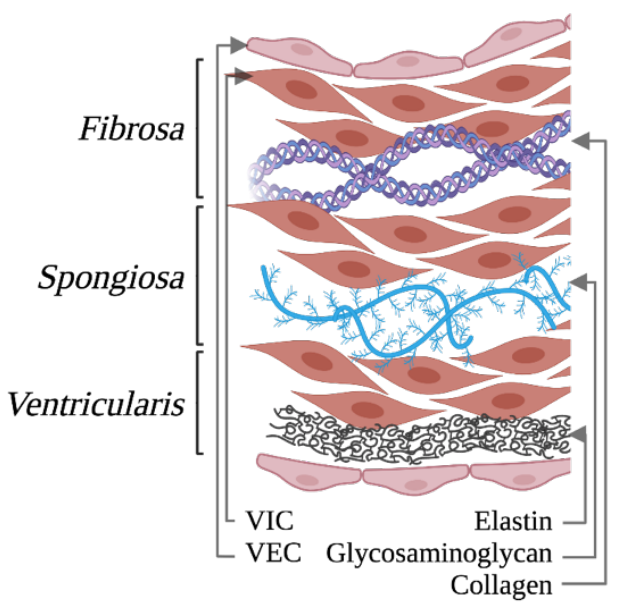

AVS Progression

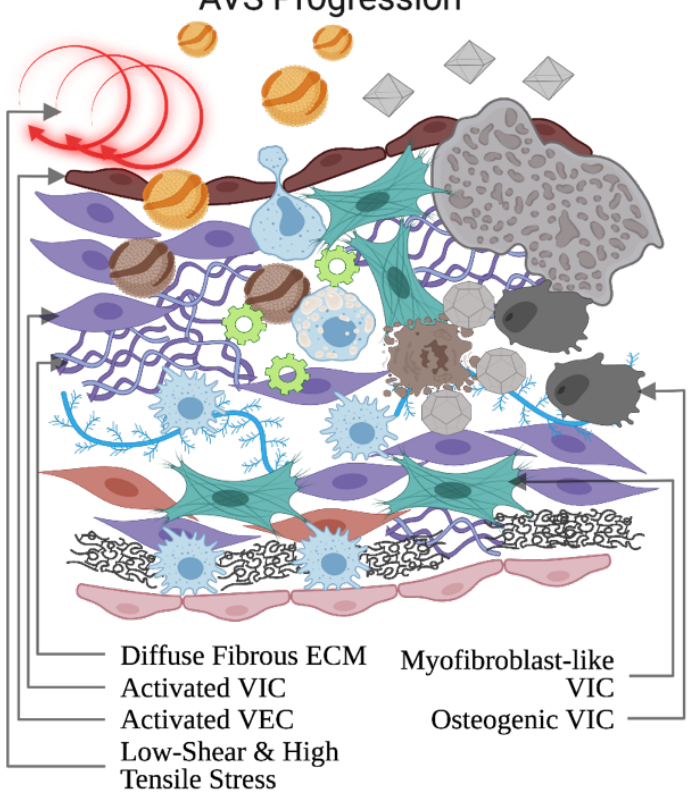

Figure 3: Schematic illustration of the healthy aortic valve composition vs tissue disruption during progressive AVS. AVS progression is mainly driven by a combination of lipid and mineral infiltration, inflammatory ECM degradation and subsequent fibrosis. Calcification is a final feature of this process commonly found within the fibrosa on the aortic side of the valve.

\subsubsection{AVS progression}

Continuous ECM degradation and chronic local inflammation generate nucleation sites for dystrophic CALC, formed by inorganic $\mathrm{Ca}$ and Pi crystals, additionally driven by the release of pro-calcific extracellular vesicles from macrophages and VICs ${ }^{103,104}$. This marks the onset of progressive pathological cusp stiffening, further activating VIC transformation towards myofibroblastic and osteogenic phenotypes ${ }^{105}$ (Figure 3). Transformed VICs start to express increasing levels of fibrotic ECM, contributing to LDL retention ${ }^{106}$. Moreover, together with activated macrophages and other immune cells, activated VICs release high levels of MMPs and cysteine endoproteases, disrupting the complex collagen and elastin network. This excessive degradation of functional ECM and replacement by inflamed fibrotic tissue forms a scaffold for further CALC, leading to valve failure. In the final stages of AVS, activated VICs adapt osteogenic expression machineries, forming heterotopic bone-like CALC towards the aortic leaflet side ${ }^{107}$.

\subsubsection{Current clinical praxis}

Characteristic clinical signs of an unstable carotid stenosis with atheroembolism are transitory ischemic attacks (TIA, symptoms resolve within less than 24 hours), sudden vision impairment 
(amaurosis fugax), minor (symptoms can last for more than 24 hours, not disabling for activities of daily living) and complete strokes (persistent neurological damage, disabling for activities of daily living). Patients diagnosed with one of these conditions carry a cumulative risk at two years of $26 \%$ to suffer any ipsilateral stroke and $13.1 \%$ to sustain a major or fatal event, despite medical care ${ }^{108}$. Nevertheless, many pathological occlusions of the carotid artery remain asymptomatic and are often diagnosed coincidentally during examinations of the neck area. Importantly, these patients still carry a remaining annual risk of $2 \%$ to suffer from stroke or myocardial infarction ${ }^{109}$.

Clinical signs of AVS, caused by significantly obstructed blood flow, include heart murmur, rapidly fluttering heartbeat, chest pain and dizziness or early fatigue with activity. However, these symptoms can also be connected to other CVDs that often coincide with severe AVS ${ }^{110}$. Therefore, more detailed diagnostic tools need to be applied in order to validate patient condition.

\subsubsection{Diagnostic tools}

In order to establish a standardized decision tree for clinical stratification of patients with symptomatic carotid stenosis at high risk for stroke as well as providing recommendations for active surgical intervention, two multi-center randomized controlled trials (European Carotid Surgery Trial (ECST) 111, North American Symptomatic Carotid Endarterectomy Trial (NASCET) ${ }^{108}$ ) were conducted in the 1990's. The aim was to elucidate the benefit of CEA on the risk of severe future events (stroke or death) in comparison to pharmacological treatment alone, in symptomatic patients. In NASCET, a benefit of surgical intervention was found for a stenosis degree of $50-69 \%$, with subsequent risk reduction of $29 \%$ in 5 years. For patients presenting with a stenosis of more than $70 \%$ the cumulative risk of fatal events was reduced from $13.1 \%$ to $2.5 \%$ in two years, prompting the assignment for surgery of all patients included in this study group. ECST indicated that a stenosis degree of over $80 \%$ was required to motivate CEA. However, this discrepancy was due to differing assessment methodologies resulting in overestimation of the stenosis degree in patients enrolled by ECST ${ }^{112}$. These studies provided the foundation for international guidelines from the Society for Vascular Surgery and European Society for Vascular Surgery, which clinicians at present use to evaluate symptomatic carotid stenosis.

While traditional risk evaluation of carotid lesions solely relies on stenosis degree assessed via invasive angiography or ultrasound (US), modern imaging modalities facilitate a direct visualization of the vessel wall morphology and thereby more direct diagnosis of plaque vulnerability ${ }^{113}$. Routine diagnostics to date are mainly based on imaging by ultrasound (US) and computed tomography angiography (CTA), in rare cases magnetic resonance imaging (MRI) is applied as a third imaging modality. Due to its flexibility, low-cost and low-risk, US has become the gold standard for assessment of stenosis degree based on blood flow velocity monitoring. Furthermore, it allows an approximation of plaque morphology based on the greyscale median, separating echo-lucent and echo-dense tissues ${ }^{114}$. While echo-lucency indicates lipid-rich necrotic cores, inflammatory cell accumulation and intra-plaque hemorrhage, echo-density suggests higher contents of stabilizing fibrous tissue, SMC-rich areas or CALC ${ }^{115}$. However, US remains subject to high operator variability and physical properties of the patient, obesity or short muscular necks can cause problems during image acquisition ${ }^{116}$. Most of these pitfalls can be overcome by the implementation of CTA as a diagnostic tool with high availability, providing a rapid high-resolution imaging of the carotid wall and lumen. Recent advances in software development allow for improved reconstruction and radiometric analysis of plaque structures and components based on CT images ${ }^{117}$. In contrast to US, CTA is outstanding in visualizing dense tissues, like CALC. Tissue density is described in Hounsfield Units (HU) per pixel. Typical thresholds have been proposed via histological validation for lipid rich areas $<60 \mathrm{HU}$ and CALCs $>130 \mathrm{HU}{ }^{118,119}$. Coronary artery CALC measured by CT is an established marker for CVD risk prediction, included in several scoring systems (Agatston, ACCF/AHA guideline) ${ }^{120-122}$. However, association of CALC score with higher risk in general is controversial as statin treatment, that exerts beneficial effects by decreasing 
systemic inflammation as well as serum LDL- cholesterol levels, has also been shown to rather increase vascular calcification (VC) ${ }^{123}$. Assessment of CALC patterns by intra-vascular US also revealed that large plaques with low CALC were at higher risk of future events ${ }^{124}$. While luminal areas are clearly depicted in CTA, assessment of the fibrous cap and IPH remains challenging due to their variable intermediate tissue densities ${ }^{125}$. The fibrous cap/lipid rich plaque ratio can be assessed via CT image analysis software ${ }^{117}$ and used as an indirect identifier of plaque phenotype ${ }^{126}$. Additional knowledge of pro-calcific components and defined molecular targets could further aid improvements of CT imaging modalities. The main disadvantage of CTA lies in the patient risk caused by increasing radiation dose and intravenous contrast agents, especially during longitudinal studies.

Echocardiography is the current routine diagnostic tool to evaluate aortic valve function based on hemodynamics (transaortic peak velocity) as well as mechanical properties such as aortic valve area (AVA) and left ventricular functionality ${ }^{127}$. The average cusp orifice opening, termed AVA, spans 3 to $4 \mathrm{~cm}^{2}$ in healthy individuals, allowing for a transaortic peak velocity below $1 \mathrm{~m} / \mathrm{s}$. According to the European Society of Cardiology guidelines severe AVS is defined by an AVA below $1 \mathrm{~cm}^{2}$ and a resulting transaortic peak velocity above $4 \mathrm{~m} / \mathrm{s}{ }^{128}$. In addition, patients are stratified according to disease progression, accounted for by an annual increase in blood peak velocity above or below to $0.3 \mathrm{~m} / \mathrm{s}$. However, resting echocardiographic assessment can lead to ambiguous or uncertain medical readouts especially in elderly patients due to its susceptibility to patient specific hemodynamic differences ${ }^{129}$. Therefore, CT was recognized as an established method in atherosclerosis to directly assess CALC grade, one of the dominant determinants for AVS severity and valvular dysfunction. Correspondingly, several studies confirmed $\mathrm{Ca}$ quantification by $\mathrm{CT}$ imaging via evaluation of $\mathrm{Ca}$ concentrations in explanted aortic valves ${ }^{130,131}$, leading to its recommendation as a complementary tool for diagnosis of AVS severity ${ }^{128}$. A remaining blind spot in current clinical AVS diagnostics is the lack of imaging modalities for non-calcific leaflet thickening. Especially in women, pro-fibrotic transformation has been shown to be a defining factor for AVS progression and pathology ${ }^{132}$.

\subsubsection{Specific biomarkers for carotid lesion vulnerability and AVS severity}

Since general risk stratification of atherosclerotic carotid lesions has transpired to be widely inefficient, greater emphasis was put on the discovery of biomarkers for the prediction of patient risk. The concept of plaque "vulnerability" refers to the identification of lesions posing a high risk of thrombosis and association with future adverse cardio- and cerebrovascular events ${ }^{133,134}$. Plaque rupture is most often connected to erosion of the endothelial layer and fibrous cap, exposing the highly thrombogenic necrotic core to the blood stream. In this regard, IPH caused by neo-angiogenesis or previous ruptures is an attractant for inflammatory infiltration and tissue disruption that recently has been identified as a prime source of circulatory biomarkers for plaque instability in a large human multi-omics study ${ }^{135}$. While there are no readily available biomarkers for SMC content, decreasing levels of collagen, elastin and proteoglycans, expressed by migrating SMCs, have recently been directly linked to adverse disease progression and may generate potential circulatory biomarkers in future ${ }^{86,136-}$ ${ }^{138}$. CALC, as a hallmark of late stage atherosclerosis and AVS, has always been an important determinant of CVD progression ${ }^{59}$. However, since clinical routine imaging is usually unable to detect the presence of early micro-CALC, monitoring of circulating CALC inhibitors like MGP and fetuin-A ${ }^{139,140}$ or drivers of CALC formation such as osteocalcin and osteomodulin ${ }^{141}$, in addition to plasma mineral imbalance ${ }^{142}$, could be beneficial. As previously mentioned, contradictory effects of CALC on the clinical outcome have become evident in recent years ${ }^{143}$, therefore it is relevant to evaluate novel circulatory biomarkers linked to CALC, as well as to investigate their role in atherosclerosis pathophysiology.

\subsubsection{Prevention and treatment}

The current clinical practice for prevention of CVD related events, such as ischemic stroke caused by carotid plaque rupture or AVS related heart failure, mainly includes changes of life 
style such as: healthy low-cholesterol diet, physical exercise, abstinence from smoking as well as blood glucose and blood pressure surveillance.

\section{Pharmacological therapies}

Additional prescription of antiplatelet therapies and HMG-CoA reductase-inhibitors (statins) has become increasingly common as a stabilizing treatment for atherosclerotic patients. In contrast to carotid lesion formation randomized clinical trials could not confirm positive effects of LDL reduction by statins on echocardiographic parameters or CALC in patients suffering from AVS ${ }^{144-146}$. While this may surprise at first due to the evident association between LDL levels and AVS progression ${ }^{15}$, other lipoproteins implicated in the initiation of AVS were found to be upregulated in patients treated with rosuvastatin, potentially abolishing any positive effects via LDL reduction ${ }^{147}$. Moreover, statins have been shown to generally increase CALC formation in atherosclerotic pathologies ${ }^{123,148}$. However, while macro-CALC has been related to stabilizing properties in late-stage atherosclerotic plaques ${ }^{136,149}$, it is inherently detrimental to cusp flexibility and therefore aortic valve function, suggesting a given discrepancy for an efficient statin treatment. Proprotein convertase subtilisin/kexin type 9 (PCSK9) inhibitors recently emerged as a novel LDL lowering therapy via upregulation of LDL receptors, interestingly also showing the capacity to downregulate other atherogenic lipoproteins ${ }^{150}$. Furthermore, direct targeting of inflammation to reduce CVD risk by IL $1 \beta$ targeting antibodies or colchicine has been investigated as a potential clinical treatment in patients with a history of myocardial infarction or chronic coronary disease ${ }^{151,152}$.

Since CVD commonly presents as systemic pathology affecting various vascular beds, combined therapeutical strategies on a patient specific level may pose a future best clinical praxis, warranting further molecular evaluation ${ }^{153}$.

\section{Surgical treatment}

As current pharmacological treatments can be used to delay or stabilize CVD progression but are unable to cure or halt pathologies like carotid stenosis or AVS, surgical intervention is necessary for symptomatic patients or those at high risk.

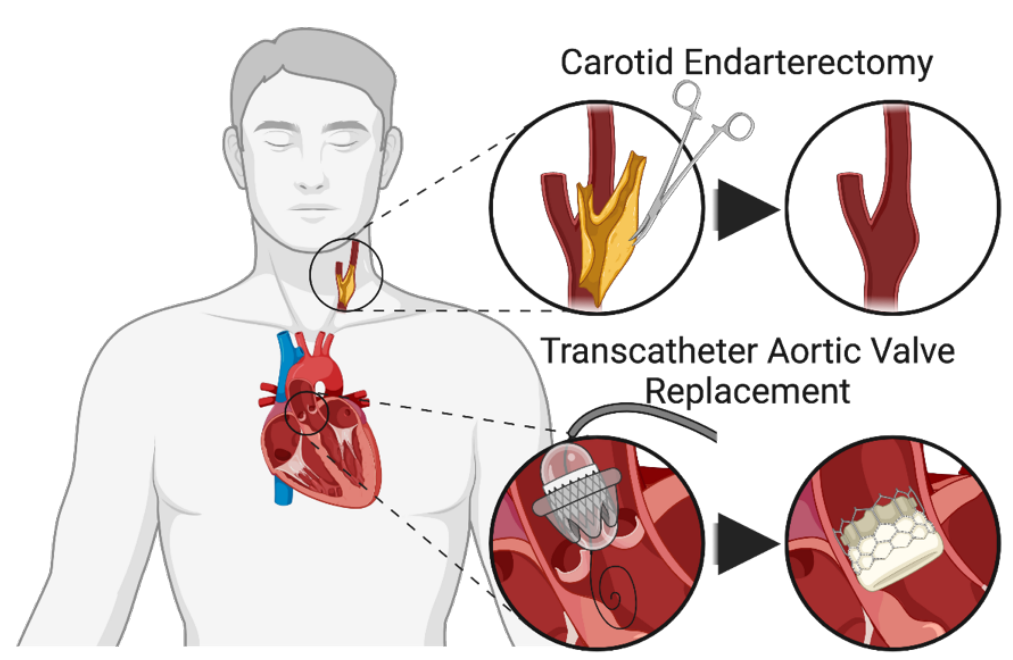

Figure 4: Schematic explanation of CEA and transcatheter aortic valve replacement. In CEA, the intimal plaque is scooped from the surgically opened vessel in order to restore blood flow and reduce risk of future rupture. Transcatheter aortic valve replacement is a less invasive method to replace a dysfunctional aortic valve with an artificial substitute.
Following ECST and NASCET, it was advised that symptomatic patients with an indicated carotid stenosis of more than $70 \%$ to $80 \%$ should undergo CEA to remove the intimal plaque from the vessel (Figure 4). Present clinical guidelines are still based on these studies even though they already showed that 9 to 15 surgical interventions had to be performed in order to prevent one stroke, revealing a major gap in diagnostic precision. A benefit of prophylactic surgical intervention on asymptomatic patients based on stenosis degree alone strongly depends on the expertise of the leading surgeon and subsequent minimalization of procedural morbidity. With increasing advancements in medical therapies, equal treatment efficiency of asymptomatic carotid stenosis by pharmacological stabilization is no longer a subject of controversy ${ }^{154,155}$. Therefore, the field is moving towards an integrative concept to grade rupture risk by rendering location and extent of the plaque, visualization of plaque composition, combined with assessment of blood parameters and 
symptoms. This way, a patient can be considered for surgery or a more intensive lipid-lowering therapy despite a rather mild stenosis or vice versa ${ }^{113}$.

In severe cases of AVS surgical replacement of the aortic valve with an artificial equivalent remains inevitable. Nevertheless, application of transcatheter aortic valve implantation, initially developed for patients not suitable for traditional surgery due to co-morbidities, is expanding to patients at moderate and low risk ${ }^{156}$ (Figure 4).

\subsection{VSMC AND VIC PLASTICITY - VASCULAR CHAMAELEONS}

While vascular SMCs arise from diverse embryonic origins where post-developmental boundaries can only be approximated (e.g. SMCs of the thoracic aorta arise from neural crest cells while abdominal aortic SMCs originates from splanchnic mesoderm) ${ }^{157}$, VICs are derived from a mesenchymal origin. Nevertheless, both cell types are major contributors to the structural integrity of our vascular system and possess the capacity to adapt and modify ECM components to maintain tissue functionality. Studies of human specimens representing the full spectrum of atherosclerosis identified early reactions of SMCs and VICs to external stimuli 2,158-160, leaving no doubt that these cells play a major role throughout all stages of cardiovascular pathologies.

The tunica media is traditionally considered the "muscular" layer of the vessel wall, home to the majority of differentiated vascular SMCs. Nevertheless, early vascular adaptation to extreme flow conditions leads to "intimal thickening" containing significant numbers of SMCs and proteoglycan rich matrix within the intimal layer ${ }^{44}$. Compared to SMCs residing in the medial layer, these intimal SMCs show distinct secretory capacities and phenotypic variability ${ }^{161}$, leading to the hypothesis of phenotypic plasticity ${ }^{162}$. Similarly, quiescent VICs found in healthy mature aortic valves can adopt a proliferative phenotype in response to VEC activation, lipid infiltration, cytokine release and high $\mathrm{Pi}$, forming early aortic valve leaflet thickening 163,164 .

Contractile SMCs represent highly specialized cells characterized by a low rate of proliferation, poor synthetic capacity, quiescence and expression of a unique set of proteins enabling them to control vascular tone. Myocardin (MYOCD) acts as a master transcriptional regulator of the SMC lineage, inducing gene-expression of cytoskeletal components such as myosin heavy chain $11(M Y H 11)$, calponin $(C N N)$ and actins (ACTA2), while inhibiting cell proliferation ${ }^{165}$. Nevertheless, SMCs retain remarkable phenotypic plasticity in response to environmental stimuli. The general term "synthetic phenotype" describes SMCs showing significantly lower expression of cytoskeleton-related proteins, alterations in $\mathrm{Ca}$ handling and substantial loss of myofilaments ${ }^{166}$. Additionally, they are highly proliferative, migratory and able to secrete chondrogenic ECM components ${ }^{167,168}$, altogether resembling mesenchymal progenitor-like or myofibroblast-like cells ${ }^{169}$ (Figure 5). In reverse, VIC activation is marked by an increase in expression of SMA as well as MMPs and TGF $\beta$ allowing them to proliferate, migrate and release fibrotic ECM, similar to synthetic SMCs ${ }^{170}$. However, latest studies strongly suggest that SMC and VIC phenotypic plasticity exceeds the simplified model of quiescent vs. synthetic cells. Various transitory SMC subphenotypes may coexist in atherosclerotic lesions that can be characterized using panels of sensitive markers for cytoskeletal integrity (e.g. SMTN, leiomodin 1 (LMOD1), PDZ and LIM domain protein 7 (PDLIM7)), contractile function (MYH11), ECM secretion (e.g. collagen 1 and 2, aggrecan (ACAN)), cell interaction and adhesion (e.g. CD34, CD44, integrin subunit alpha M (ITGAM)), surface receptors, Ca channels or vesicle transport $44,139,166,169,171,172$. Nevertheless, SMC identification can become challenging when their phenotypic switch results in dedifferentiation and loss of typical markers. In vivo fate-tracing models in mice showed that $30-70 \%$ of cells within atherosclerotic plaques belong to the SMC lineage but lack sensitive contractile markers, becoming almost indistinguishable from macrophages, mesenchymal stem cells and myofibroblasts ${ }^{173,174}$.

During intimal and valvular CALC, SMCs and VICs have been shown to acquire phenotypes similar to chondrocytes and osteoblasts, composing calcified ECM ${ }^{175-177}$ (Figure 5). Initial clues were collected in studies on medial CALC showing mineralized matrix in direct proximity to SMCs expressing alkaline phosphatase (AP) and collagen II ${ }^{178}$. These findings 
were confirmed in atherosclerotic intimal lesions showing SMCs positive for osteoblastic (Runt-related transcription factor 2 (RUNX2)) and chondrocytic markers (BMP2, osterix (OSX), SRY-box transcription factor 9 (SOX9)) ${ }^{179-181}$. Moreover, SMCs executed an osteogenic phenotype change, characterized by the loss of SMC markers and gain of RUNX2, osteopontin (OPN), osteocalcin (OCN) and AP, upon high Pi stimulation in vitro ${ }^{172}$. Similar changes could be triggered in vivo, where increased expression of TGF $\beta 1$ in the arterial endothelium caused cartilaginous metaplasia in the underlying media of rats ${ }^{182}$. Importantly, in vitro and in vivo studies also identified MYOCD, RUNX2 and SOX9 to exhibit counteractive roles during SMC differentiation, confirming that SMCs maintain basic lineage identity ${ }^{183,184}$. Such transitional cells, termed "myochondrocytes", showing both SMC and chondrocyte properties, have been morphologically identified by electron microscopy in human and mouse atherosclerotic lesions ${ }^{180}$. Accordingly, VICs involved in active regulation of ectopic CALC in severe AVS have been identified to express high levels of RUNX2 and BMP2, activating subsequent CALC-related signaling pathways ${ }^{176}$. Especially bone morphogenic protein receptor type 2 (BMPR2) signaling has been shown to accelerate osteogenic transformation by phosphorylation and activation of several SMAD intracellular transducer proteins ${ }^{185,186}$. Recent development of single cell sequencing technologies allowed even more detailed tracking of the differential contribution and multitude of SMC phenotypes during vascular pathologies. Novel transition states, not defined by a specific functional role, were either identified or predicted based on central transcription factors such as krüppel-like factor 4 (KLF4) ${ }^{169,174,187 .}$

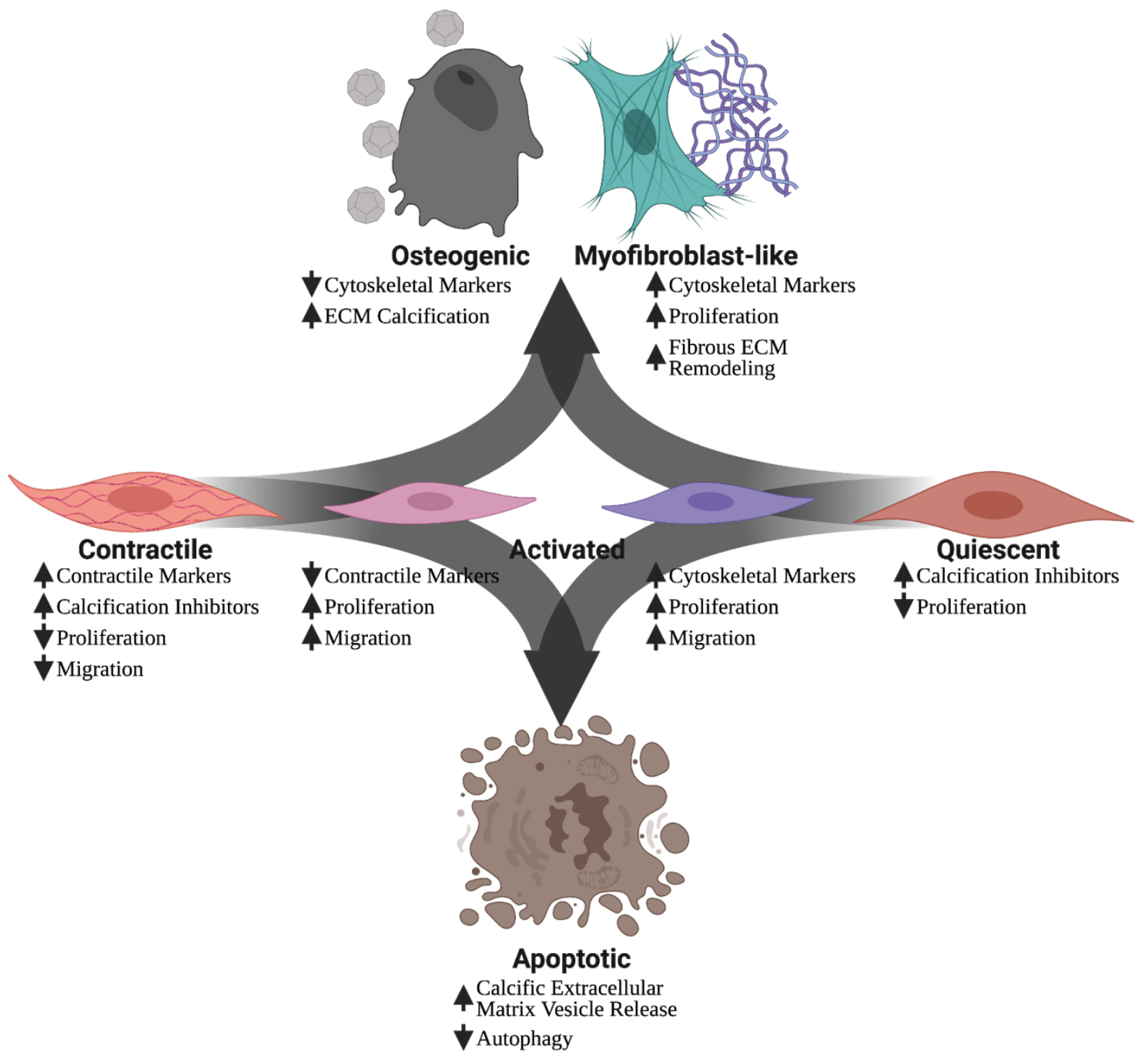

Figure 5: Graphical summary of SMC and VIC phenotypic transformation related to calcification. Both vascular SMCs and VICs actively contribute to fibrotic and osteogenic ECM remodeling in atherosclerotic disease and AVS. They can acquire a multitude of transdifferentiated states that are difficult to classify as the transition phases are seamless. Interestingly, during the activation process both cell types generate a phenotype not unlike mesenchymal progenitors. 
Finally, pathogenic stress (in particular hyperphosphatemia and hypercalcemia) can lead to VIC and vascular SMC apoptosis, connected to the release of pro-calcific extracellular matrix vesicles (EVs), creating nucleation nidi for dystrophic CALC ${ }^{139,188}$ (Figure 5). Autophagy, a highly conserved mechanism to clear damaged or aging cells ${ }^{189}$, has recently been identified as an important process to mitigate $\mathrm{VC}{ }^{190}$. It was shown to both inhibit osteogenic transdifferentiation and $\mathrm{EV}$ release as well as rescuing overall cell viability within the tissue 191,192

\subsection{VASCULAR CALCIFICATION - BONES IN ARTERIES AND VALVES}

CALC of the cardiovascular system is a systemic pathology that has been shown to afflict humans for millennia. Both the ice mummy "Ötzi" (who died approximately 5300 years ago) as well as ancient Egyptians have been diagnosed with significant CALC of their arteries ${ }^{193,194}$. Histological manifestations of $\mathrm{VC}$ as well as their respective clinical impact have been found to be as diverse as the numerous inductors leading to cellular ossification (e.g. biomechanical forces, oxidative stress, inflammation or $\mathrm{Ca} / \mathrm{Pi}$ and lipid overload). VCs, affecting the tunica media and intima as well as arterial valve tissues, can be defined as micro-CALC (from $0.5 \mu \mathrm{m}$, "speckled calcification" up to $2 \mathrm{~mm}$ ) or macro-CALC ("fragmented calcification" $2-5 \mathrm{~mm}$, "diffuse calcification" $>5 \mathrm{~mm}$ ), the latter forming sheet-like continuous structures of calcified tissue. This classification mostly relies on histopathological assessment as radiology is only able to discriminate macro-calcified structures ${ }^{75,119,195,196}$.

Progressive plaque CALC is classically considered to be a marker for increasing atherosclerotic disease burden ${ }^{77,197}$. Micro-CALC as well as early stages of speckled and fragmented VC, aggregating within the necrotic core, fibrous cap and medial tissue matrix ${ }^{198}$, have been related to adverse clinical outcome. This effect is most likely caused by the inherently unfavorable geometry and tissue property of these types of $\mathrm{VC}$, creating tissue stress concentrations, activating further inflammatory response mechanisms and ultimately leading to plaque rupture or thrombus formation ${ }^{199}$. In studies of sudden coronary death, assessment by CT identified exclusive presence of speckled CALC in $65 \%$ of acute plaque ruptures and either an absence or speckled CALC in over $50 \%$ of vulnerable thin-cap fibroatheroma ${ }^{200}$. In contrast, macro-CALC has rather been reported to be a predominant feature of clinically stable "asymptomatic" lesions 136,149,201,202, while it has been suggested that non-calcified plaques contain more destabilizing inflamed and lipid rich regions ${ }^{203-205}$. In support of these observations, carotid plaques from asymptomatic patients have shown enrichment of biological processes associated with CALC together with markers of SMC differentiation ${ }^{149}$. Moreover, gene expression analyses of lesions stratified by pre-operative CTA associated macro-CALC with molecular signatures typically linked to plaque stability and in particular genes related to a differentiated SMC phenotype ${ }^{136}$. Estimation of structural plaque stresses via computational in silico modeling has indicated that wide-spread macro-CALC can lower overall tissue stress due to greater stiffness and load bearing capacity ${ }^{206}$ and might result in advantageous stress redistribution ${ }^{207}$. The diagnostic discrepancy between densely formed continuous CALC and loosely arranged early aggregations is directly highlighted by clinical CAC evaluation. While estimation of CAC volume alone was found to be positively associated with CVD events, the addition of CAC density was identified as a negative predictor across all levels of CAC volume as well as other risk factors in the general population ${ }^{208}$.

Therefore, a better understanding of molecular mechanisms driving different forms of $\mathrm{VC}$ formation as well as their impact on tissue remodeling is crucial to improve patient diagnostics and risk prediction.

\subsubsection{Molecular mechanisms of vascular calcification}

The continuous process of pathological $\mathrm{VC}$ is driven by the interconnection of passive physiochemical and active biological events leading to tissue transformation. While the temporal sequence and clinical consequences remain disputed, consensus exists that $\mathrm{VC}$ is generally initiated by a loss of CALC inhibitors and phenotypic changes of structural cells. 
Circulating inhibitors such as matrix Gla proteins (MGP) and fetuin-A exhibit protective functions in heathy arteries ${ }^{140}$. However, in response to inflammatory priming (characteristic for atherosclerosis and AVS), mineral imbalance (typical for chronic kidney disease (CKD)) and other cell-damaging stimuli, SMCs and VICs can begin to release matrix vesicles loaded with high concentrations of calcium-phosphate (CaPi) or hydroxyapatite ${ }^{139,209}$. In addition, multiple different resident and circulating cells have been shown to be subject to similar processes, including endothelial progenitor cells, mesenchymal stem cells and macrophages ${ }_{181,210}$. These microparticles and uncleared debris of apoptotic cells act as the first nidus for further mineralization due to their surface-bound Ca binding complexes ${ }^{188,211}$. Subsequently, micro-CALCs develop via transformation of amorphous $\mathrm{CaPi}$ into mature crystalline hydroxyapatite particles of spherical or needle like structure, with a diameter of typically up to $50 \mu \mathrm{m} \mathrm{198,212,213}$. Extensive degradation of organized ECM structures and replacement by fibrotic tissue, containing large amounts of scattered collagen filaments, forms a scaffold prone for the aggregation of micro-CALC particles ${ }^{198}$. This initial stage of mineralization is accompanied by an osteo-chondrogenic phenotypic transition of SMCs and VICs marked by upregulation of transcription factors typically known as master regulators of chondrocyte and osteoblast development and maturation (SOX9 and RUNX2) ${ }^{172,183,214}$. In vitro experiments have shown a direct connection between the degradation of elastin and accelerated Pi-provoked CALC of SMCs ${ }^{215}$. The acquired transcriptional program induces other factors such as OSX, $\mathrm{AP}, \mathrm{OPN}$ and OCN, which actively regulate extensive formation of sheet-like ossified matrix $210,216,217$, partially replicating physiological mineralization processes like endochondral ossification ${ }^{218-221}$. As a consequence, expression of tissue-nonspecific AP will promote the conversion of CALC inhibiting pyrophosphate to $\mathrm{Pi}$, further contributing to mineral imbalance 222 .

Pathological examination of human tissues spanning all age groups identified CALC formation as a dynamic process, characterized by co-existence of micro- and macro-CALC throughout plaque progression. Very advanced CALC formations detected in end-stage CVD can resemble mature calcified matrix with a lamellar structure, including osteoclastic remodeling processes ${ }^{223}$ and even bone marrow ${ }^{219}$.

\subsubsection{Lessons learned from bone biology}

VC in late stages of CVD pathologies is often compared to skeletal bone formation. While this comparison usually stems from morphological similarities observed by radiography or histology, it has become increasingly evident that bone is an endocrine organ capable of influencing systemic vascular health ${ }^{224}$. Osteotropic hormones, such as parathyroid hormone (PTH), exhibit systemic regulatory functions both in skeletal and vascular mineralization. In particular osteocyte-derived fibroblast growth factor 23 (FGF23), a hormone that enhances Pi secretion by the kidney, has been shown to be an important connector between bone-forming cells and VC ${ }^{225}$. Elevations in FGF23 might serve as a PTH mediated defense mechanism to attenuate toxicities of early hyperphosphatemia. However, common CVD co-morbidities and risk factors including diabetes, uremia and hyperlipidemia, further disrupt the bone-vascular signaling axis due to reduced Klotho co-factor expression, leading to vascular CALC and endothelial dysfunction ${ }^{226-228}$. A potent PTH responsive inhibitor of matrix mineralization is phosphorylated OPN, secreted by skeletal osteoblasts. Due to its stability to proteolysis it serves as a systemic defense to $\mathrm{VC}$ when released into circulation ${ }^{229-231}$. The role of bone-derived OCN appears more complex as it has the capacity to support adiponectin production by adipocytes, thereby suppressing TNF stimulated VC, on the one hand ${ }^{232,233}$. On the other hand, it may also directly promote osteogenic SMC transformation ${ }^{234}$.

With an increasing understanding of the co-regulatory pathways connecting the bone-vascular axis it becomes evident to directly compare the active processes mediating metabolic effects of skeletal and vascular CALC. Both CVD related VC and bone formation are multistage processes following controlled temporal and spatial sequences. Complex molecular mechanisms, involving intra- and extracellular molecular signaling, regulate mineralized tissue formation and have been described so far in more details in bone biology. Commonly, a variety 
of local and systemic regulatory factors, including growth respectively differentiation factors, hormones, cytokines and ECM, interact with cell types like bone and cartilage forming cells or even circulating mesenchymal and inflammatory cells ${ }^{235}$.

Similar to early mineralization initiation in atherosclerotic lesions, pro-inflammatory cytokines IL 1, IL 6 and TNF $\alpha$ are mainly known to play an important role in initiating the repair cascade after bone tissue disruption ${ }^{236}$. Therefore peak expression is found within the first 24 hours following fracture, but again later during fracture remodeling. Their main function is the induction of further downstream responses to injury by enhancing ECM synthesis, stimulating angiogenesis and recruiting endogenous fibrotic cells to the injury site. The second peak expression occurs due to involvement of all above mentioned cytokines in tissue remodeling. Especially $\mathrm{TNF} \alpha$ promotes endochondral ossification by mesenchymal progenitor cell recruitment ${ }^{237}$, induction of cell death in hypertrophic chondrocytes and stimulation of osteoclastic function by upregulation of the TNF-related cytokine RANKL ${ }^{238}$. Atherosclerosis is commonly accepted to be linked to chronic inflammatory processes, driving disease progression. Cytokines like ILs, IFNs and TGFs play a crucial role in tissue remodeling and initiation of pro-calcific processes ${ }^{239}$. However, apart from its key role in mediating inflammatory disease $\mathrm{TNF} \alpha$ also controls VC via TNF-related apoptosis inducing ligand (TRAIL), an OPG resembling ligand ${ }^{240}$. Due to the striking similarities with TNF $\alpha$ regulation in bone-homeostasis, this system has also been described to mediate bone turnover in the vasculature $^{241}$.

Two universal transcription factors affecting chondrogenic and osteogenic fate are SOX9 and RUNX2. SOX9 is expressed by proliferative but not hypertrophic chondrocytes, inducing secretion of proteoglycan rich ECM including collagen II ${ }^{242}$ and ACAN ${ }^{243}$. It is crucial for normal chondrocyte proliferation rates and delay of apoptosis. In opposition to SOX9, RUNX2 activates the Indian hedgehog $(\mathrm{IHH})$ promoter and thereby maintains a balance of proliferation and hypertrophy of chondrocytes as well as osteoblast differentiation during bone development. Recently, another transcription factor, myocyte enhancer factor-2 (MEF2C), known to regulate muscle and cardiovascular development, has been shown to act upstream to RUNX2 ${ }^{244}$. In vitro and in vivo studies on vascular SMCs were able to causally link RUNX2 and SOX9 expression to osteogenic transformation and concurrent SMC CALC, as discussed in more detail in section 1.2.

Differentiating chondrocytes express OSX, an essential transcription factor for osteoblast differentiation, just like SMCs undergoing an osteogenic phenotypic transition. Acting downstream of RUNX2, null mutations of OSX result in a complete absence of bone formation ${ }^{245}$. In bone homeostasis, OSX is chiefly expressed by osteoblasts, but skeletal deformity in the chondrocyte-specific OSX conditional knockout mice proves that OSX expression by chondrocyte lineage cells is essential for bone development ${ }^{246}$. Just like intimal CALC, new bone material is composed of mineralized collagen matrix also containing OCN, OPN, BMPs, and inorganic hydroxyapatite. Specific matrix proteins such as OCN and OPN are secreted by mature osteoblasts and regulate the mineralization of the surrounding matrix ${ }^{247}$. In the past several years, Wnt signaling was revealed to not only serve as a master controller of bone formation, as it occurs downstream of additional signaling cascades, but also to regulate osteoclast formation and hence bone resorption ${ }^{248}$. Wnt/ $\beta$-catenin signaling not only promotes the differentiation of mesenchymal progenitors into osteoblasts but also the generation of cardiovascular progenitor cells from mesenchymal stromal cells ${ }^{249}$. During bone formation this signaling pathway positively regulates expression of OPG, thereby suppressing osteoclastogenesis and enhancing mineralized matrix formation ${ }^{248}$. Similarly, several studies on hypercholesterolemic mice and SMC cultures were able to replicate the regulatory function of Wnt-signaling, inducing an osteogenic phenotypic switch by upregulation of RUNX2, BMPs and ALP ${ }^{250,251}$.

Independent hormonal mediators of cartilage and bone growth are insulin-like growth factors (IGFs) and thyroid hormone. During bone growth IGF-I and IGF-II are mainly derived from the bone matrix, endothelial cells, osteoblasts and chondrocytes ${ }^{235,252}$. The serum concentration of IGF-I is regulated by growth hormone $(\mathrm{GH})$, therefore it is considered the local mediator of GH's systemic effects ${ }^{242}$. Both IGF-I and IGF-II promote cartilage matrix formation in form of 
collagen I and non-collagenous matrix proteins and have been implicated during atherosclerotic plaque formation ${ }^{253}$ as well as intimal hyperplasia ${ }^{254}$. Thyroid hormone and tri-iodothyronine (T3) are systemic factors stimulating hypertrophy and death of chondrocytes as well as hypertrophic markers including collagen $\mathrm{X}$ and $\mathrm{AP}{ }^{255}$. In vitro studies on vascular $\mathrm{SMCs}$ from rats were able to translate the regulatory function of $\mathrm{T} 3$ to $\mathrm{VC}$, revealing capacities of $\mathrm{T} 3$ to downregulate RUNX2, ALP, OCN, OPN and OSX expression under calcifying conditions ${ }^{256}$. A large group of important growth and differentiation factors like BMP's, activins and inhibins is included in the TGF $\beta$ superfamily. Most of these molecules act on serine/threonine kinase membrane receptors, affecting nuclear gene expression and thereby ultimately promote various stages of intramembranous and endochondral ossification ${ }^{186}$. BMP inhibition in LDL receptor deficient mice $\left(\mathrm{Ldll}^{-/}\right)$was able to inhibit atheroma development and associated $\mathrm{VC}$ or osteogenic activity ${ }^{257}$. BMP antagonistic FGFs are expressed upon thyroid hormone induction and suppress chondrocyte proliferation in growth cartilage independently of IHH. FGFs are additionally synthesized by monocytes, macrophages, mesenchymal cells and osteoblasts, playing a critical role in early angiogenesis and mesenchymal cell mitogenesis ${ }^{258}$. Interestingly, in vivo experiments on $\mathrm{ApoE}^{-/-}$mice constitutively overexpressing endothelial FGF showed increased EC apoptosis, endothelial to mesenchymal transition and SMC proliferation ${ }^{259}$. This effect together with concurrent TGF $\beta$ activation implies an overall pro-atherogenic outcome of high FGF levels ${ }^{260}$, even though they have been clinically applied to treat ischemic diseases ${ }^{261}$. In summary, the combination of knowledge gathered in preclinical and clinical studies related to skeletal and cardiovascular health highlights the presence of a bone-vascular regulatory axis. The balance between positive signaling molecules and their inhibitors is a critical determinant of osteogenesis and thus development of mineralized matrix in different tissues. Systemic dysmetabolic states, commonly found in connection to CVD, perturb this sensitive balance, giving rise to severe calciotropic dysfunctions.

\subsubsection{Proteoglycan 4 and other important proteoglycans}

The group of proteoglycans (PGs) encompasses 43 distinct genes and great variance of different proteins due to alternative splicing. Proteoglycans are often considered as a subclass of glycoproteins with the key difference of repeating units of long unbranched disaccharide chains $v s$ short highly branched, non-repeating glycan chains.

Finding a comprehensive classification of the different subgroups has turned out to be a challenging task. However, current literature proposes a simplified categorization according to three criteria: i) cellular and subcellular location, ii) overall gene/protein homology and iii) the presence of specific protein modules within their respective protein cores ${ }^{262}$. According to this classification, PGs are found intracellularly (within secretory granules), on the cell surface (transmembrane spanning or glycosylphosphatidylinositol (GPI) -anchored), in the pericellular and basement membrane zone or extracellularly (e.g. hyalectans and small leucine-rich PGs). While there is only one intracellular PG, serglycin, mainly responsible for granule integrity in mast cells ${ }^{263}$, a big group of heparan sulfate PGs function as major biological modifiers of growth factors at the cell surface, pericellular matrix and basement membrane zone ${ }^{264}$. Due to their ability to interact and bind with each other as well as to key components of the basement membrane, they achieve optimal growth factor-receptor presentation, as well as maintenance of morphogen gradients ${ }^{265,266}$. Chondroitin and dermatan sulfate containing PGs additionally function as structural constituents of complex ECM, providing fiber organization, viscoelastic properties and retain water ${ }^{267}$. Small leucine-rich PGs are the most numerous class, functioning both as structural part and signaling molecules within the ECM. By acting on receptor tyrosine kinases and toll-like receptors (TLRs) ECM PGs are able to modulate fundamental processes involved in development and pathology, such as migration, proliferation, apoptosis, inflammation and autophagy ${ }^{268-273}$.

Proteoglycans secreted by vascular SMCs exhibit important regulatory functions within the vascular environment. HSPG2, a modular heparan sulfate PG and essential component of the basement membrane in healthy arterial walls, has been shown to maintain endothelial barrier function and inhibit SMC proliferation in the context of intimal hyperplasia ${ }^{37,54,271}$. However, 
in conjunction with its wide expression within other vascular and avascular tissues, HSPG2 has also been shown to modulate cell adhesion ${ }^{274}$, lipid metabolism ${ }^{275}$ as well as vascular and skeletal biomechanics ${ }^{276,277}$. Increased vascular expression of ACAN during intimal hyperplasia formation and atherosclerotic lesion development has been related to SMC activation, phenotypic transformation and apoptosis ${ }^{278}$. Nevertheless, ACAN is known to form large supramolecular complexes $(>200 \mathrm{MDa}$ ) generating a densely packed gel to support the load-bearing capacities of cartilage tissues ${ }^{279}$. In addition to its mechanical stabilization, ACAN has the physical properties to counteract oxidative stress by scavenging redox-active cations ${ }^{280}$. These cation-scavenging capabilities are mainly generated by a large amount of negatively charged carbohydrate chains, a general feature of most PGs. In connection to the lipid retention hypothesis, one of the most accepted theorems to explain initiation of atherosclerotic lesion formation ${ }^{281}$, PGs have been shown to particularly bind positively charged regions of apoB-containing lipoproteins ${ }^{55}$, thereby contributing to lipid accumulation within the media and neo-intima. Genetic modification of the heparan sulfate side-chain formation in the HSPG2 protein of $\mathrm{ApoE}^{-/-}$mice has been shown to result in significantly reduced lipid retention during the early phases of disease development ${ }^{54}$. This example highlights the conflicting roles of PG's inherent physical properties within the vasculature, on the one hand providing vital structural support to maintain vessel wall homeostasis, but becoming a contributor to pathological processes typical for atherosclerosis on the other.

We identified lubricin/PRG4 as the most significantly upregulated transcript in calcified plaques, correlated to bone metabolism and inhibition of inflammatory pathways. PRG4 is a large molecule $(\sim 345 \mathrm{kDa})$ that consists of approximately equal proportions protein and
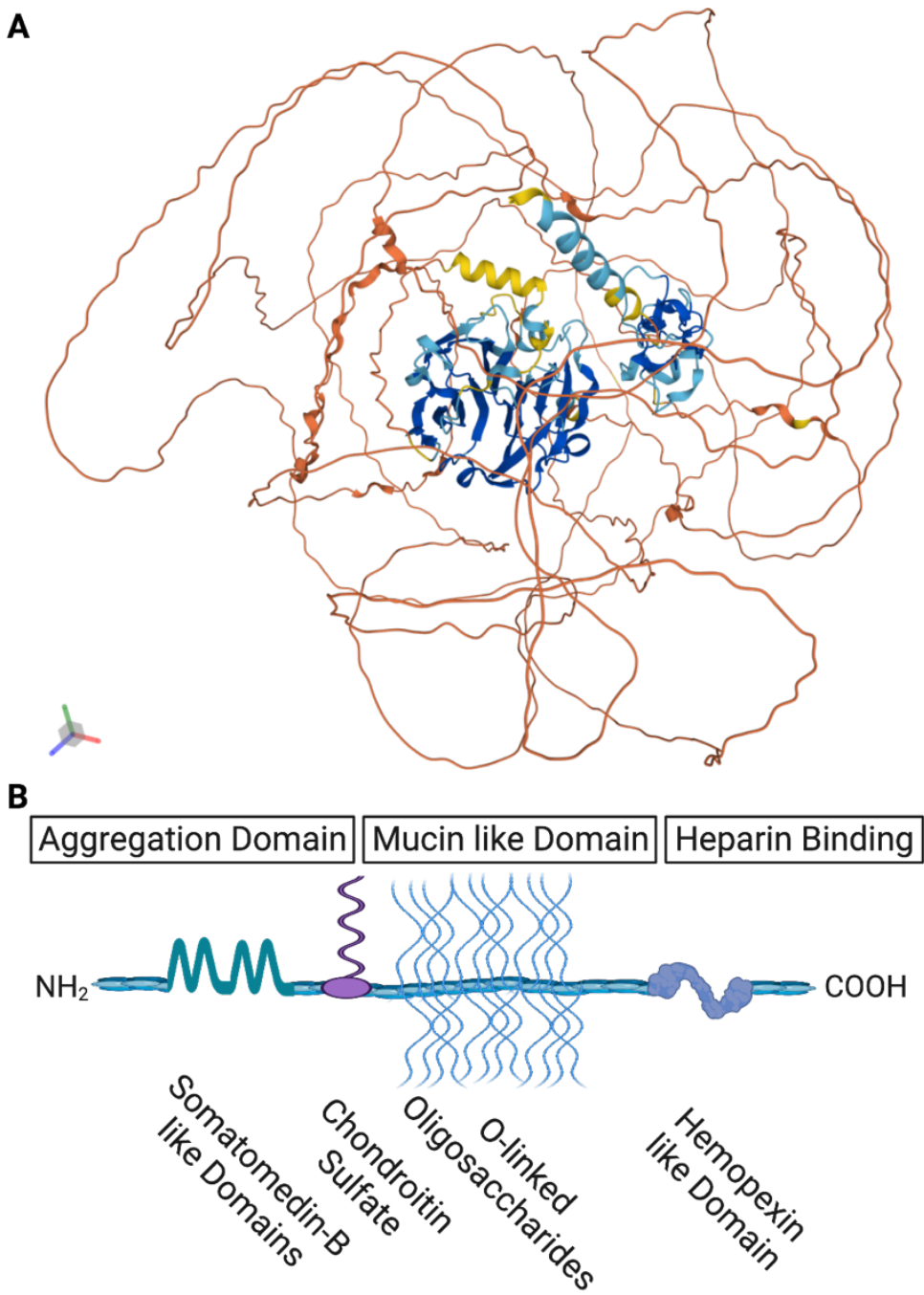

Figure 6: Illustration of the PRG4 protein structure. (A) Predicted 3D structure using AlphaFold ${ }^{1}$. (B) Simplified schematic of the main domains. oligosaccharides, either referred to as proteoglycan or glycoprotein due to harboring structural features of both classes (Figure 6A). Besides heparin-binding domains, multiple mucin-like repeats and an aggregation domain, it contains more than 168 glycosylation sites, making it highly hydrophilic ${ }^{282}$, while the non-glycosylated regions can bind to collagens and other cartilage proteins ${ }^{283,284}$ (Figure 6B). Mainly produced by synovial fibroblasts and superficial zone chondrocytes ${ }^{285}$, PRG4 has been shown to be crucial for joint homeostasis via surface lubrication, suppression of inflammatory responses and exhibiting other cytoprotective functions 286,287 . Its biological functions are mediated by direct binding to a number of receptors including CD44 as well as TLR 2 and 4. PRG4-CD44 interaction inhibits nuclear factor kappa B (NF-кB) translocation in human synovial fibroblasts attenuating IL $1 \beta$-induced synoviocyte proliferation and expression of 
matrix-degrading enzymes ${ }^{288-292}$. PRG4 has also been shown to affect synovial fibroblast to myofibroblast transition by reducing fibrotic marker expression (SMA and collagen I) ${ }^{293}$ and to regulate accumulation and polarization of macrophages in the synovium ${ }^{294}$.

However, PRG4 expression is not limited to joints and cartilage as it has also been detected in other tissues like tendon, lung, liver, heart, bone, ligament, muscle, and skin 285,295,296. Moreover, it poses neutrophil binding capacities within human plasma via L-selectin ligand activity ${ }^{297}$.

Therapeutically, recombinant forms of PRG4 have been shown to exhibit disease-mitigating effects in pre-clinical osteoarthritis (OA) models ${ }^{288,298}$. In this thesis, we investigated whether PRG4 has similar roles in late stages of atherosclerosis and osteogenic SMC transition. 



\section{RESEARCH AIMS}

This $\mathrm{PhD}$ project is part of the EU Marie Curie International Training Network program INTRICARE that has a focus on various aspects of $\mathrm{VC}$ and its role in vascular disease.

The aims of this program were to:

- Identify and functionally characterize novel sensitive markers of calcification.

- Understand the underlying mechanisms associated to cellular phenotypic switching in atherosclerotic ossification.

- Address the outstanding clinical need for improved diagnostic accuracy, to reliably predict future strokes and other lethal CVD related events, by highlighting a potential translational pipeline between clinical imaging, in silico analysis and basic cell biology.

More specifically, the objectives of this thesis were to:

I. Relate calcification grade, assessed by patient diagnostic CT imaging, to the overall gene expression profiles in human plaques. (Study I)

II. Investigate the role of PRG4 in atherosclerotic disease progression, intimal and valvular calcification. (Study II and III)

III. Define the influence of macro-calcification on local plaque biomechanics and SMC phenotype in human carotid lesions. (Study IV) 



\section{MATERIALS AND METHODS}

In an effort to connect clinical diagnostics with a deepened understanding of the underlying basic biology, all studies presented in this thesis originate from human biobank data, subsequently investigated and validated by in silico, in vivo and in vitro methodologies.

\subsection{HUMAN BIOBANKS}

In order to facilitate translatability of our studies into clinical settings, discovery and initial characterization was conducted utilizing several human biobanks.

The Biobank of Karolinska Endarterectomies (BiKE), prospectively enrolls patients undergoing surgery for $\left(>50 \%\right.$ NASCET $\left.{ }^{299}\right)$ carotid stenosis at the Department of Vascular Surgery, Karolinska University Hospital, Stockholm, Sweden. Symptoms are defined as TIA, minor stroke and amaurosis fugax. Patients not showing symptoms within 3 months prior to surgery are categorized as asymptomatic. The biobank was established in 2002 and currently consists of more than 1500 patients comprising i) a BioBank with plaque tissues, plasma, PBMCs, DNA and RNA including a material register, ii) an ImageBank with quantified diagnostic images by CT/US and iii) a DataBank of 100 clinical variables (i.e. age, gender, comorbidities, therapy and blood measurements), microarrays from plaques and peripheral blood monocytes, proteomic analysis of lesions by mass spectrometry and plasma by Luminex. Additionally, biomaterial for further analysis is deposited as cDNA for qPCR and paraffinembedded plaque tissues for histology.

Study $I$ and III were based on a selected cohort of BiKE patients $(\mathrm{n}=40)$, stratified according to the presence of macro-CALC visualized by preoperative CTA. The cohort included 20 highly calcified carotid plaques and 20 lesions diagnosed with low CALC grade, collected from 2008 to 2013.

In study I, findings related to CALC grade were investigated and validated using a subcohort $(n=61)$ from an independent biobank called KärITx, enrolling CKD patients undergoing living donor kidney transplantation surgery since 2009 at the Department of Transplantation Surgery, Karolinska University Hospital, Stockholm, Sweden. This biobank is designed to deepen the understanding of bone turnover and VC in CKD patients by collection of prospective and retrospective blood and urine samples as well as arterial (epigastric artery), fat and muscle biopsies obtained during transplant surgery. These samples facilitate a wide range of analyses, including discovery of biomarkers for disrupted inflammatory, and metabolic processes as well as tissue characterization by IHC, DNA and RNA assays. Moreover, arterial biopsies are subjected to histopathological examination assessing the medial CALC grade, also called Mönckeberg calcification, occurring systemically in the arterial media of patients with advanced chronic kidney disease, diabetes mellitus or other chronic inflammatory conditions. Of note, while the median age of these patients was only 45 years, $10 \%$ already suffered from CVD comorbidities.

To investigate mechanisms related to human disease progression, study III utilized a rare collection of peri-renal aortic biopsies representing atherosclerotic pathology within all age groups between 5 and 76 years ${ }^{76}$. Samples included in this biobank called SOKRATES are collected during organ transplantation and classified according to the adapted American Heart Association classification ${ }^{3}$ as proposed by Virmani et al ${ }^{300}$.

Extending our investigations of PRG4 in intimal CALC to AVS in study II, we benefitted from a third biobank at Karolinska University Hospital collecting tricuspid aortic valves from AVS patients undergoing aortic valve replacement. After surgery, macroscopic evaluation of the aortic valve leaflets is conducted to visually identify and dissect non-calcified from calcified regions, thereby establishing a model of disease progression within each individual valve. Observed pathology ranges from healthy or fibrotic (non-calcified) to advanced stages, characterized by the presence of macro-calcified nodules. Subsequently, the separate tissues can be used for proteomic, transcriptomic and histological analyses as well as VIC isolation to characterize and compare expression profiles and cell phenotypes in relation to progressive 
AVS. In study II, 64 valves were used for transcriptomic analyses, 4 for immunohistochemistry and 20 for cell isolation, respectively.

\subsection{IN SILICO CTA IMAGE ANALYSIS AND BIOMECHANICAL MODELING}

In silico analysis of carotid intimal lesions, included in study $I, I I I$ and $I V$, was conducted on CTA exams routinely performed in preoperative health care at hospitals in Stockholm area. Image acquisition with a kilovoltage peak of 100 or 120 was performed in caudo-cranial direction from aortic arch to vertex after intravenous contrast injection. Axial images were constructed with a common slice thickness of $0.625 \mathrm{~mm}$.

\section{Image analysis}

The initial vessel segmentation is a semi-automated process requiring digital placement of the vessel centerline and selection of the plaque area within the respective software workstation for vascular CT-scans (Figure 7). Outer and inner borders of the artery are then automatically recognized, with an option for manual adjustment, to calculate wall and lumen volumes. Following these initializing steps, specialized software can be used for morphological tissue analysis.

Study I utilized TeraRecon (iNtuition, TeraRecon, Foster City, CA, USA, 2015), a modular software that can be optimized for many applications due to the free adjustment of HU thresholds according to the examination objectives. We used settings specifically developed for plaque analysis, with a threshold of $>400 \mathrm{HU}$ to mark intimal CALC volume (Figure 7). The CALC degree was then calculated in relation to the total wall volume in the same region.
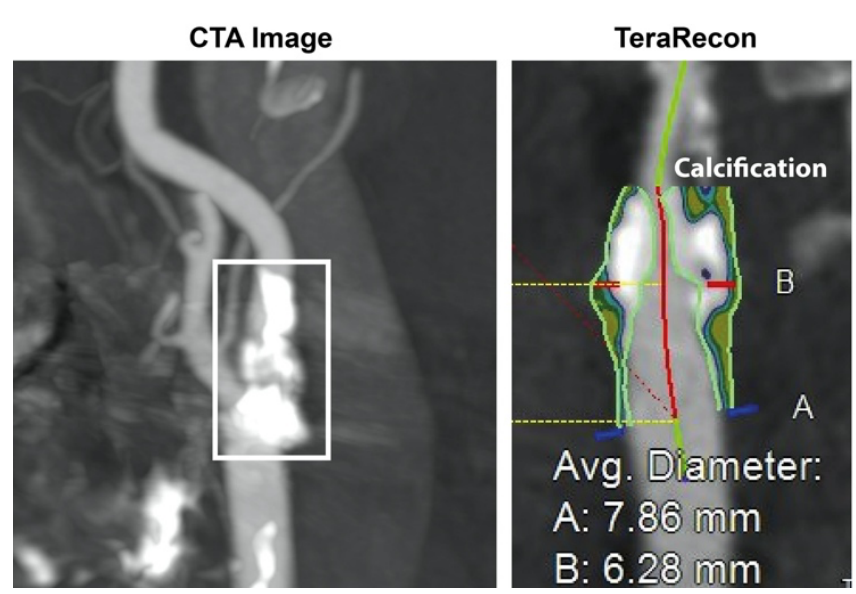

Figure 7: Representative images of a classic CTA view in comparison with TeraRecon and vascuCAP analysis software.

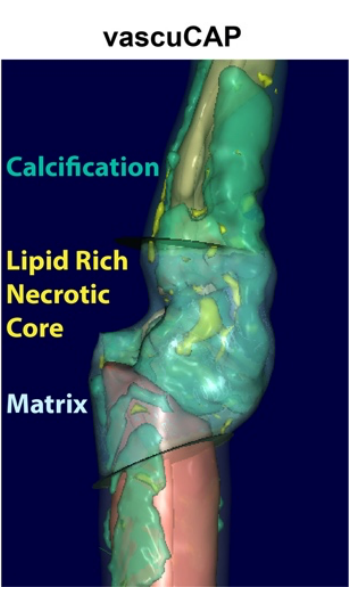

Study III and IV upgraded this simple annotation by use of vascuCAP (Elucid Bioimaging, Wenham, MA, USA), a histologyvalidated tool for computer-aided phenotyping of atherosclerotic lesions based on diagnostic CTA images ${ }^{117}$. After

the initial vessel segmentation and manual adjustment, this software allows for automated tissue composition analysis including many additional components (lipid rich necrotic core (LRNC), IPH and tissue matrix (MATX)) (Figure 7) and structural measurands (plaque burden and cap thickness). To avoid limitations of fixed thresholds, accuracy is achieved by algorithms that account for distributions of tissue constituents, for which overlapping densities were classified by expert-annotated histology, rather than assuming constant material density ranges. The implementation of these algorithms not only enhances separation of complex tissue compositions but also reduces inter-observer variability by increased automation.

\section{Biomechanical modeling}

As previously introduced, the arterial wall is constantly subjected to complex biomechanical forces induced by the pulsatile intraluminal blood flow. Changes of these forces due to turbulent flow or pathological hypertension have been proposed as one of the earliest causal drivers of atherosclerotic disease initiation. In short, mechanical load on solid materials can be quantified as stress, measured in pascal $(\mathrm{Pa})$. Forces applied in parallel to the matrix surface are defined as shear stress, while forces acting perpendicular to the matrix are called normal stress. 
Due to the multidirectional transmission of forces within a tissue matrix a numerical terminology becomes very complex, therefore conversion to von Mises stress allows the expression of a general multiaxial stress state by a single number. The physical deformation of a matrix in response to stress is measured as unitless strain or stretch in \%, representing the relative change of angle or length. The degree of tissue strain is determined by the specific tissue properties and quantified as stiffness. Healthy non-calcified vascular tissue has non-linear stress-strain properties with increasing stiffness over strain due to elastin and collagen fiber elongation. Calcified tissue adopts linear non-elastic stress-strain properties due to the greatly increased ECM stiffness. A material that preserves its volume during deformation is defined as incompressible, in biological tissues this is a rather idealized characteristic but often necessary to design computationally feasible modeling tasks. In order to generate a constitutive biomechanical model, these and other mechanical properties would have to be consistently formulated. To bypass the complexity of such a comprehensive model, continuum mechanics define a macro-material by a continuum of representative elements, thereby modeling a structure based on one known sub-module. Using this approach, successful modeling can be conducted while heterogeneity is gradually increased.

Evaluation of structural plaque stresses requires computational FEM due to the complex geometries and non-linear material properties. In study IV, FEM analysis of four selected patients was performed using COMSOL Multiphysics 5.6 (COMSOL AB, Stockholm, Sweden) by creating a converted matrix mesh based on segmentations obtained through vascuCAP ${ }^{301}$. Slight manual surface smoothing was applied to avoid local mesh irregularities due to the limited resolution of routine clinical CTA imaging. The generated surface mesh was then converted into a 3D solid domain of the vessel wall and represented by approximately $20 \mathrm{k}$ quadratic tetrahedral finite elements. A spatial interpolation function was used to specify the local tissue characteristics of LRNC, CALC and MATX. The mechanics of each of these tissues were modeled using material properties based on previous experimental research ${ }^{302}$ and enforced tissue incompressibility. Diastolic and respective systolic blood pressure were applied to the wall and the tissue stretch assessed at three cross-sections distal to the bifurcation to cover different regions around the maximal-stenotic part of the lesion.

\subsection{IN VIVO MODELS OF OSTEOGENIC TRANSFORMATION AND CALCIFICATION}

Since wild-type (WT) rodents are widely resistant to the development of atherosclerotic disease burden or CVD in general, most in vivo models to study mechanisms of disease progression in a complete organism have to be induced by either genetic, surgical or pharmacological manipulation.

Commonly applied genetical modifications to induce susceptibility for atherosclerosis in mice are $\mathrm{Ldlr}^{-/-} 303$ and $\mathrm{ApoE}^{-/-} 304$. Both modifications target the clearance of lipids from the circulation which is mainly controlled by binding of the LDL receptor to the ApoE and ApoB-100 components of LDL particles. The importance of functional LDL receptor binding had already been shown in studies on familial hyperlipidemia in humans. Accordingly, $\mathrm{Ldlr}^{-/}$as well as $\mathrm{ApoE}^{-/-}$mice suffer from chronically elevated circulating cholesterol levels, initiating atherosclerotic plaque formation ${ }^{305}$. Old $\mathrm{ApoE}^{-/-}$mice will develop atherosclerotic lesions even on normal chow, however plaque formation is significantly more severe when combined with a western-type diet. Despite noticeably different lipid profiles compared to human patients diagnosed with severe atherosclerosis, lesions in $\mathrm{ApoE}^{-/-}$mice resemble human plaque progression in many morphological features, such as lipid accumulation, inflammatory cell infiltration, SMC proliferation and migration, fibrous cap as well as late-stage necrotic core and even CALC formation ${ }^{306}$. Therefore, $\mathrm{ApoE}^{-/-}$mice were used in study III to model different stages of carotid plaque formation and CALC.

\section{Osteogenic transformation in intimal hyperplasia}

Intimal thickening, triggered by endothelial activation is one of the first signs of atherosclerotic disease initiation. It is known that structural cells like SMCs and VICs are able to respond to 
injury and changes in biomechanical stress by proliferation, migration and ECM remodeling. However, it remains unclear to what extend osteogenic phenotypic transformation is involved during these early steps of vascular remodeling.

Two surgical methods have been established to reliably induce intimal hyperplasia in rodents. One triggers endothelial activation and neo-intima formation by disturbing the blood flow. This model is commonly generated via ligation of the left carotid artery in proximity of the bifurcation and has been presented as an efficient method to study SMC phenotypic changes during vessel remodeling ${ }^{307}$. Complete ligation induces obstruction of the blood flow and subsequent thrombus formation. Significant intimal thickening can already be observed 2 to 4 weeks post-surgery, characterized by inflammatory cell infiltration and vascular SMC proliferation leading to complete lumen occlusion distal to the ligation. While this model is generally easily reproducible, omitting complex surgical manipulations, it lacks more complex disease characteristics that are provoked by disturbed blood flow. Alternatively, more experienced animal surgeons perform partial ligations in order to create turbulent flow conditions, even more enhanced by the addition of a rigid cuff surrounding a short area of the vessel. These techniques are able to replicate human lesion formation to a larger extend and in combination with genetic manipulation even clinical complications ${ }^{308}$. Therefore, to unravel the contribution of osteogenic SMC transformation and PRG4 expression during early lesion formation in study III, transcriptomic analysis and IHC was conducted on $\mathrm{ApoE}^{-/}$mice

\section{A}

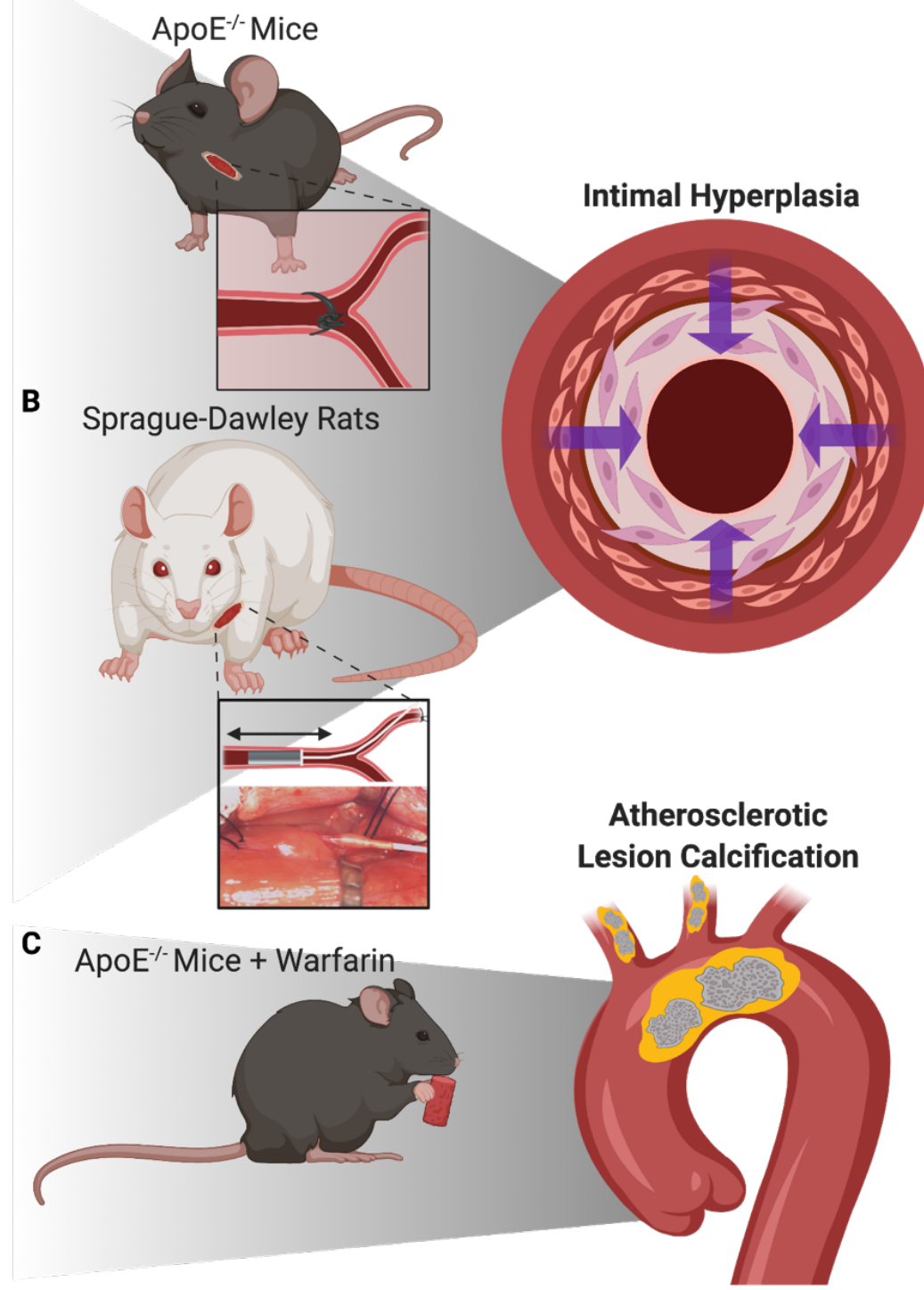

Figure 8: Schematic illustration of the three animal models utilized in this thesis to study SMC phenotypic transition throughout intimal hyperplasia and atherosclerotic lesion calcification. undergoing partial carotid ligation on a western-type diet (Figure 8A).

Another surgical method inflicts endothelial denudation by mechanical injury to the vessel wall. This technique is either performed by repeatedly moving a spring wire through the carotid artery of mice or utilizing a balloon catheter in larger rodents like rats ${ }^{309}$. The endothelial damage causes platelet aggregation to the injury site as well as inflammatory infiltration, subsequently activating vascular SMCs. Neo-intima formation is commonly observed within 2 weeks after surgery. This method consistently replicates complex biological processes following endothelial injury in order to regain vascular homeostasis and has been used for detailed description of cellular adaptation and ECM remodeling 44 . However, in rodents the vasculature is usually able to regain homeostasis while in human pathology remodeling processes would 
lead to chronic intimal hyperplasia and luminal stenosis. Hence, study III applied the carotid balloon injury model in Sprague-Dawley rats (Figure 8B) as an additional in vivo study of intimal hyperplasia with a focus on SMC contribution to vascular healing via osteogenic phenotypic changes, ECM remodeling and PRG4 expression.

\section{Atherosclerotic plaque calcification}

$\mathrm{ApoE}^{-/-}$mice are a widely accepted model to achieve atherosclerotic lesion formation in rodents. However, only very old mice have been shown to sporadically develop late-stage disease features, like macro-CALC, as found in human tissues.

Different additional methods have been developed to accelerate vascular mineralization processes. Genetic deletion of systemic CALC inhibitors (MGP, Fetuin-A and Klotho) has been shown to cause extensive VC, however in many cases with the drawback of associated disruption of skeletal homeostasis and symptoms of premature aging 227,310,311. Surgical removal of 5/6th of the kidney has been shown to mimic CALC processes similar to severe CKD ${ }^{312,313}$. A pharmacological treatment to induce rapid hyperphosphatemia and medial CALC utilizes high-dose subcutaneous injections of vitamin D3 ${ }^{314}$, while low levels of vitamin D3 in connection to uremic conditions have also been shown to induce VC similar to pathologies found in CKD, causing somewhat ambiguous interpretations in relation to general CVD related $\mathrm{VC}^{315}$. Warfarin, an anticoagulant in clinical use (including CVD patients), has been shown to cause $\mathrm{VC}$ by inhibiting the carboxylation of Gla proteins via blocking of vitamin-K recycling. Although requiring longer treatment in mice, this model provides a reliable approach for CVD related VC with clinical impact. A previous study validated the accelerated atherosclerotic lesion progression and CALC ${ }^{316}$ which was utilized in study III to achieve conditions similar to fibro-calcific plaques (Figure 8C), thereby identifying the temporal involvement of PRG4 throughout atherosclerotic plaque CALC. In brief, $\mathrm{ApoE}^{-/-}$mice received either a western-type diet + vitamin $\mathrm{K} 1$ or a western-type diet + vitamin $\mathrm{K} 1+$ warfarin. Additional vitamin K1 supplementation is necessary to control toxic effects on the liver and prevent bleeding, while introducing vitamin K-deficiency in the vasculature.

\subsection{IN VITRO MODELS OF OSTEOGENIC TRANSFORMATION AND CALCIFICATION}

Primary human vascular SMCs and VICs are a resource for mechanistic studies of CALC processes as well as high throughput screening of pharmacological interventions without deviating too far from a natural setting. While these cells, when used at low passage numbers, express typical markers and show functional features of differentiated structural cells, some of the more sensitive markers may already be downregulated during cell isolation, contributing to the onset of phenotypic modulation. Moreover, cells isolated from different donors might show inherently distinct predispositions to CALC and transdifferentiation. In study $I I I$ and $I V$, we conducted exploratory studies on commercially available primary ascending aortic SMCs from donors not diagnosed with any vascular comorbidities or risk factors for CVD. For study III, we extended our analysis to SMCs isolated from biopsies classified as normal aortic wall tissue, in patients undergoing thoracic aneurysm surgery. Primary human VICs used in study II were isolated from aortic valves directly after valve-replacement surgery and phenotypically characterized. Nevertheless, it cannot be excluded that results are affected by interpatient variability.

In vitro CALC is commonly achieved by supplementation of either inorganic $\mathrm{Pi}$ and $\mathrm{Ca}$ or organic $\beta$-glycerophosphate. $\beta$-glycerophosphate supplementation relies on the active excision of glycerol by SMC or VIC derived tissue non-specific AP, to increase free phosphate levels in the cell culture media. Additional supplementation with ascorbic acid and dexamethasone promotes collagen production, leading to calcified nodules containing collagenous inner cores 317,318. Inorganic Pi and $\mathrm{Ca}$ overload has been shown to exhibit direct effects on SMC and VIC osteogenic transformation. On the one hand, $\mathrm{Pi}$ can act as a direct signaling molecule, promoting osteoblastic transformation ${ }^{319}$. On the other hand, inorganic $\mathrm{Pi}$ and $\mathrm{Ca}$ will form $\mathrm{CaPi}$-crystal precipitations in a concentration-dependent manner (at approximately $2 \mathrm{mM}$ ) if 
not actively inhibited by released CALC inhibitors. Moreover, in the presence of live cells these CaPi-crystals are embedded in an organic amorphous matrix, resembling the structure of hydroxyapatite crystals ${ }^{320}$. High Ca treatment has also been connected to active release of calcifying EVs, similar to early CALC processes in vivo ${ }^{139}$. SMCs in early passages have been reported to react to these ossifying stimuli by phenotypic modulation in a similar fashion as observed in vivo, showing increased expression levels of osteogenic markers such as BMP2, SOX9 and RUNX2 ${ }^{66,183,184,209,230,320}$. We applied this methodology in studies II and III to test different factors typical for the atherosclerotic plaque milieu and assess their effect on SMC CALC and phenotypic changes.

To induce CALC, medium was supplemented with $3.6 \mathrm{mM}$ Ca or $2.6 \mathrm{mM}$ Pi for up to 12 days and refreshed every 3 days. In order to address the specific impact of typical cytokines previously implicated in atherosclerotic disease progression and particularly osteogenic transformation, primary SMCs were stimulated with $20 \mathrm{ng} / \mathrm{ml}$ of human IGF1, IGF2, TGF $\beta$, $\mathrm{TNF} \alpha$ or IFN $\gamma$, or $50 \mathrm{ng} / \mathrm{ml}$ of human PDGFB, respectively. VICs were treated with $10 \mathrm{ng} / \mathrm{ml}$ TGF $\beta$ or $20 \mathrm{ng} / \mathrm{ml} \mathrm{BMP2}$. In a functional assay investigating the impact of extracellular PRG4 on SMC and VIC CALC, we combined $\mathrm{Ca}$ and Pi mediated CALC with full length rhPRG4 (Lubris BioPharma, USA) supplementation at concentrations of 10 and $100 \mu \mathrm{g} / \mathrm{ml}$.

\subsection{IN VITRO MODELS OF TISSUE STRETCH}

Nevertheless, VC does not only have direct effects on the phenotype of structural cells. Especially sheet-like macro-CALC leads to a significant increase in tissue stiffness, reaching an average Young's modulus of up to $25 \mathrm{GPa}^{321}$, approximately $10 \mathrm{k}$-fold higher than soft or only partially calcified fibrous tissue. This causes changes in load-bearing and stress-redistribution within the tissue. Vascular SMCs are known for their phenotypic adaptation in order to maintain vessel function under stretch ${ }^{322,323}$ but pathologically increased tissue stress, typical for chronic hypertension and CVD, has been shown to induce apoptosis of differentiated SMCs 324. Different in vitro models of cyclic stretch have been established to delineate SMC phenotypic changes according to frequency and level of applied stress ${ }^{325}$. These models mostly utilize stretchable membranes instead of rigid culture plates as culture surface. While matrix gels further enhance tissue-resemblance, experimental set-up and analysis becomes increasingly complicated. In study $I V$, we applied a $2 \mathrm{D}$ system to investigate the impact of specific stretch-parameters, acquired within highly calcified human carotid plaques by in silico FEM, on vascular SMC morphology, phenotype and survival. In addition to stretchable silicone membranes, used to model the soft tissue environment, we included standard rigid culture plates as the closest biomechanical replication of a calcified plaque matrix.

\subsection{GENE EXPRESSION ANALYSIS}

Analytical methods to detect and quantify changes in gene and protein expression due to disease processes, phenotypic adaptations or pharmacological interventions are crucial to understand underlying molecular mechanisms resulting in pathological tissue modification and clinical symptomatology. Scientists have developed many methods mostly applicable to tissues and cell culture bulk samples, allowing for simultaneous assessment of gene-sets or specific detection of few targets.

\section{Gene expression analysis by microarray}

In order to characterize differences in gene expression from human carotid lesions (Study I), human aortic valves (Study II) and in vivo models of intimal hyperplasia (Study III), we conducted microarray profiling. The basic principle of this technique is to utilize specific DNA probes, bound to a solid surface, to simultaneously study the relative expression of a large number of genes. Sample preparation includes reverse transcription of high quality RNA samples into cDNA which hybridizes to the complementary probes on the microarray and is subsequently labeled by a fluorescent dye. Signal intensity is then quantified by a fluorescence scanner. Commonly, several probes of slightly different sequence but targeting the same transcript are randomly distributed across the chip, referred to as a probe set. However, the raw 
readout cannot be linearly correlated with the absolute RNA concentration but needs to be assessed relative to other samples within the same batch. Additional data post-processing steps are performed in order to summarize probe sets, perform data normalization (e.g. guanine cytosine count normalization to adjust probe affinity variations) and transformation (e.g. background correction and log transformation) for clear graphical presentation. Microarray analysis has become a fast and increasingly affordable method with the ability to quantify a myriad of coding and non-coding transcripts. However, relative quantification always requires direct comparison of treatment conditions within the same batch and chip design can introduce a bias towards already known and expected transcripts.

\section{Gene expression analysis by $q P C R$}

Quantitative real-time polymerase chain reaction (qPCR) is a technique to monitor amplification of target DNA molecules during a PCR process. Similar to microarrays, a reverse transcription step is required to generate cDNA from RNA samples. Common methods for the detection of PCR products include non-specific fluorescent dyes (e.g. SYBR green) that intercalate with any double-stranded DNA and sequence-specific DNA probes (e.g. TaqMan) consisting of oligonucleotides that are labelled with a fluorescent reporter, ensuring detection only after hybridization of the probe with its complementary sequence. Generally, the PCR process requires a series of temperature cycles that are sequentially repeated 25 to 40 times. Each cycle normally consist of three stages: i) the denaturation (around $95{ }^{\circ} \mathrm{C}$ ) enforces separation of the nucleic acid double chain, ii) probe and primer to DNA hybridization is facilitated at a temperature of around 50 to $60^{\circ} \mathrm{C}$ and iii) strand elongation and polymerization by DNA polymerase is executed between 68 to $72{ }^{\circ} \mathrm{C}$. Optimized polymerase enzymes and short target sequences allow to skip the last step as DNA replication is completed already during the change between alignment/hybridization and the next denaturing stage. In addition, fluorescence intensity is quantified during short phases at the end of each cycle, with a temperature of around $80{ }^{\circ} \mathrm{C}$ to reduce background caused by the presence of primer dimers in case of non-specific dyes. The specific temperatures and timings depend on a wide variety of parameters such as the polymerase enzyme, divalent ions and deoxyribonucleotide triphosphate (dNTPs) concentration and primer design. The fluorescent readout-data of qPCR assays is represented for each sample by the cycle threshold $(\mathrm{Ct})$ value, the number of amplification cycles required to generate a fluorescence signal significantly above the background fluorescence. Therefore, $\mathrm{Ct}$ values are inversely proportional to the original relative RNA expression level. Similar to microarray data, $\mathrm{Ct}$ values have to be compared to samples run within the same batch and are commonly transformed via the $\Delta \Delta \mathrm{Ct}$ method to present the fold change of a target gene relative to a reference or "housekeeping" gene. Good reference genes have to show stable expression under all treatment conditions, hence it can be an advantage to test several reference genes for optimization. Apart from the necessity for good reference genes, qPCR data strongly depends on high quality RNA extraction and storage. DNA contaminations within the original samples could otherwise cause positive signal detection independently of the existence of transcribed RNA.

In studies II / III and IV we utilized qPCR analysis based on TaqMan assays to quantify genes of interest in samples from in vitro experiments. Ribosomal Protein Lateral Stalk Subunit P0 (RPLP0) was used as reference gene in SMC samples and hypoxanthine phosphoribosyltransferase 1 (HPRT) in samples extracted from VICs.

\subsection{HISTOLOGICAL PROTEIN ANALYSIS}

Transcription products assessed in gene expression assays are often subjected to multiple post-transcriptional modifications (e.g. alternative splicing, 5'capping and 3'polyadenylation) affecting temporal and quantitative parameters of protein translation as well as creating several protein variations from one transcript. For that reason, it is necessary to validate the relationship between transcriptomic dysregulation and protein presence, localization and interaction within morphological distinct tissue features. 


\section{Tissue characterization by histology}

Histology (new Latin from Greek histos = tissue and logia = study, first mentioned using this terminology in 1919 by August F.J.K. Mayer) studies the microscopic anatomy, combining assessment of organs, tissues and cells. Histopathology is the delineated clinical application to identify dysfunctional tissues, often required for accurate diagnosis of cancer or other diseases.

General sample preparation includes fixation of cell and tissue structures (e.g. by $4 \%$ formaldehyde creating methylene bridges, $2,5 \%$ glutaraldehyde creating pentene bridges or snap freezing), dehydration and embedding within protective substrates preserving antigens and tissue integrity, such as paraffin wax, epoxy resin or cryo embedding matrix (e.g. OCT) for hydrated samples. For staining and microscopy, the samples are sectioned utilizing a microtome or cryostat, with common section thickness between 4 to $12 \mu \mathrm{m}$.

Sections can be stained with a multitude of different histological stains derived from natural sources or chemical reactions, developed to generate tissue contrast for morphological assessment as well as to highlight specific cellular features. In the studies presented in this thesis we utilized:

1) Alizarin red, a dihydroxyanthraquinone isomer forming precipitates with free $\mathrm{Ca}$ ions and generating bright red staining of tissue components containing $\mathrm{Ca}$. This procedure works best under acidic conditions, slightly degrading the mineralized matrix to expose contained $\mathrm{Ca}$ ions.

2) Weigert's elastin, a combination of stains often including orcein (natural extract from lichen) or a combination of resorcinol (an isomeric benzenediol) and fuchsine (a chemical magenta dye), staining elastin fibers dark purple. Cell nuclei were counterstained using hematoxylin (a dark, almost black natural stain extracted from the logwood tree).

3) Masson's trichrome, combining hematoxylin, acid fuchsin, xylidine ponceau (a red azo dye), phosphomolybdic acid and methyl blue (chemical blue dye) to create dark red stain of muscle fibers, dark blue collagen matrix, light red cytoplasm and dark nuclei.

4) Movat's pentachrome, a very complex stain originally developed by Henry Z. Movat in 1955 to highlight the various constituents of connective tissue, especially cardiovascular tissue, by five colors in a single stained slide ${ }^{326}$. This stain was subsequently modified multiple times and optimized protocols differ greatly between laboratories. General components usually include alcian blue (a polyvalent basic dye), Verhoeff hematoxylin, crocein scarlet (a bright red azo dye) combined with acidic fuchsine and saffron. This stain allows identification of elastic fibers (black or blue), nuclei (black or blue), collagen and reticular fibers (yellow), mucin and proteoglycans (bright blue), fibrin (bright red) and muscle (dark red).

\section{Specific protein detection by IHC and IF}

IHC and immunofluorescence (IF) are sensitive and specific methods to detect and visualize the presence of proteins in tissues by use of antibodies. Based on similar sample preparation as general histology, this detection procedure involves deparaffinization and antigen retrieval to expose proteins of interest (e.g. by heating, citrate buffers or proteases), however these steps are usually not necessary for cryopreserved specimens. Subsequently, unspecific antibody binding sites are blocked and a primary antibody targeting the protein of interest added. A detectable signal is commonly generated by a tagged secondary antibody specific for the species of the primary antibody, thereby attaching either an enzyme based colorimetric (e.g. horseradish peroxidase or alkaline phosphatase) or fluorescent assay. This method heavily relies on the primary antibody specificity and blocking of unspecific binding, whereas assay sensitivity can be enhanced by optimized secondary antibodies and improved tags.

While IHC and IF are excellent qualitative methods for specific protein detection and localization, they have inherent weaknesses when it comes to high throughput or stringent quantitative requirements. Nevertheless, optimized staining protocols and good microscopic set-ups allow for semi-quantitative analysis by counting of positive signal in relation to total area. 
We applied both IHC (Study I, II, III) and IF (Study I, III, IV) in order to validate and characterize changes in protein expression on tissue and cellular level in comparison to detected transcriptomic dysregulations. The specific protocols are described within each manuscript's methods section.

\subsection{ETHICAL CONSIDERATIONS}

This thesis aims to not only understand the basic disease mechanism of atherosclerosis but to also generate knowledge about potential new targets which could be applied to directly improve diagnostics and patient health. These are two very important motivations for all experiments conducted.

The starting point of our studies was human tissue collected during carotid endarterectomy or kidney transplantation surgery. Each patient signed an informed consent upon being introduced to the procedure and project by the leading surgeon. This material was then analyzed with various molecular-biological and histological methods and correlated to important clinical risk factors. Patient ID's are pseudonymized and only accessible to selected staff over secure hospital computers. Human tissues and plasma samples are also coded and stored in monitored freezers to ensure the security of the respective biobank. The use of human material within this project was granted by Swedish ethical permits following the guidelines of the declaration of Helsinki or in agreement with the guidelines of the Dutch medical and ethical committee and the code of conduct of the Dutch federation of biomedical scientific societies. Sample extraction didn't confer additional risk to the patient as the surgery was conducted in exactly the same procedure. Patients without symptoms were only assigned for CEA in cases of severe stenosis, after being informed about the risks by a surgeon.

To understand the complex mechanisms of age related diseases animal models are unfortunately still irreplaceable. Since zebrafish, mice and rats never develop atherosclerotic lesions in their wildtype forms, either genetically modified or surgically induced models have to be used. This drawback is most probably caused by the much shorter lifespan and higher healing capacity of animals. To induce different kinds of plaque phenotypes and test possible treatments, genetically modified animals can be injected with compounds that would also be used in clinical practice. One example is the injection of warfarin, a commonly used anticoagulant, which induces a more calcified plaque phenotype. When using genetically modified mice it is of highest importance to ensure that the animals are not subjected to prolonged suffering or effects that severely decrease their quality of life. Apart of developing early to medium stages of CVD, $\mathrm{ApoE}^{-/-}$mice showed normal behavior and no signs of distress. We also used rats to create surgical models of vascular injury and follow the healing and remodeling process. All animals lived under monitored conditions in a professional animal facility. They were anesthetized prior to any surgery and received pain relieve afterwards. In case of complications and for tissue harvesting animals were sacrificed using a quick and painless method. All animal care and experimental procedures were performed in accordance with the guidelines for use of experimental animals and were approved by the local animal experimentation ethics committee.

In order to track functional mechanisms and molecular targets, cell culture models have to be applied. We used primary vascular SMCs either sourced from commercial providers or isolated from surplus tissue fragments extracted during aneurysm surgery, in agreement with the Dutch code for proper secondary use of human tissue. These cells can only be kept for a limited amount of time until they die or lose their typical phenotype due to complex transdifferentiation processes. Therefore these cultures are very valuable and have to be used in a responsible manner. If cells have to be moved between universities special agreements have to be signed to ensure secure handling.

With this considerate approach we try to build an ethical fundament that allows us to justify our experiments with the gain of knowledge and the prospect of improving life span as well as life quality of future patients. 



\section{RESULTS AND DISCUSSION}

Combined, the studies presented in this thesis aspired to unravel the intricacies of SMC and VIC phenotypic changes, leading to osteogenic ECM remodeling and VC. Moreover, we aimed to link molecular biology and clinical routine diagnostics by in silico modeling techniques in order to contribute to a better understanding of risk prediction based on atherosclerotic plaque morphology.

In short, we characterized PRG4 as a novel marker for early osteogenic SMC and VIC transformation, playing a key role in subsequent ECM remodeling and VC. With respect to clinical diagnostics, we demonstrated that macro-CALC in human carotid atherosclerosis assessed by routine CTA was associated to general biological processes of plaque stabilization and contributed to favorable tissue biomechanics.

\subsection{MACRO-CALCIFICATION RELATES TO STABILIZING BIOLOGICAL PATHWAYS IN LATE-STAGE CAROTID LESIONS}

In study $I$, we investigated the general genetic signatures of human carotid lesions stratified by the morphological feature of high $v s$ low CALC grade. Patients $(\mathrm{n}=40)$ enrolled in this study were matched for symptomatology, comorbidities, age and sex. Since the level of CALC was assessed by routine clinical CTA, only macro-CALC could be accounted for. Per definition micro-CALC falls below the spatial resolution of this technique.

Global gene expression analysis revealed a majority of upregulated genes in highly calcified plaques to be connected to cytoskeletal formation and contractility, typically expressed by differentiated SMCs, but to some extend also by myofibroblasts (e.g. MYOCD, CNN1, ACTA2). Moreover, genes that have been characterized to sensitively indicate SMC differentiation, such as MYH11, LMOD1 and PDLIM7, showed a corresponding increase together with genes involved in ECM and basement membrane integrity (e.g. elastin, collagens and HSPG2). Overall, this transcriptomic data indicated activation of multiple pathways in high CALC plaques commonly connected to reacquisition of vessel homeostasis, previously only known from rodent in vivo models but not human pathology. These findings were confirmed on protein level by IHC and histological tissue analysis. In contrast, genes related to inflammatory cells and their recruitment (e.g. IL 8, CD68, CD36), lipid metabolism and ECM degradation (MMPs

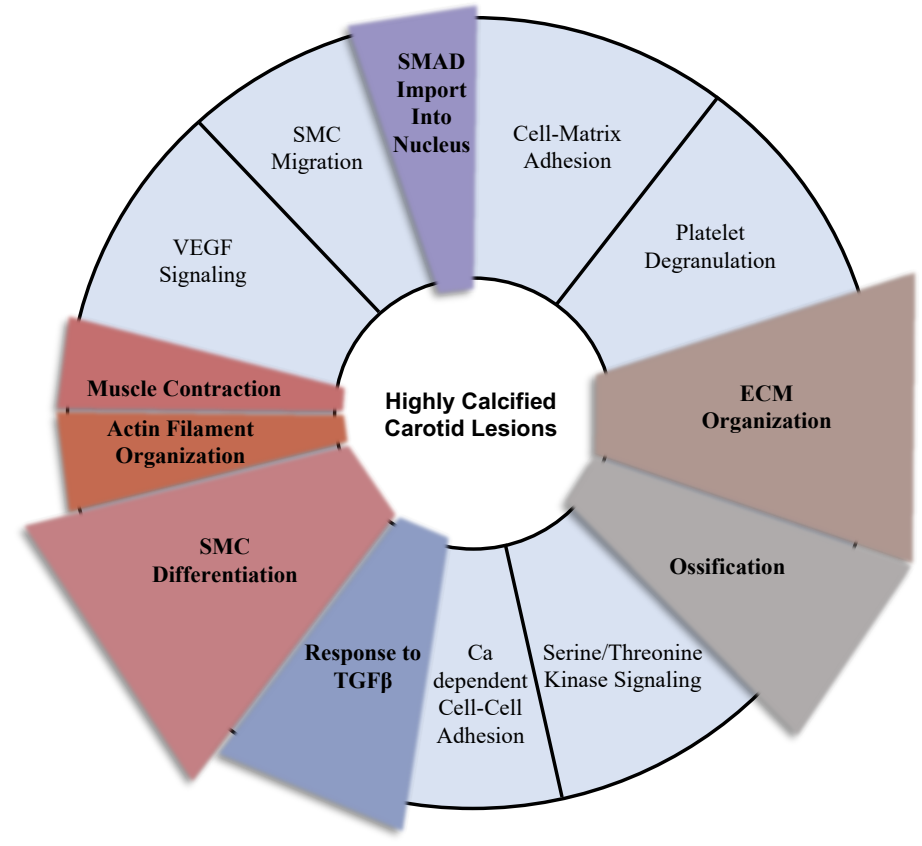

Figure 9: Graphical representation of major upregulated biological pathways in highly calcified plaques. Slice size indicates gene set enrichment. and cathepsin) were downregulated. SMC contractility, ECM integrity and fibrous cap formation are commonly considered to be major stabilizing attributes of advanced atherosclerotic lesions ${ }^{75}$, while increased inflammation and MMP activity leading to ECM fiber degradation has been linked to adverse clinical outcome ${ }^{80,327-329}$. Therefore, these results are a first indication for a more stable expression profile of highly calcified lesions in late-stage atherosclerosis. Gene set enrichment analysis, estimating the impact of dysregulated genes on biological pathways, supported our initial findings (upregulation of SMC differentiation, muscle contraction, ECM organization), but additionally revealed induction 
of processes involved in both SMC fate and osteogenic transformation, such as SMAD and TGF $\beta$ signaling ${ }^{186,330,331}$ (Figure 9). Repressed biological pathways confirmed mitigation of inflammation, ECM degradation, cholesterol metabolism and cytokine responses, with TNF, IL $1 \beta$, IFN $\gamma$ mediated signaling among the most significantly affected. When conducting the same analysis on highly calcified plaques from symptomatic patients only, upregulated pathways of ECM organization and elastic fiber formation were accompanied by processes most likely related to IPH, such as platelet degranulation, fibrin clot formation and iron uptake. Nevertheless, ECM degradation and inflammation remained repressed compared to low calcified plaques from symptomatic patients, suggesting that macro-CALC can be a feature of lesion stabilization even after partial rupture. Extraction of such "healed" lesions is not uncommon since patients are often referred for CEA after a sequence of minor symptoms.

Importantly, this profiling revealed a distinct genetic signature for highly calcified lesions that allowed for complete separation of high $v s$ low calcified plaques by predictive modeling using a panel of only 20 genes. We had previously utilized a similar model including 30 genes to separate symptomatic from asymptomatic carotid lesions with a precision of $78 \%{ }^{149}$, suggesting that the inclusion of high CALC grade as phenotypic determinant could improve clinical risk prediction for patients diagnosed with advanced carotid stenosis. On a cellular level, detection of sensitive markers for differentiated SMCs within intimal plaques in close proximity to macro-CALC indicated that this plaque phenotype could facilitate SMC redifferentiation, a novelty in late-stage human CVD.

\subsection{FORMATION OF INTIMAL AND VALVULAR MACRO-CALCIFICATION IS MARKED BY PRG4 EXPRESSION}

In study I, PRG4 emerged as the top significantly upregulated gene in highly calcified advanced carotid lesions, interestingly correlating with markers for differentiated SMCs (SMTN, MYH11, $A C T A 2)$ but also several genes typically strongly involved in matrix mineralization and remodeling (BMP2, SOX9, RUNX2, TRAP/ACP5) ${ }^{186,242,332,333}$. More detailed characterization of histological sections found a significant overlap of extracellular PRG4 with areas also showing strong signal for OPN and OCN expression. Moreover, IF identified direct overlap with SMA and TRAP positive cells surrounding macro-calcified nodules. Together these findings suggest a connection of PRG4 expression to intimal CALC formation, likely involving osteogenic SMC transformation. The presence of PRG4 in plaques classified as low-calcified can be explained by the limited resolution of clinical CTA, making micro-CALC undetectable. This was supported by speckled Alizarin-red positive areas in low-calcified lesions, a histological technique specifically staining tissue $\mathrm{Ca}$. The ambivalent relationship to both mineralized matrix anabolism $(B M P 2, R U N X 2, O C N)$ as well as catabolism (TRAP/ACP5, $O P N$ ) could reflect their temporal overlap throughout atherosclerotic lesion progression ${ }^{256}$. PRG4 appeared to have effects on both processes as a major part of the plaque ECM.

Biological pathway analysis associated PRG4 mainly to repression of SMC migration and hematopoietic progenitor differentiation, nevertheless PRG4 had previously been shown to directly mitigate inflammation in joint tissue ${ }^{289,294}$ as well as atherosclerotic disease in mice 137,334. This biological function may explain the positive correlation of $P R G 4$ gene expression with $C D 36, T N F$ and $I L I \beta$ as well as overlapping IF signals between PRG4 and CD68 positive cells in human carotid plaques from our study. Of note, PRG4 protein was only found sporadically within highly calcified medial biopsies from CKD patients which often lack the severe inflammatory response typically driving atherosclerotic intimal lesion progression. While PGs have generally been proposed as molecular components of the ECM contributing to lipid retention when overexpressed within the media and neo-intima ${ }^{55}$, a more detailed morphological analysis of late-stage carotid plaques, performed in study III, rather found a negative relationship between PRG4 and LRNC plaque volume proportion. However, multiple linear regression analysis indicated that this effect was mainly caused by increased levels of CALC.

Another CVD pathology with strong inflammatory contribution and severe late-stage CALC formation is AVS. In study II, we analyzed PRG4 expression in a cohort of 64 patients 
undergoing aortic valve replacement. While the analyzed valves are mainly representative of end-stage disease, similar to carotid plaques removed by CEA, leaflet dissection according to severity of pathological changes in tissue morphology (healthy, thickened and calcified regions) allowed for an estimation of disease progression areas within the same patient. PRG4 expression levels were elevated in both thickened and calcified tissues compared to morphologically healthy regions but there was no further increase between thickened and calcified areas. Overall, PRG4 positively correlated to genes facilitating matrix mineralization $(B M P 2$, $R U N X 2$, dentin matrix acidic phosphoprotein 1 (DMPl) and integrin binding sialoprotein $(I B S P)$ ) and inflammation (IL 6$)$. Interestingly, the significance of these correlations diminished with increasing grade of CALC, suggesting that PRG4 expression is part of the early osteogenic transformation, likely triggered by chronic tissue inflammation, but not directly involved in genetic processes driving accumulation and remodeling of macro-CALC. Another valid explanation is the increasing heterogeneity of the thickened and calcified cusp tissue, making a strict separation difficult. Accordingly, PRG4 protein deposition was detected by IHC within the ECM of thickened leaflet regions surrounding macro-calcified nodules. These areas were histologically characterized by high proteoglycan and collagen content and partially overlapped with RUNX2 and BMP2 positive cells in close proximity to calcified matrix.

In order to track PRG4 contribution to human atherosclerotic lesion formation in a more stringent manner, we employed a rare cohort of aortic biopsies representing the full disease spectrum, classified from AHA stages I to V (SOKRATES biobank, Study III). By IHC, intracellular PRG4, together with SOX9 positive cells, was detected within the intima and media already during early intimal thickening and xanthoma formation. In later stages, PRG4 localization shifted towards the ECM, surrounding necrotic core regions and overlapping with SOX9 and RUNX2 positive cells. These areas also contained neo-vascularization, likely facilitating tissue oxygenation, remodeling and bone-like macro-CALC processes.

Overall, our analysis of human tissues representing different vascular beds and stages of CVD progression indicates that elevated PRG4 expression marks osteogenic tissue transformation, likely triggered by chronic inflammatory processes and other atherogenic stimuli, preceding the formation of severe macro-CALC.

\subsection{PRG4 EXPRESSION IS DEPENDANT ON SMC AND VIC OSTEOGENIC PHENOTYPIC MODULATION}

Our findings from human tissues were supported by three rodent in vivo models (Study III), showing that elevated PRG4 levels were involved in early medial activation and intimal hyperplasia, accumulating in areas later undergoing severe mineralization. Additionally, these models suggested a possible molecular pathway consisting of $\operatorname{Tg} f \beta$ mediated induction of Prg4 expression, coupled to Sox9 and other osteogenic factors (Bmp2, Runx2), during the acute response to vascular injury and atherosclerotic disease initiation. Moreover, initial PRG4 induction was connected to SMC activation marked by significant negative correlation to Myocd, Myh11 and Smtn. Nevertheless, in rat carotid intimal hyperplasia induced by balloon injury PRG4 protein persisted within the extracellular matrix throughout the late resolution phase while its gene expression slowly returned to baseline, suggesting a functional contribution of the extracellular protein to the reacquisition of vascular homeostasis and SMC differentiation.

Considering the central contribution of structural cells like SMCs and VICs to the formation of intimal hyperplasia and valvular thickening we investigated their connection to $P R G 4$ expression in more detail using primary human cells (Study II and III, Figure 10). Indeed, our experiments showed a strong induction of $P R G 4$ by TGF $\beta$ signaling in carotid and aortic SMCs isolated from patients not diagnosed with CVD as well as aortic SMCs and VICs isolated from patients undergoing surgery due to CVD related pathologies. In SMCs $P R G 4$ activation was related to a strong initial upregulation of $S O X 9$, while VICs showed a spontanous SOX9 upregulation over time in vitro. This effect might be explained by the isolation from diseased aortic valves and concomitant predisposition for osteogenic phenotypic transition as SMCs 
isolated from CVD patients also showed varying levels of osteogenic susceptibility. Moreover, siRNA knock-down experiments on healthy aortic SMCs confirmed a signaling axis via $S M A D 3$ and $S O X 9$ to be an upstream regulator of $P R G 4$ expression, similar to the genetic machinery controlling PG expression in chondrocytes ${ }^{335}$. Both VICs and vascular SMCs showed a strong upregulation of PRG4 when stimulated with high inorganic $\mathrm{Pi}$, a factor known

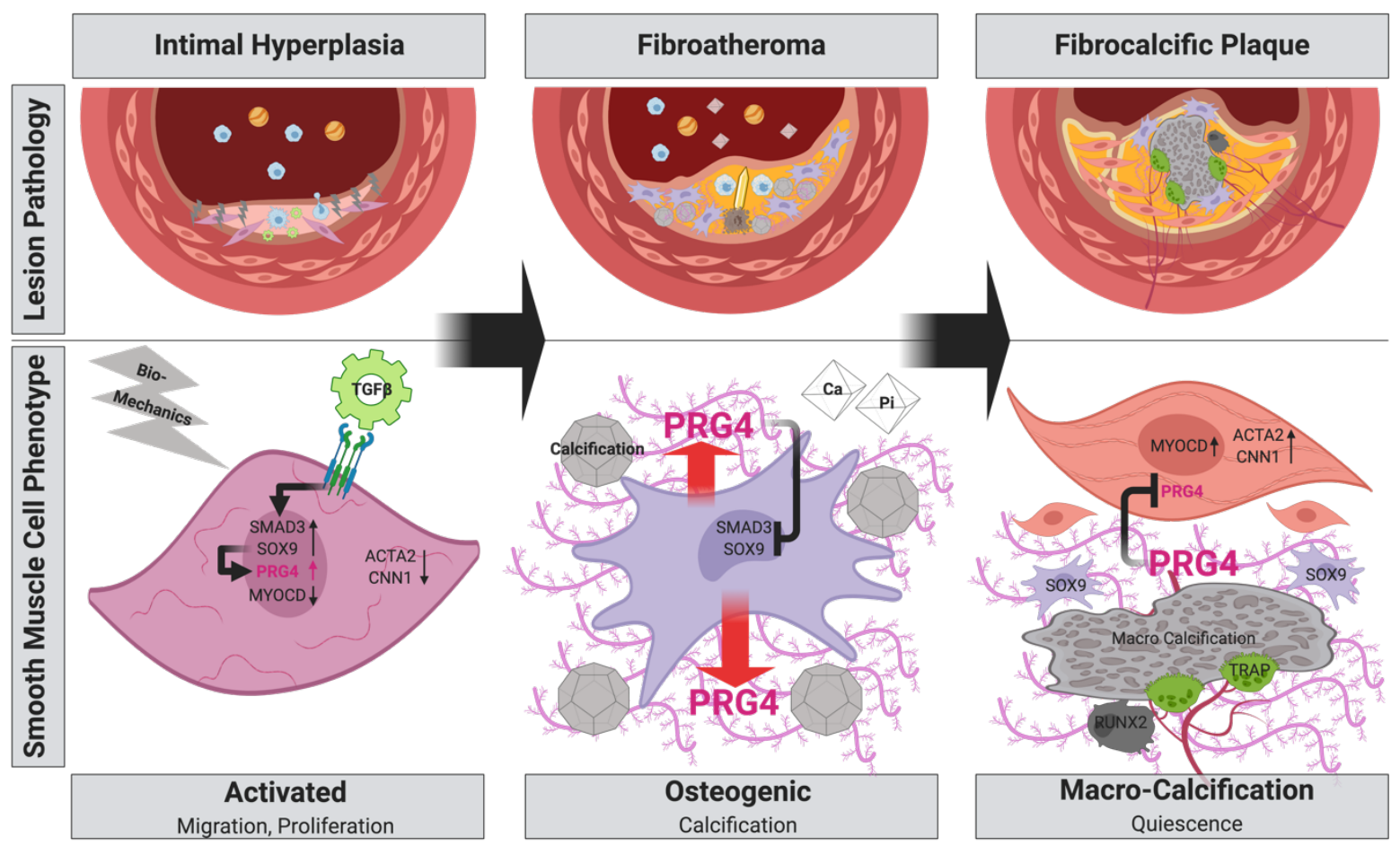

Figure 10: The role of PRG4 in atherosclerotic lesion progression and its influence on SMC phenotypic modulation. PRG4 expression is upregulated during SMC activation by TGF $\beta$, mineral imbalance or changed tissue biomechanics. It marks the onset of osteogenic phenotypic transformation and increases ectopic calcification formation as a key component of the remodeled ECM. In a negative feedback mechanism, extracellular PRG4 has the capacity to inhibit SMC proliferation, migration and osteogenic transformation.

to induce osteogenic phenotypic modulation. Accordingly, high $\mathrm{Ca}$ treatment resulted in a similar transition of SMCs, indicating mineral imbalance to be a general driver of $P R G 4$ activation. However, while $P R G 4$ expression positively correlated with $S M A D 3$ and $S O X 9$ in both conditions, we observed some striking differences in the effect on typical SMC markers. Under high $\mathrm{Ca}, P R G 4$ levels correlated to a strong loss of all typical SMC markers, even affecting MYOCD, ACTA2 and CNN1, opposed to Pi treatment where PRG4 upregulation positively correlated to $M Y O C D$ and $A C T A 2$ levels. These findings may reflect different phenotypic modulations of vascular SMCs in response to mineral overload as Pi has been shown to directly activate osteogenic transformation ${ }^{66}$, while Ca overload increased EV release and SMC apoptosis ${ }^{139}$. In both scenarios, strong expression of $P R G 4$ appeared to be a cellular response mechanism, probably via capturing the positively charged ions and mineralizing particles within the dense proteoglycan matrix, thereby releasing structural cells from osteogenic pressure. This hypothesis is complemented by an increased formation of ectopic CALC when calcifying conditions were combined with extracellular rhPRG4 supplementation.

\subsection{EXTRACELLULAR PRG4 COUNTERACTS SMC MIGRATION AND DEDIFFERENTIATION}

The initial identification of macro-CALC as a morphological feature of a more stable lesion phenotype in late-stage carotid atherosclerosis seemed ambivalent considering the clear implication of CALC as a marker of increased disease burden. Nevertheless, high levels of extracellular PRG4 may present one possible mediator responsible for its positive molecular and cellular impact. In study III we could show that addition of rhPRG4 to the culture medium of vascular SMCs significantly reduced proliferation and migration even under TGF $\beta$, PDGFB and high serum treatments, all known to induce SMC activation ${ }^{166}$. Moreover, it was able to 
reduce endogenous $P R G 4, S O X 9$ and $S M A D 3$ expression under calcifying conditions and prevented further loss of general markers for SMC differentiation (MYOCD, CNN1) (Figure 10). However, it appeared unable to prevent increased $R U N X 2$ and $S O X 9$ expression over time in VICs and even induced BMP2 without additional osteogenic stimuli (Study II), indicating inherently different cellular effects of a PRG4-rich ECM on osteogenic transformation in different vascular beds.

\subsection{MACRO-CALCIFICATION EXERTS LOAD-BEARING CAPACITIES IN HUMAN CAROTID PLAQUES, SUPPORTING SMC SURVIVAL AND DIFFERENTIATION}

A passive effect of continuous sheet-like macro-CALC is the significant increase of tissue stiffness. Purely hypothetical in silico models had previously suggested that such CALC-related stress redistribution may exhibit advantageous load-bearing capacities in atherosclerotic lesions, depending on position and geometry within the tissue ${ }^{199,204}$. In study I, we showed that extensive macro-CALC was associated with a reacquisition of more differentiated properties of plaque SMCs and ECM formation in late-stage carotid atherosclerosis. To evaluate whether

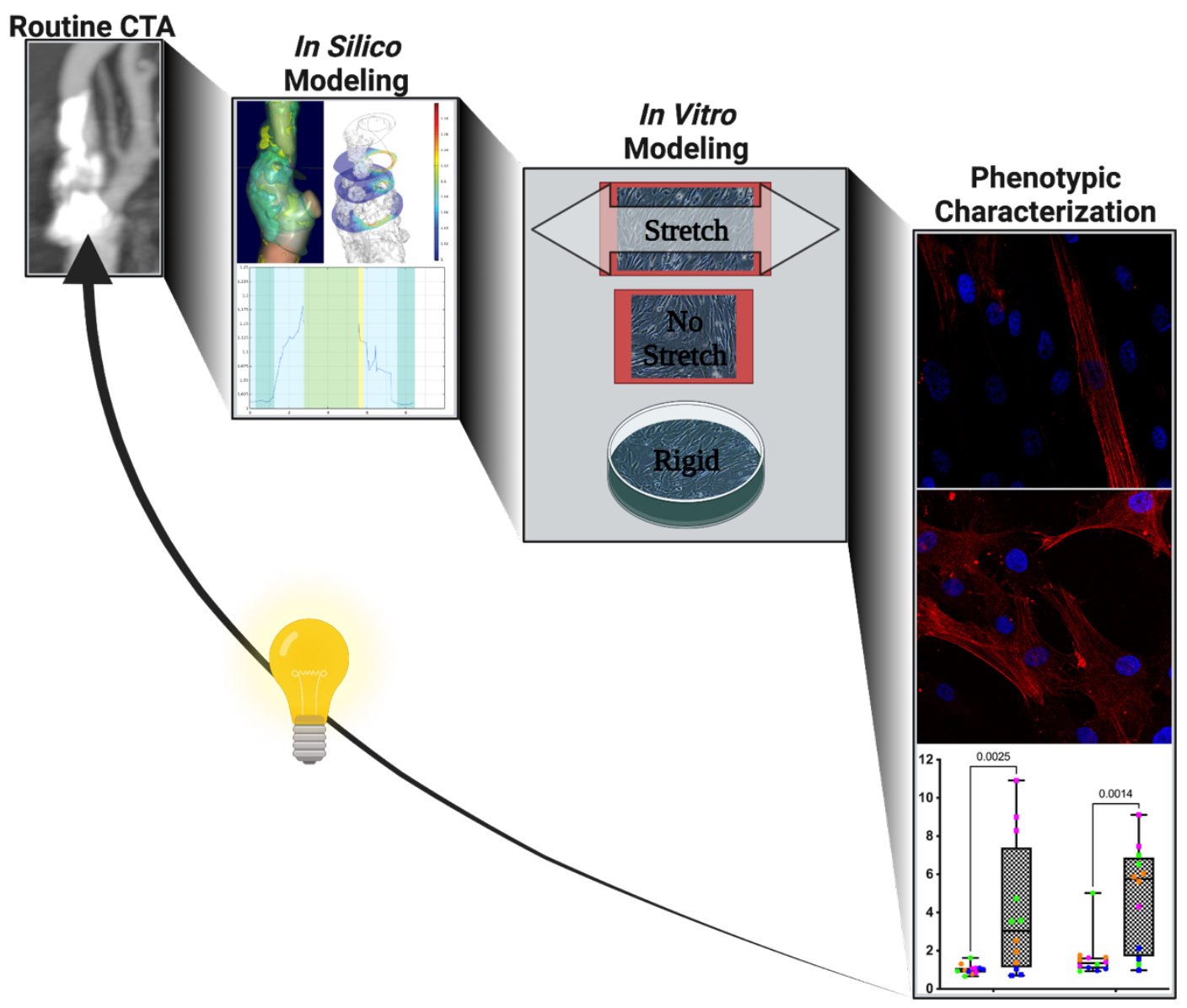

Figure 11: Graphical summary of the analysis pipeline utilized in study IV to connect routine clinical diagnostics, in this case CTA, with laboratory analytics via in silico and in vitro modeling techniques.

macro-CALC related biomechanical forces can influence SMC phenotype and contribute to plaque stabilization, we generated an analysis pipeline connecting routine clinical CTA with in vitro experiments via in silico modeling (Figure 11).

FEM analysis based on in silico tissue morphology annotation confirmed a significant reduction of tissue stretch within and in close proximity to macro-CALC areas, while other soft tissue components of the carotid lesion were subjected to stretch values commonly found in pathological hypertension. When replicating these conditions in a $2 \mathrm{D}$ in vitro cyclic stretch model we found that neither condition was physiologically optimal, as some stretch is required to stimulate SMC alignment and functional contractility requiring MYH11 expression ${ }^{336}$. 
Nevertheless, the general gene expression profile of SMCs growing on unstretched soft membranes (modeling soft tissue surrounding CALC) and standard rigid culture plates (most similar to the CALC surface) was characterized by increased expression of cytoskeletal markers including genes previously shown to be lost early during SMC dedifferentiation (ACTA2, CNN1, LMOD1, PDLIM7) ${ }^{166}$. Additionally, higher HSPG2 expression under unstretched conditions may indicate reacquisition of a basement membrane composition favoring SMC differentiation. However, complete depletion of cyclic stretch also led to an increase in RUNX2, suggesting an increased potential of these SMCs for continued matrix mineralization. In late-stage atherosclerotic disease this may still pose the lesser of two evils as SMCs were able to adapt to high levels of $\mathrm{Ca}$ and $\mathrm{Pi}$ without stretch, but in combination with elevated stretch committed to rapid cleaved CASP3 driven apoptosis. Interestingly, high amounts of PRG4 were detected on transcriptomic and proteomic level in SMCs on both stretched and unstretched silicone membranes, while it was widely absent on rigid plates. Considering the effects on SMC differentiation, proliferation and migration described in study III, this may be another factor for increased osteogenic potential under rigid conditions but on the other hand inhibit SMCs to efficiently adapt to pathological stretch. This hypothesis is supported by increased SMC apoptosis under stretch in combination with rhPRG4 supplementation, warranting further functional investigation. 


\section{CONCLUSIONS}

The results presented in this thesis demonstrate that macro-CALC in late-stage human atherosclerosis, can be connected to stabilizing biological processes, in particular SMC differentiation and survival. Moreover, routine clinical CTA in combination with in silico analysis can be utilized to assess the impact of patient specific plaque morphology on tissue biomechanics and SMC phenotype.

PRG4 emerged as a specific target marking the onset of osteogenic transformation and matrix mineralization in intimal carotid atherosclerosis as well as AVS, while being a key component of the ECM with the capacity to modulate SMC differentiation. Together, these findings contribute to a better understanding of atherosclerotic lesion remodeling and vulnerability, consequently with the potential to improve diagnostic accuracy and risk prediction for the individual patient, warranting further clinical evaluations.

I. Our analysis uncovered that highly calcified carotid lesions exhibit a distinct phenotype related to SMC differentiation and ECM organization as well as reduction of inflammatory activity. As macro-calcification is a morphological plaque feature that is rather easily detectable utilizing diagnostic tools already in routine clinical use, position and geometry of densely calcified nodules should be investigated as surrogate marker in clinical risk prediction (Study I).

II. Analysis of pathological samples, representing different vascular beds and stages of human CVD progression, identified elevated PRG4 expression as a marker for osteogenic tissue transformation, likely triggered by chronic atherogenic stimuli, preceding the formation of severe macro-calcification (Study I, II, III).

III. In vivo and in vitro models identified early upregulation of PRG4 in VICs and vascular SMCs by osteogenic phenotypic transformation in response to TGF $\beta$ signaling and calcifying conditions. We showed that PRG4 expression is part of the vascular remodeling response, preceding and enhancing the formation of ectopic CALC (Study II, III).

IV. While endogenous $P R G 4$ expression is connected to osteogenic phenotypic transformation via SMAD3 and SOX9, extracellular PRG4 mediates positive effects on SMC differentiation and quiescence, indicating a feedback mechanism (Study III).

V. We were able to generate a potential pipeline to connect plaque composition, biomechanics and molecular processes on a patient specific level. Our data confirms, based on clinical CTA imaging and in vitro studies, that macro-calcifications can support SMC survival and differentiation under atherosclerotic conditions by generating low stretch zones within advance lesions. 



\section{SOCIETAL IMPACT AND RESEARCH PERSPECTIVE}

CVD treatment has been a focus of clinical research for many years, being the major cause of death worldwide but the World Health Organization (WHO) predicts these numbers to still rise towards claiming a staggering annual 22 million lives by the year $2030{ }^{337}$. Coupled to an aging population, the rising prevalence of CVD is putting pressure and substantial additional costs on healthcare systems and businesses worldwide. In particular, the treatment of heart attacks and strokes not only requires intensive clinical care but also substantial recovery time, adding to the total cost. In Europe, the annual expenditure for CVD is estimated at 210 billion Euro per year, with about $53 \%$ (111 billion) due to health care costs and 26\% (54 billion) due to productivity losses. The considerable remaining part of approximately $21 \%$ (€45 billion) mostly affects the family of patients and other informal care-givers, who invest crucial time and effort in order to restore quality of life ${ }^{338}$. While clinical procedures improve, major risk can still be attributed to failing recovery from cardiovascular episodes, leading to premature death and decreased productivity. Innovative medicine has the responsibility to reduce hospitalizations and expensive surgical procedures by improving routine diagnostics as well as patient specific medical care.

To date, most patients with advanced carotid stenosis are classified by the degree of luminal stenosis and clinical symptomatology. In most centers the indication for CEA is still depending on a stenosis degree above $50-70 \%$ (NASCET) and the occurrence of neurological symptoms, unprecise tools for the assessment of lesion morphology, disease biology and future risk prediction. However, interest in the assessment of plaque morphology has increased over the past years, especially after new recommendations were included within the 2017 ESVS guidelines. In study $I$ and $I V$ of this thesis, we demonstrate the translational potential of utilizing detailed in silico analysis of clinical CTA images to generate a more accurate representation of patient specific disease morphology. Moreover, we were able to link this modeling data to specific disease modifying biological pathways and cellular responses. Macro-CALC of carotid atherosclerotic lesions stood out as a positive modifier of biological pathways related to plaque stabilization. Biomechanical analysis in combination with in vitro experiments confirmed a positive effect on SMC differentiation and survival in proximity to macro-CALC compared to other regions of the same plaque. Expanding this analysis to a wider range of biomechanical conditions as well as comprehensive transcriptomic and proteomic analysis would generate valuable data to make one step forward towards predictive modeling of disease progression on a patient specific level. Ideally, future patients suffering from vulnerable atherosclerotic lesions would be detected prior to developing severe symptoms. Combined screening methods, including detection of circulating blood biomarkers, CT imaging of the neck and heart vasculature and subsequent in silico analysis, could form a valuable foundation to predict disease progression, detect patients at high risk and suggest personalized treatments.

On a molecular level PRG4, a novel proteoglycan in the context of CVD, emerged as a key factor within the ECM matrix of atherosclerotic lesions, marking osteogenic transformation. Matrix bound proteins can be utilized as biomarkers following their release into circulation by tissue erosion or injury, commonly occurring in late-stage atherosclerotic lesions. Moreover, the specific biological functions of extracellular PRG4 could be translated towards clinical application. Pre-clinical studies have already confirmed disease mediating capacities of recombinant PRG4 in osteoarthritis via reconstitution of joint lubrication and protection from articular cartilage degeneration ${ }^{298}$. Additionally, it has been shown to modulate cellular responses by direct binding to TLR 2 and 4 as well as CD44 receptors ${ }^{292}$ and is a substrate for proprotein convertase subtilisin/kexin type 6 (PCSK6) ${ }^{339}$, a protease more recently identified as key mediator of SMC migration, vascular and cardiac remodeling ${ }^{340-342}$. It is likely that the modulating effects of rhPRG4 on SMC proliferation, migration and gene expression (described in study III) are driven by direct interaction, possibly manipulated by post-translational modification, warranting more detailed investigation of mechanistic pathways in vitro. Moreover, in vivo disease intervention models on conditional PRG4 gene-trap mice should 
investigate the potential of PRG4 to prevent vascular pathologies, improve vascular healing and reduce risk of complications after interventions like stenting or aneurysm repair. As rhPRG4 treatment of dry eye disease is already subject of a phase 2 clinical trial (LubrisBiopharma), positive pre-clinical findings can be expected to find clinical translation more rapidly in future. Importantly, the studies presented in this thesis are available to the public in peer-reviewed journals and the results have been largely disseminated and shared with the scientific community through posters and oral presentations at international conferences, symposiums, and other meetings. In addition to outlining several important directions towards improved CVD diagnostics, risk prediction and novel pharmacological approaches, this thesis may stimulate a deeper understanding and interdisciplinary discussions regarding $\mathrm{VC}$ formation and its clinical implications. 


\section{ACKNOWLEDGEMENTS}

To me, research is more than a hobby or even a profession, it is a lifestyle. Choosing to embark on a $\mathrm{PhD}$ gives the curious mind carte blanche to question traditional concepts and contribute new perspectives. While pointing at scientific holes may still look like an easy game for restless minds, getting to the bottom of them and emerge with answers requires determination, resilience and remarkable people backing your journey. This is to everyone whom I had the honor to meet, be inspired, supported and encouraged by during these last four years of asking questions and searching for answers.

Great supervisors will not only guide the way to scientific answers and professional development but embody role models to strive for while finding your own way. I couldn't have been more lucky. To start with my main supervisor Ulf Hedin, who has inspired me with his enthusiasm for science, magnitude of medical and molecular knowledge as well as never ending energy. Thank you for giving me the freedom to grow and providing experience when I struggled. You gave me the tools to succeed in my cardiovascular challenge, coaching me through a PhD double degree, $90 \mathrm{~km}$ cross country skiing, $3 \mathrm{~km}$ open water swimming, $315 \mathrm{~km}$ cycling and $30 \mathrm{~km}$ off-road running - and made it fun. Talking about role models, my cosupervisor at Karolinska Institutet Ljubica Perisic Matic is an outstanding example of a young successful scientist with the drive to tackle every task with the utmost sense for perfection, there is no one quite like her. Ljubica, I will always be impressed by your proactive mindset to exceed expectations and commitment to elevate any project you are involved in. I'm forever grateful for the honest discussions about all aspects of becoming an independent scientist. To be reassured that research and scientific entrepreneurship are fun, one just has to take example at my two co-supervisors from Maastricht University Leon Schurgers and Chris Reutelingsperger. To both of you, I'm deeply thankful for welcoming me during my secondment, providing invaluable scientific support. Moreover, you were always approachable and tackled obstacles with a fundamentally positive attitude. I hope that one day I can radiate as much confidence and cheerfulness as you do.

To live science becomes that much easier when surrounded by people who think alike and make the lab a familiar happy place. That is the Vascular Surgery Division, with all its basic and clinical scientists. Urszula Rykaczewska and Bianca Suur, two clever beauties, who were forced to sit next to me all this time and made it look like it wasn't so bad. Ula, spelling out your full name will always give me a headache and I admit to have copy pasted it this time as well. However, I will remember the great times we had, mixing scientific discussions with banter about everyday life. Don't worry, I will gladly grant you those extra minutes to think about a spicy come back line, you are the elder after all (in authority and experience of course). Bianca, there are not enough words to thank you for always being there to cancel out my forgetfulness, sharing the good as well as the tough times and coping with me - well, being me. I know you have a bright future ahead, science needs successful girls like you, with all your ideas, knowledge, thoroughness, commitment and perfect hair. Nikolaos-Taxiarchis Skenteris, thank god I'm allowed to call you Nikos and for having you join our lab to collaborate on the one truly important topic in cardiovascular science - calcification. I'm glad that we had the chance to not only be connected by the INTRICARE consortium but to work side by side and share scientific experience and emotions that go along with pursuing science with all our heart. I know you do and have the utmost respect for that. Andrew Buckler, I'm so happy that you took the opportunity to do a $\mathrm{PhD}$ in our group, in turn allowing me to meet and work with you. The computational depth of your ideas may have overwhelmed me at times but also taught me completely new angles to approach a task. I thoroughly enjoyed every conversation with you and admit to have mentioned that it feels good knowing someone who sometimes struggles just as much as I do to find a simple way to explain an idea. Melody Chemaly and Sampath Narayanan, I remember how excited we $\mathrm{PhD}$ students were to finally have some postdoc support in the lab again and both of you truly lived up to it. Within this rather short time, I learned so much from you not only related to research but also national cultures and social events. Glykeria Karadimou and Xiang Zhang (Bob), we didn't have 
much time to interact as part of the same group, but I know you as a very nice colleague from the same floor. I'm sure you will be a great part of this group in the future. Hong Jin, after first meeting you in the Vascular Biology course and experiencing your exceptional skills in animal surgery and scientific rigor, I was very happy when you joined the lab with all your kindness and camaraderie. Otto Bergman, your scientific and social impact on the Vascular Surgery group is most impressive considering the limited time that you are allowed to play with us. Nevertheless, much like the exceptional data you generate, your uncanny sense of humor often leaves plenty of material to think about in the meantime. Colin Willems, Sofija Vuckovic and Xinran Dong (Aurora), you are the freshest additions to the team and definitely brought along the supportive breeze of scientific drive and positive attitude. It is always a good feeling to see new people picking up the necessary curiosity and stamina for science as well as sharing impressions and expectations on life as a student.

Suvi Mäkinen, unfortunately we could only spend a brief time together in the lab but I'm not the only one who felt that you fit right in and misses you now. Nevertheless, times change and opportunities present themselves that one shouldn't pass by. I wish you all the best! Malin Kronqvist and Mette Lengquist (I contemplated to write Mariette but nobody would know whom I'm talking about), I could write at least three pages trying to thank you and still fall short. Simply put, you are the glue that holds everything together, you fill the holes that we leave in our lab work and you combine us into a social unit. Moreover, you do all of it like a duck takes to water (yeah that's English figurative speech at its best, I hope you like ducks), even when you clearly work too much you still do your best to not make us feel guilty. From the bottom of my heart, I hope you understand my gratitude for all the help and good times you gave me during this $\mathrm{PhD}$. When talking about irreplaceable people one can't overlook Siw Frebelius, you have been part of this group for so long and guided so many students on their way, still you always have time for our issues and help with matters where nobody else could. I always knew that I could rely on you. Many thanks also to Ann-Britt Wikström for all your support and for looking out for the PhD students' best interests.

No Vascular Surgery Division could be complete without their "clinicians", a bunch of (over) motivated surgeons, medical students and nurses, who just can't shake the temptation of research. Anton Razuvaev and Joy Roy, I'm very grateful for all the time you have taken from your busy schedules to discuss science, collaborate on great projects or to simply socialize and muse over aspects of life, traveling and what the future may hold. I'm certain you will inspire many more people not only to do vascular science but to walk through life with open eyes. Eva Karlöf, Katarina Wadén, Marko Bogdanovic, Samuel Röhl, Moritz Lindquist Liljeqvist and Antti Siika, it was a pleasure to share the office with you and get some news of the madness that is clinical work. Sadly the duty always called you back way too quickly, before we had the chance to excite you with all the last details of immunohistochemistry, quantitative real-time PCR or cell culture. On a serious note, having you around immensely helped to grasp the idea of translational science and to re-focus on the greater purpose of research. I really appreciate all the expertise that you contributed to my work throughout my $\mathrm{PhD}$ and hope to reconnect over new projects in the future. Olga Nilsson and Alicia Garcia Lantz, coming to Sweden I had never heard of a "research-nurse", meeting you and getting to know the perfect combination of warm-hearted patient care and scientific interest was truly inspiring. The Vascular Surgery Division and clinical research in general is lucky to have people like you.

None of the science described in this thesis would have been possible without the help from a multitude of great collaborators.

Being part of the European Union's Horizon 2020 program INTRICARE connected me to a consortium of outstanding scientists to whom I would like to express my appreciation. Rory R. Koenen, Peter Stenvinkel, Joachim Jankowski, Claudia Goettsch, Tilman Hackeng, Eline Kooi, Felix M. Mottaghy, Wilhelm E. Jahnen-Dechent, Johan Frostegard, Sébastien Foulquier, Jürgen Floege, Dawid Kaczor, Lu Dai, Shruti Bhargava, Marina Heuschkel, Anouk Gentier, Mueez Aizaz, Alexandru Florea, Robert Dzhanaev, Shailesh Kumar Samal, Stefan Reinhold, Maurice Halder, thank you for the shared knowledge and great times spent at program meetings and courses. Many thanks also to Tara de Koster, who made my life so much easier with her help and coordination within the INTRICARE consortium. 
I would like to extend special thanks to the whole Department of Biochemistry, Cardiovascular Research Institute Maastricht, Maastricht University, for welcoming me during my secondment and providing exceptional help to get settled and be scientifically productive in such a short amount of time. In particular, I would like to thank Cengiz Akbulut for sharing an office, long working days, high quality research and abstruse hypothesis with me. I will fondly remember those days and the great mix of discussing the latest scientific advances and just philosophizing away. Rick van Gorp and Armand Jaminon, thank you for making time to share your expertise and research material with me in the midst of preparing your own PhD defenses.

I'm also very grateful to the whole Department of Pathology, Cardiovascular Research Institute Maastricht, Maastricht University Medical Center, for their outstanding support throughout our collaborations. Erik Biessen, I greatly appreciate your confidence and commitment towards our projects as well as giving me the freedom to contribute own ideas and directions. It is truly uplifting to be supported by such an esteemed scientist. Special thanks also to Olivia Waring, your infectious excitement for research amazed me and working together with you was always a special motivation. Above all, you approach everything else in life with the same buzz, energizing everyone who was about to falter. I was very lucky to share this time with you and will always remember who's favorite cell the macrophage is.

Furthermore, I want to thank Magnus Bäck, Miguel Carracedo Ortiz and Gonzalo Artiach Castañón for the great experience working together with them in our collaborative project.

Embarking on novel territory (tissue biomechanics) within the final year of my $\mathrm{PhD}$ would have been a futile task without the distinguished help of Christian Gasser and Staffan Johansson, kickstarting my understanding of basic solid mechanics and in vitro stretch. Your patience and talent to maneuver interdisciplinary discussions made this project a very motivating experience.

I would also like to thank Zhichao Zhou, Aida Collado Sánchez, Ali Mahdi and Greg Winski for pleasant collaborations and conversations about the struggles in scientific publishing.

Every professional advancement can only be achieved via personal growth and I know that my friends all over the world have a big part in that. I'm blessed to know that I can rely on people in Germany, Austria, India, Australia, Sweden and almost everywhere in between, what could go wrong with such a safety net of support?

In particular, I want to express my deepest gratitude to you Nicki. People say that it's not good to share the same profession, because one should be able to separate work from leisure. However, what is a researcher supposed to do when the questions keep circling, better to have someone to discuss than trying to leave ones head in the lab. The nomadic lifestyle of modern scientists hasn't left us unscarred but I know there isn't one person who knows me better than you and I know we understand each other's worries.

The people who will always have to take full responsibility for me being me and who deserve to receive full praise from time to time in return are my family. Thank you Ines and Falko for supporting my curiosity, freedom and believing in me, whatever I set out to do. You made difficult decisions easy by sharing excitement about the unknown and reassuring me that there is no problem that can't be solved together. Thank you Anne for enduring to grow up just one year ahead of me and being pestered by a competitive brother. I admire your fearlessness once you have set your mind on something. To my grandparents, aunts and uncles, nephews and nieces, I'm grateful for your unconditional support even though we saw each other more rarely in the past years. I'm glad that we are a family where everyone is supported to achieve what they desire.

Last but not least, I want to thank the two purest souls in my life, Cheyenne and Nico, for their support on this journey. If ever in doubt what really matters in life and how to make the best of it, listen to your dog and listen carefully. They know, they always knew and they will remain by your side until the last minute in case you need their wisdom. 



\section{REFERENCES}

\section{Illustrations created using BioRender}

1. Jumper J, Evans R, Pritzel A, et al. Highly accurate protein structure prediction with AlphaFold. Nature. 2021;596(7873):583589 .

2. McGill HC, Jr., McMahan CA, Gidding SS. Preventing heart disease in the 21st century: implications of the Pathobiological Determinants of Atherosclerosis in Youth (PDAY) study. Circulation. 2008;117(9):1216-1227.

3. Stary HC. Natural history and histological classification of atherosclerotic lesions: an update. Arterioscler Thromb Vasc Biol. 2000;20(5):1177-1178.

4. Hansson GK, Libby P. The immune response in atherosclerosis: a double-edged sword. Nature reviews Immunology. 2006;6(7):508-519.

5. Wissler RW, Strong JP. Risk factors and progression of atherosclerosis in youth. PDAY Research Group. Pathological Determinants of Atherosclerosis in Youth. The American journal of pathology. 1998;153(4):1023-1033.

6. Yanez ND, Burke GL, Manolio T, Gardin JM, Polak J. Sibling history of myocardial infarction or stroke and risk of cardiovascular disease in the elderly: the Cardiovascular Health Study. Ann Epidemiol. 2009;19(12):858-866.

7. Martinsson A, Li X, Andersson C, Nilsson J, Smith JG, Sundquist K. Temporal trends in the incidence and prognosis of aortic stenosis: a nationwide study of the Swedish population. Circulation. 2015;131(11):988-994.

8. Lindroos M, Kupari M, Heikkilä J, Tilvis R. Prevalence of aortic valve abnormalities in the elderly: an echocardiographic study of a random population sample. J Am Coll Cardiol. 1993;21(5):1220-1225.

9. Organization WH. Global health risks : mortality and burden of disease attributable to selected major risks. Geneva: World Health Organization;2009.

10. Global, regional, and national life expectancy, all-cause mortality, and cause-specific mortality for 249 causes of death, 1980 2015: a systematic analysis for the Global Burden of Disease Study 2015. Lancet. 2016;388(10053):1459-1544.

11. Townsend N, Nichols M, Scarborough P, Rayner M. Cardiovascular disease in Europe 2015: epidemiological update. Eur Heart J. 2015;36(40):2673-2674.

12. Townsend N, Kazakiewicz D, Lucy Wright F, et al. Epidemiology of cardiovascular disease in Europe. Nat Rev Cardiol. 2021.

13. Turina J, Hess O, Sepulcri F, Krayenbuehl HP. Spontaneous course of aortic valve disease. Eur Heart J. 1987;8(5):471-483.

14. Landgren AJ, Bilberg A, Eliasson B, et al. Cardiovascular risk factors are highly overrepresented in Swedish patients with psoriatic arthritis compared with the general population. Scand J Rheumatol. 2019:1-5.

15. Stewart BF, Siscovick D, Lind BK, et al. Clinical factors associated with calcific aortic valve disease. Cardiovascular Health Study. J Am Coll Cardiol. 1997;29(3):630-634.

16. Grattan M, Prince A, Rumman RK, et al. Predictors of Bicuspid Aortic Valve-Associated Aortopathy in Childhood: A Report From the MIBAVA Consortium. Circ Cardiovasc Imaging. 2020;13(3):e009717.

17. Murray CJ, Lopez AD. Measuring the global burden of disease. N Engl J Med. 2013;369(5):448-457.

18. Cheng C, Tempel D, van Haperen R, et al. Atherosclerotic lesion size and vulnerability are determined by patterns of fluid shear stress. Circulation. 2006;113(23):2744-2753.

19. Bäck M, Gasser TC, Michel JB, Caligiuri G. Biomechanical factors in the biology of aortic wall and aortic valve diseases. Cardiovascular research. 2013;99(2):232-241.

20. Siri-Tarino PW, Krauss RM. The early years of lipoprotein research: from discovery to clinical application. $J$ Lipid Res. 2016;57(10):1771-1777.

21. Vidal F, Colome C, Martinez-Gonzalez J, Badimon L. Atherogenic concentrations of native low-density lipoproteins downregulate nitric-oxide-synthase mRNA and protein levels in endothelial cells. Eur J Biochem. 1998;252(3):378-384.

22. Assmann G, Schulte H, von Eckardstein A, Huang Y. High-density lipoprotein cholesterol as a predictor of coronary heart disease risk. The PROCAM experience and pathophysiological implications for reverse cholesterol transport. Atherosclerosis. 1996;124 Suppl:S11-20.

23. Badimon L, Vilahur G. LDL-cholesterol versus HDL-cholesterol in the atherosclerotic plaque: inflammatory resolution versus thrombotic chaos. Ann N Y Acad Sci. 2012;1254:18-32.

24. Brown MS, Goldstein JL. Expression of the familial hypercholesterolemia gene in heterozygotes: mechanism for a dominant disorder in man. Science. 1974;185(4145):61-63.

25. Brown MS, Goldstein JL. How LDL receptors influence cholesterol and atherosclerosis. Sci Am. 1984;251(5):58-66.

26. Brown MS, Anderson RG, Goldstein JL. Mutations affecting the binding, internalization, and lysosomal hydrolysis of low density lipoprotein in cultured human fibroblasts, lymphocytes, and aortic smooth muscle cells. J Supramol Struct. 1977;6(1):8594.

27. Goldstein JL, Brown MS. The LDL receptor defect in familial hypercholesterolemia. Implications for pathogenesis and therapy. Med Clin North Am. 1982;66(2):335-362.

28. Goldstein JL, Kita T, Brown MS. Defective lipoprotein receptors and atherosclerosis. Lessons from an animal counterpart of familial hypercholesterolemia. N Engl J Med. 1983;309(5):288-296.

29. Marenberg ME, Risch N, Berkman LF, Floderus B, de Faire U. Genetic susceptibility to death from coronary heart disease in a study of twins. N Engl J Med. 1994;330(15):1041-1046.

30. Bjorkegren JLM, Kovacic JC, Dudley JT, Schadt EE. Genome-wide significant loci: how important are they? Systems genetics to understand heritability of coronary artery disease and other common complex disorders. J Am Coll Cardiol. 2015;65(8):830845 .

31. Deloukas P, Kanoni S, Willenborg C, et al. Large-scale association analysis identifies new risk loci for coronary artery disease. Nat Genet. 2013;45(1):25-33.

32. Nikpay M, Goel A, Won HH, et al. A comprehensive 1,000 Genomes-based genome-wide association meta-analysis of coronary artery disease. Nat Genet. 2015;47(10):1121-1130.

33. Samani NJ, Erdmann J, Hall AS, et al. Genomewide association analysis of coronary artery disease. $N$ Engl $J$ Med. 2007;357(5):443-453.

34. Gray H. Grays Anatomy. London, England: Arcturus Publishing; 2013.

35. Holm Nielsen S, Tengryd C, Edsfeldt A, et al. Markers of Basement Membrane Remodeling Are Associated With Higher Mortality in Patients With Known Atherosclerosis. J Am Heart Assoc. 2018;7(21):e009193.

36. Michiels C. Endothelial cell functions. J Cell Physiol. 2003;196(3):430-443.

37. Tran PK, Tran-Lundmark K, Soininen R, Tryggvason K, Thyberg J, Hedin U. Increased intimal hyperplasia and smooth muscle cell proliferation in transgenic mice with heparan sulfate-deficient perlecan. Circ Res. 2004;94(4):550-558. 

Vasc Med. 2011;16(5):365-377.

39. De Caterina R, Libby P, Peng HB, et al. Nitric oxide decreases cytokine-induced endothelial activation. Nitric oxide selectively reduces endothelial expression of adhesion molecules and proinflammatory cytokines. J Clin Invest. 1995;96(1):60-68.

40. Biasetti J, Spazzini PG, Hedin U, Gasser TC. Synergy between shear-induced migration and secondary flows on red blood cells transport in arteries: considerations on oxygen transport. J R Soc Interface. 2014;11(97):20140403.

41. Hastings NE, Simmers MB, McDonald OG, Wamhoff BR, Blackman BR. Atherosclerosis-prone hemodynamics differentially regulates endothelial and smooth muscle cell phenotypes and promotes pro-inflammatory priming. Am J Physiol Cell Physiol. 2007;293(6):C1824-1833. Lancaster JR. Historical origins of the discovery of mammalian nitric oxide (nitrogen monoxide) production/physiology/pathophysiology. Biochem Pharmacol. 2020;176:113793.

43. Wagenseil JE, Mecham RP. Vascular extracellular matrix and arterial mechanics. Physiol Rev. 2009;89(3):957-989.

44. Röhl S, Rykaczewska U, Seime T, et al. Transcriptomic profiling of experimental arterial injury reveals new mechanisms and temporal dynamics in vascular healing response. J Vasc Surg-Vasc Sci. 2020;10.1016/j.jvssci.2020.01.001.

45. Sherratt MJ. Tissue elasticity and the ageing elastic fibre. Age (Dordr). 2009;31(4):305-325.

46. Majesky MW, Dong XR, Hoglund V, Mahoney WM, Daum G. The adventitia: a dynamic interface containing resident progenitor cells. Arterioscler Thromb Vasc Biol. 2011;31(7):1530-1539.

47. Mekala SR, Wörsdörfer P, Bauer J, et al. Generation of Cardiomyocytes From Vascular Adventitia-Resident Stem Cells. Circ Res. 2018;123(6):686-699.

48. Stenmark KR, Yeager ME, El Kasmi KC, et al. The adventitia: essential regulator of vascular wall structure and function. Annu Rev Physiol. 2013;75:23-47.

49. Bo WJ, McKinney WM, Bowden RL. The origin and distribution of vasa vasorum at the bifurcation of the common carotid artery with atherosclerosis. Stroke. 1989;20(11):1484-1487.

50. Wang Y, Cao W, Cui J, et al. Arterial Wall Stress Induces Phenotypic Switching of Arterial Smooth Muscle Cells in Vascular Remodeling by Activating the YAP/TAZ Signaling Pathway. Cell Physiol Biochem. 2018;51(2):842-853.

51. Zaragoza C, Marquez S, Saura M. Endothelial mechanosensors of shear stress as regulators of atherogenesis. Curr Opin Lipidol. 2012;23(5):446-452.

52. Finn AV, Kolodgie FD, Virmani R. Correlation between carotid intimal/medial thickness and atherosclerosis: a point of view from pathology. Arterioscler Thromb Vasc Biol. 2010;30(2):177-181.

53. Maor I, Hayek T, Coleman R, Aviram M. Plasma LDL oxidation leads to its aggregation in the atherosclerotic apolipoprotein Edeficient mice. Arterioscler Thromb Vasc Biol. 1997;17(11):2995-3005.

54. Tran-Lundmark K, Tran PK, Paulsson-Berne G, et al. Heparan sulfate in perlecan promotes mouse atherosclerosis: roles in lipid permeability, lipid retention, and smooth muscle cell proliferation. Circ Res. 2008;103(1):43-52.

55. Khalil MF, Wagner WD, Goldberg IJ. Molecular interactions leading to lipoprotein retention and the initiation of atherosclerosis. Arterioscler Thromb Vasc Biol. 2004;24(12):2211-2218.

56. Navab M, Berliner JA, Watson AD, et al. The Yin and Yang of oxidation in the development of the fatty streak. A review based on the 1994 George Lyman Duff Memorial Lecture. Arterioscler Thromb Vasc Biol. 1996;16(7):831-842.

57. Leitinger N. Oxidized phospholipids as modulators of inflammation in atherosclerosis. Curr Opin Lipidol. 2003;14(5):421-430.

58. Libby P. Vascular biology of atherosclerosis: overview and state of the art. Am J Cardiol. 2003;91(3a):3a-6a.

59. Stary HC, Chandler AB, Glagov S, et al. A definition of initial, fatty streak, and intermediate lesions of atherosclerosis. A report from the Committee on Vascular Lesions of the Council on Arteriosclerosis, American Heart Association. Circulation. 1994;89(5):2462-2478.

60. Tabas I, Bornfeldt KE. Macrophage Phenotype and Function in Different Stages of Atherosclerosis. Circ Res. 2016;118(4):653667.

61. Newby AC. Matrix metalloproteinases regulate migration, proliferation, and death of vascular smooth muscle cells by degrading matrix and non-matrix substrates. Cardiovascular research. 2006;69(3):614-624.

62. Austin MA, Hutter CM, Zimmern RL, Humphries SE. Genetic causes of monogenic heterozygous familial hypercholesterolemia: a HuGE prevalence review. Am J Epidemiol. 2004;160(5):407-420.

63. Pidkovka NA, Cherepanova OA, Yoshida T, et al. Oxidized phospholipids induce phenotypic switching of vascular smooth muscle cells in vivo and in vitro. Circ Res. 2007;101(8):792-801.

64. Hautmann MB, Madsen CS, Owens GK. A transforming growth factor beta (TGFbeta) control element drives TGFbeta-induced stimulation of smooth muscle alpha-actin gene expression in concert with two CArG elements. The Journal of biological chemistry. 1997;272(16):10948-10956.

65. Li X, Van Putten V, Zarinetchi F, et al. Suppression of smooth-muscle alpha-actin expression by platelet-derived growth factor in vascular smooth-muscle cells involves Ras and cytosolic phospholipase A2. Biochem J. 1997;327 ( Pt 3):709-716.

66. Jono $\mathrm{S}$, McKee MD, Murry $\mathrm{CE}$, et al. Phosphate regulation of vascular smooth muscle cell calcification. Circ Res. 2000;87(7):E10-17.

67. Kalampogias A, Siasos G, Oikonomou E, et al. Basic Mechanisms in Atherosclerosis: The Role of Calcium. Medicinal chemistry (Shariqah (United Arab Emirates)). 2016;12(2):103-113.

68. Massy ZA, Ivanovski O, Nguyen-Khoa T, et al. Uremia accelerates both atherosclerosis and arterial calcification in apolipoprotein E knockout mice. Journal of the American Society of Nephrology : JASN. 2005;16(1):109-116.

69. Rong JX, Shapiro M, Trogan E, Fisher EA. Transdifferentiation of mouse aortic smooth muscle cells to a macrophage-like state after cholesterol loading. Proceedings of the National Academy of Sciences of the United States of America. 2003;100(23):13531-13536.

70. Clarke MC, Bennett MR. Cause or consequence: what does macrophage apoptosis do in atherosclerosis? In: Arterioscler Thromb Vasc Biol. Vol 29. United States2009:153-155.

71. Mayr M, Xu Q. Smooth muscle cell apoptosis in arteriosclerosis. Exp Gerontol. 2001;36(7):969-987.

72. Martinet W, Schrijvers DM, De Meyer GR. Necrotic cell death in atherosclerosis. Basic Res Cardiol. 2011;106(5):749-760.

73. Kojima Y, Volkmer JP, McKenna K, et al. CD47-blocking antibodies restore phagocytosis and prevent atherosclerosis. Nature. 2016;536(7614):86-90.

74. Schrijvers DM, De Meyer GR, Kockx MM, Herman AG, Martinet W. Phagocytosis of apoptotic cells by macrophages is impaired in atherosclerosis. Arterioscler Thromb Vasc Biol. 2005;25(6):1256-1261.

75. Virmani R, Burke AP, Farb A, Kolodgie FD. Pathology of the vulnerable plaque. J Am Coll Cardiol. 2006;47(8 Suppl):C13-18.

76. van Dijk RA, Virmani R, von der Thusen JH, Schaapherder AF, Lindeman JH. The natural history of aortic atherosclerosis: a systematic histopathological evaluation of the peri-renal region. Atherosclerosis. 2010;210(1):100-106.

77. Kolodgie FD, Yahagi K, Mori H, et al. High-risk carotid plaque: lessons learned from histopathology. Semin Vasc Surg. 2017;30(1):31-43.

78. Schwartz SM, Virmani R, Rosenfeld ME. The good smooth muscle cells in atherosclerosis. Current atherosclerosis reports. 2000;2(5):422-429. 
79. Jonasson L, Holm J, Skalli O, Bondjers G, Hansson GK. Regional accumulations of T cells, macrophages, and smooth muscle cells in the human atherosclerotic plaque. Arteriosclerosis. 1986;6(2):131-138.

80. Hansson GK, Libby P, Tabas I. Inflammation and plaque vulnerability. Journal of internal medicine. 2015;278(5):483-493.

81. Jain T, Nikolopoulou EA, Xu Q, Qu A. Hypoxia inducible factor as a therapeutic target for atherosclerosis. Pharmacol Ther. 2018;183:22-33.

82. Lee J, Kang H. Hypoxia Promotes Vascular Smooth Muscle Cell Proliferation through microRNA-Mediated Suppression of Cyclin-Dependent Kinase Inhibitors. Cells. 2019;8(8).

83. Nie X, Laforest R, Elvington A, et al. PET/MRI of Hypoxic Atherosclerosis Using 64Cu-ATSM in a Rabbit Model. J Nucl Med. 2016;57(12):2006-2011.

84. Kumamoto M, Nakashima Y, Sueishi K. Intimal neovascularization in human coronary atherosclerosis: its origin and pathophysiological significance. Hum Pathol. 1995;26(4):450-456.

85. Sluimer JC, Kolodgie FD, Bijnens AP, et al. Thin-walled microvessels in human coronary atherosclerotic plaques show incomplete endothelial junctions relevance of compromised structural integrity for intraplaque microvascular leakage. $\mathrm{J} \mathrm{Am} \mathrm{Coll}$ Cardiol. 2009;53(17):1517-1527.

86. Kolodgie FD, Gold HK, Burke AP, et al. Intraplaque hemorrhage and progression of coronary atheroma. $N$ Engl $J$ Med. 2003;349(24):2316-2325.

87. Michel JB, Virmani R, Arbustini E, Pasterkamp G. Intraplaque haemorrhages as the trigger of plaque vulnerability. Eur Heart J 2011;32(16):1977-1985, 1985a, 1985b, 1985c.

88. Saam T, Hetterich H, Hoffmann V, et al. Meta-analysis and systematic review of the predictive value of carotid plaque hemorrhage on cerebrovascular events by magnetic resonance imaging. J Am Coll Cardiol. 2013;62(12):1081-1091.

89. Shioi A, Ikari Y. Plaque Calcification During Atherosclerosis Progression and Regression. J Atheroscler Thromb. 2018;25(4):294-303.

90. Balachandran K, Sucosky P, Yoganathan AP. Hemodynamics and mechanobiology of aortic valve inflammation and calcification. Int J Inflam. 2011;2011:263870.

91. Butcher JT, Penrod AM, García AJ, Nerem RM. Unique morphology and focal adhesion development of valvular endothelial cells in static and fluid flow environments. Arterioscler Thromb Vasc Biol. 2004;24(8):1429-1434.

92. Vesely I. Reconstruction of loads in the fibrosa and ventricularis of porcine aortic valves. ASAIO J. 1996;42(5):M739-746.

93. Schoen FJ. Evolving concepts of cardiac valve dynamics: the continuum of development, functional structure, pathobiology, and tissue engineering. Circulation. 2008;118(18):1864-1880.

94. Bashey RI, Torii S, Angrist A. Age-related collagen and elastin content of human heart valves. J Gerontol. 1967;22(2):203-208.

95. Otto CM, Kuusisto J, Reichenbach DD, Gown AM, O'Brien KD. Characterization of the early lesion of 'degenerative' valvular aortic stenosis. Histological and immunohistochemical studies. Circulation. 1994;90(2):844-853.

96. O'Brien KD, Reichenbach DD, Marcovina SM, Kuusisto J, Alpers CE, Otto CM. Apolipoproteins B, (a), and E accumulate in the morphologically early lesion of 'degenerative' valvular aortic stenosis. Arterioscler Thromb Vasc Biol. 1996;16(4):523-532.

97. Sucosky P, Balachandran K, Elhammali A, Jo H, Yoganathan AP. Altered shear stress stimulates upregulation of endothelial VCAM-1 and ICAM-1 in a BMP-4- and TGF-beta1-dependent pathway. Arterioscler Thromb Vasc Biol. 2009;29(2):254-260.

98. Abdelbaky A, Corsini E, Figueroa AL, et al. Early aortic valve inflammation precedes calcification: a longitudinal FDG-PET/CT study. Atherosclerosis. 2015;238(2):165-172.

99. Miller JD, Chu Y, Brooks RM, Richenbacher WE, Peña-Silva R, Heistad DD. Dysregulation of antioxidant mechanisms contributes to increased oxidative stress in calcific aortic valvular stenosis in humans. J Am Coll Cardiol. 2008;52(10):843-850.

100. Miller JD, Weiss RM, Serrano KM, et al. Lowering plasma cholesterol levels halts progression of aortic valve disease in mice. Circulation. 2009;119(20):2693-2701.

101. Weiss RM, Ohashi M, Miller JD, Young SG, Heistad DD. Calcific aortic valve stenosis in old hypercholesterolemic mice. Circulation. 2006;114(19):2065-2069.

102. Aikawa E, Nahrendorf M, Sosnovik D, et al. Multimodality molecular imaging identifies proteolytic and osteogenic activities in early aortic valve disease. Circulation. 2007;115(3):377-386

103. New SE, Goettsch C, Aikawa M, et al. Macrophage-derived matrix vesicles: an alternative novel mechanism for microcalcification in atherosclerotic plaques. Circ Res. 2013;113(1):72-77.

104. Blaser MC, Aikawa E. Roles and Regulation of Extracellular Vesicles in Cardiovascular Mineral Metabolism. Front Cardiovasc Med. 2018;5:187.

105. Rajamannan NM, Gersh B, Bonow RO. Calcific aortic stenosis: from bench to the bedside--emerging clinical and cellular concepts. Heart. 2003;89(7):801-805.

106. Osman N, Grande-Allen KJ, Ballinger ML, et al. Smad2-dependent glycosaminoglycan elongation in aortic valve interstitial cells enhances binding of LDL to proteoglycans. Cardiovasc Pathol. 2013;22(2):146-155.

107. Mohler ER, Gannon F, Reynolds C, Zimmerman R, Keane MG, Kaplan FS. Bone formation and inflammation in cardiac valves. Circulation. 2001;103(11):1522-1528.

108. Barnett HJ, Taylor DW, Eliasziw M, et al. Benefit of carotid endarterectomy in patients with symptomatic moderate or severe stenosis. North American Symptomatic Carotid Endarterectomy Trial Collaborators. N Engl J Med. 1998;339(20):1415-1425.

109. Nadareishvili ZG, Rothwell PM, Beletsky V, Pagniello A, Norris JW. Long-term risk of stroke and other vascular events in patients with asymptomatic carotid artery stenosis. Arch Neurol. 2002;59(7):1162-1166.

110. Otto CM. Calcific aortic stenosis--time to look more closely at the valve. N Engl J Med. 2008;359(13):1395-1398.

111. Randomised trial of endarterectomy for recently symptomatic carotid stenosis: final results of the MRC European Carotid Surgery Trial (ECST). Lancet. 1998;351(9113):1379-1387.

112. Oates CP, Naylor AR, Hartshorne T, et al. Joint recommendations for reporting carotid ultrasound investigations in the United Kingdom. European journal of vascular and endovascular surgery : the official journal of the European Society for Vascular Surgery. 2009;37(3):251-261.

113. Saba L, Yuan C, Hatsukami TS, et al. Carotid Artery Wall Imaging: Perspective and Guidelines from the ASNR Vessel Wall Imaging Study Group and Expert Consensus Recommendations of the American Society of Neuroradiology. AJNR Am $J$ Neuroradiol. 2018;39(2):E9-e31.

114. Gray-Weale AC, Graham JC, Burnett JR, Byrne K, Lusby RJ. Carotid artery atheroma: comparison of preoperative B-mode ultrasound appearance with carotid endarterectomy specimen pathology. J Cardiovasc Surg (Torino). 1988;29(6):676-681.

115. Goncalves I, Lindholm MW, Pedro LM, et al. Elastin and calcium rather than collagen or lipid content are associated with echogenicity of human carotid plaques. Stroke. 2004;35(12):2795-2800.

116. Huibers A, de Borst GJ, Wan S, et al. Non-invasive Carotid Artery Imaging to Identify the Vulnerable Plaque: Current Status and Future Goals. European journal of vascular and endovascular surgery : the official journal of the European Society for Vascular Surgery. 2015;50(5):563-572.

117. Sheahan M, Ma X, Paik D, et al. Atherosclerotic Plaque Tissue: Noninvasive Quantitative Assessment of Characteristics with Software-aided Measurements from Conventional CT Angiography. Radiology. 2018;286(2):622-631. 
118. de Weert TT, Ouhlous M, Meijering E, et al. In vivo characterization and quantification of atherosclerotic carotid plaque components with multidetector computed tomography and histopathological correlation. Arterioscler Thromb Vasc Biol. 2006;26(10):2366-2372.

119. de Weert TT, Ouhlous M, Zondervan PE, et al. In vitro characterization of atherosclerotic carotid plaque with multidetector computed tomography and histopathological correlation. Eur Radiol. 2005;15(9):1906-1914.

120. Detrano R, Guerci AD, Carr JJ, et al. Coronary calcium as a predictor of coronary events in four racial or ethnic groups. $N$ Engl $J$ Med. 2008;358(13):1336-1345.

121. Greenland P, Alpert JS, Beller GA, et al. 2010 ACCF/AHA guideline for assessment of cardiovascular risk in asymptomatic adults: a report of the American College of Cardiology Foundation/American Heart Association Task Force on Practice Guidelines. J Am Coll Cardiol. 2010;56(25):e50-103.

122. Taylor AJ, Bindeman J, Feuerstein I, Cao F, Brazaitis M, O'Malley PG. Coronary calcium independently predicts incident premature coronary heart disease over measured cardiovascular risk factors: mean three-year outcomes in the Prospective Army Coronary Calcium (PACC) project. J Am Coll Cardiol. 2005;46(5):807-814.

123. Houslay ES, Cowell SJ, Prescott RJ, et al. Progressive coronary calcification despite intensive lipid-lowering treatment: a randomised controlled trial. Heart. 2006;92(9):1207-1212.

124. Vazquez-Figueroa JG, Rinehart S, Qian Z, et al. Prospective validation that vulnerable plaque associated with major adverse outcomes have larger plaque volume, less dense calcium, and more non-calcified plaque by quantitative, three-dimensional measurements using intravascular ultrasound with radiofrequency backscatter analysis : results from the ATLANTA I Study. $J$ Cardiovasc Transl Res. 2013;6(5):762-771.

125. Trelles M, Eberhardt KM, Buchholz M, et al. CTA for screening of complicated atherosclerotic carotid plaque--American Heart Association type VI lesions as defined by MRI. AJNR Am J Neuroradiol. 2013;34(12):2331-2337.

126. $\mathrm{Xu} \mathrm{D}$, Hippe DS, Underhill HR, et al. Prediction of high-risk plaque development and plaque progression with the carotid atherosclerosis score. JACC Cardiovasc Imaging. 2014;7(4):366-373.

127. Baumgartner H, Hung J, Bermejo J, et al. Echocardiographic assessment of valve stenosis: EAE/ASE recommendations for clinical practice. J Am Soc Echocardiogr. 2009;22(1):1-23; quiz 101-102.

128. Baumgartner H, Falk V, Bax JJ, et al. 2017 ESC/EACTS Guidelines for the management of valvular heart disease. Eur Heart J. 2017;38(36):2739-2791.

129. Pibarot P, Clavel MA. Management of paradoxical low-flow, low-gradient aortic stenosis: need for an integrated approach, including assessment of symptoms, hypertension, and stenosis severity. J Am Coll Cardiol. 2015;65(1):67-71.

130. Messika-Zeitoun D, Aubry MC, Detaint D, et al. Evaluation and clinical implications of aortic valve calcification measured by electron-beam computed tomography. Circulation. 2004;110(3):356-362.

131. Linde L, Carter-Storch R, Christensen NL, et al. Sex differences in aortic valve calcification in severe aortic valve stenosis: association between computer tomography assessed calcification and valvular calcium concentrations. Eur Heart $J$ Cardiovasc Imaging. 2021;22(5):581-588.

132. Sritharen Y, Enriquez-Sarano M, Schaff HV, Casaclang-Verzosa G, Miller JD. Pathophysiology of Aortic Valve Stenosis: Is It Both Fibrocalcific and Sex Specific? Physiology (Bethesda). 2017;32(3):182-196.

133. Schaar JA, Muller JE, Falk E, et al. Terminology for high-risk and vulnerable coronary artery plaques. Report of a meeting on the vulnerable plaque, June 17 and 18, 2003, Santorini, Greece. Eur Heart J. 2004;25(12):1077-1082.

134. Arbab-Zadeh A, Fuster V. From Detecting the Vulnerable Plaque to Managing the Vulnerable Patient: JACC State-of-the-Art Review. J Am Coll Cardiol. 2019;74(12):1582-1593.

135. Matic LP, Jesus Iglesias M, Vesterlund M, et al. Novel Multiomics Profiling of Human Carotid Atherosclerotic Plaques and Plasma Reveals Biliverdin Reductase B as a Marker of Intraplaque Hemorrhage. JACC Basic Transl Sci. 2018;3(4):464-480.

136. Karlof E, Seime T, Dias N, et al. Correlation of computed tomography with carotid plaque transcriptomes associates calcification with lesion-stabilization. Atherosclerosis. 2019.

137. Nahon JE, Hoekstra M, Van Eck M. Total body proteoglycan 4 (Prg4) deficiency increases atherosclerosis susceptibility in apolipoprotein E knockout and low-density lipoprotein receptor knockout mice. Atherosclerosis. 2018;278:315-316.

138. Hultman K, Edsfeldt A, Bjorkbacka H, et al. Cartilage Oligomeric Matrix Protein Associates With a Vulnerable Plaque Phenotype in Human Atherosclerotic Plaques. Stroke. 2019;50(11):3289-3292.

139. Kapustin AN, Chatrou ML, Drozdov I, et al. Vascular smooth muscle cell calcification is mediated by regulated exosome secretion. Circ Res. 2015;116(8):1312-1323.

140. Willems BA, Furmanik M, Caron MMJ, et al. Ucma/GRP inhibits phosphate-induced vascular smooth muscle cell calcification via SMAD-dependent BMP signalling. Scientific reports. 2018;8(1):4961.

141. Edsberg LE, Crowgey EL, Osborn PM, Wyffels JT. A survey of proteomic biomarkers for heterotopic ossification in blood serum. J Orthop Surg Res. 2017;12(1):69.

142. Kapustin AN, Schoppet M, Schurgers LJ, et al. Prothrombin Loading of Vascular Smooth Muscle Cell-Derived Exosomes Regulates Coagulation and Calcification. Arterioscler Thromb Vasc Biol. 2017;37(3):e22-e32.

143. Nicoll R, Henein MY. Arterial calcification: friend or foe? Int J Cardiol. 2013;167(2):322-327.

144. Cowell SJ, Newby DE, Prescott RJ, et al. A randomized trial of intensive lipid-lowering therapy in calcific aortic stenosis. $N$ Engl J Med. 2005;352(23):2389-2397.

145. Chan KL, Teo K, Dumesnil JG, Ni A, Tam J, Investigators A. Effect of Lipid lowering with rosuvastatin on progression of aortic stenosis: results of the aortic stenosis progression observation: measuring effects of rosuvastatin (ASTRONOMER) trial. Circulation. 2010;121(2):306-314.

146. Rossebø AB, Pedersen TR, Boman K, et al. Intensive lipid lowering with simvastatin and ezetimibe in aortic stenosis. $N$ Engl $J$ Med. 2008;359(13):1343-1356.

147. Tsimikas S, Gordts PLSM, Nora C, Yeang C, Witztum JL. Statin therapy increases lipoprotein(a) levels. Eur Heart J. 2020;41(24):2275-2284.

148. Saremi A, Bahn G, Reaven PD. Progression of vascular calcification is increased with statin use in the Veterans Affairs Diabetes Trial (VADT). Diabetes care. 2012;35(11):2390-2392.

149. Perisic L, Aldi S, Sun Y, et al. Gene expression signatures, pathways and networks in carotid atherosclerosis. Journal of internal medicine. 2016;279(3):293-308.

150. Bittner V. Pleiotropic Effects of PCSK9 (Proprotein Convertase Subtilisin/Kexin Type 9) Inhibitors? Circulation. 2016;134(22):1695-1696.

151. Ridker PM, Everett BM, Thuren T, et al. Antiinflammatory Therapy with Canakinumab for Atherosclerotic Disease. $N$ Engl $J$ Med. 2017;377(12):1119-1131.

152. Nidorf SM, Fiolet ATL, Mosterd A, et al. Colchicine in Patients with Chronic Coronary Disease. $N$ Engl $J$ Med. 2020;383(19):1838-1847.

153. Koh KK. Letter by Koh Regarding Article, "Pleiotropic Effects of PCSK9 (Proprotein Convertase Subtilisin/Kexin Type 9) Inhibitors?". Circulation. 2017;135(17):e1006-e1007. 
154. Barnett HJ, Meldrum HE, Eliasziw M. The dilemma of surgical treatment for patients with asymptomatic carotid disease. Ann Intern Med. 1995;123(9):723-725.

155. Selim MH, Molina CA. Medical versus surgical treatment of asymptomatic carotid stenosis: the ever-changing nature of evidence-based medicine. Stroke. 2011;42(4):1156-1157.

156. Leon MB, Smith CR, Mack M, et al. Transcatheter aortic-valve implantation for aortic stenosis in patients who cannot undergo surgery. N Engl J Med. 2010;363(17):1597-1607.

157. Majesky MW. Developmental basis of vascular smooth muscle diversity. Arterioscler Thromb Vasc Biol. 2007;27(6):1248-1258.

158. Enos WF, Holmes RH, Beyer J. Coronary disease among United States soldiers killed in action in Korea; preliminary report. $J$ Am Med Assoc. 1953;152(12):1090-1093.

159. Aikawa E, Whittaker P, Farber M, et al. Human semilunar cardiac valve remodeling by activated cells from fetus to adult: implications for postnatal adaptation, pathology, and tissue engineering. Circulation. 2006;113(10):1344-1352.

160. Liu AC, Joag VR, Gotlieb AI. The emerging role of valve interstitial cell phenotypes in regulating heart valve pathobiology. The American journal of pathology. 2007;171(5):1407-1418.

161. Mosse PR, Campbell GR, Wang ZL, Campbell JH. Smooth muscle phenotypic expression in human carotid arteries. I. Comparison of cells from diffuse intimal thickenings adjacent to atheromatous plaques with those of the media. Lab Invest. 1985;53(5):556-562.

162. Gomez D, Owens GK. Smooth muscle cell phenotypic switching in atherosclerosis. Cardiovascular research. 2012;95(2):156164.

163. Latif N, Sarathchandra P, Chester AH, Yacoub MH. Expression of smooth muscle cell markers and co-activators in calcified aortic valves. Eur Heart $J$. 2015;36(21):1335-1345.

164. Porras AM, van Engeland NC, Marchbanks E, et al. Robust Generation of Quiescent Porcine Valvular Interstitial Cell Cultures. J Am Heart Assoc. 2017;6(3).

165. Wang Z, Wang DZ, Pipes GC, Olson EN. Myocardin is a master regulator of smooth muscle gene expression. Proceedings of the National Academy of Sciences of the United States of America. 2003;100(12):7129-7134.

166. Perisic Matic L, Rykaczewska U, Razuvaev A, et al. Phenotypic Modulation of Smooth Muscle Cells in Atherosclerosis Is Associated With Downregulation of LMOD1, SYNPO2, PDLIM7, PLN, and SYNM. Arterioscler Thromb Vasc Biol. 2016;36(9):1947-1961.

167. Desmouliere A, Gabbiani G. The cytoskeleton of arterial smooth muscle cells during human and experimental atheromatosis. Kidney Int Suppl. 1992;37:S87-89.

168. Kocher O, Gabbiani F, Gabbiani G, et al. Phenotypic features of smooth muscle cells during the evolution of experimental carotid artery intimal thickening. Biochemical and morphologic studies. Lab Invest. 1991;65(4):459-470.

169. Yap C, Mieremet A, de Vries CJM, Micha D, de Waard V. Six Shades of Vascular Smooth Muscle Cells Illuminated by KLF4 (Krüppel-Like Factor 4). Arterioscler Thromb Vasc Biol. 2021:ATVBAHA121316600.

170. Santoro R, Scaini D, Severino LU, et al. Activation of human aortic valve interstitial cells by local stiffness involves YAPdependent transcriptional signaling. Biomaterials. 2018;181:268-279.

171. Speer MY, Yang HY, Brabb T, et al. Smooth muscle cells give rise to osteochondrogenic precursors and chondrocytes in calcifying arteries. Circ Res. 2009;104(6):733-741.

172. Steitz SA, Speer MY, Curinga G, et al. Smooth muscle cell phenotypic transition associated with calcification: upregulation of Cbfa1 and downregulation of smooth muscle lineage markers. Circ Res. 2001;89(12):1147-1154.

173. Chappell J, Harman JL, Narasimhan VM, et al. Extensive Proliferation of a Subset of Differentiated, yet Plastic, Medial Vascular Smooth Muscle Cells Contributes to Neointimal Formation in Mouse Injury and Atherosclerosis Models. Circ Res. 2016;119(12):1313-1323.

174. Shankman LS, Gomez D, Cherepanova OA, et al. KLF4-dependent phenotypic modulation of smooth muscle cells has a key role in atherosclerotic plaque pathogenesis. Nature medicine. 2015;21(6):628-637.

175. Alves RD, Eijken M, van de Peppel J, van Leeuwen JP. Calcifying vascular smooth muscle cells and osteoblasts: independent cell types exhibiting extracellular matrix and biomineralization-related mimicries. BMC Genomics. 2014;15:965.

176. Kaden JJ, Bickelhaupt S, Grobholz R, et al. Expression of bone sialoprotein and bone morphogenetic protein-2 in calcific aortic stenosis. J Heart Valve Dis. 2004;13(4):560-566.

177. Nadlonek NA, Weyant MJ, Yu JA, et al. Radiation induces osteogenesis in human aortic valve interstitial cells. $J$ Thorac Cardiovasc Surg. 2012;144(6):1466-1470.

178. Shanahan CM, Cary NR, Salisbury JR, Proudfoot D, Weissberg PL, Edmonds ME. Medial localization of mineralizationregulating proteins in association with Monckeberg's sclerosis: evidence for smooth muscle cell-mediated vascular calcification. Circulation. 1999;100(21):2168-2176.

179. Tyson KL, Reynolds JL, McNair R, Zhang Q, Weissberg PL, Shanahan CM. Osteo/chondrocytic transcription factors and their target genes exhibit distinct patterns of expression in human arterial calcification. Arterioscler Thromb Vasc Biol. 2003;23(3):489-494.

180. Bobryshev YV. Transdifferentiation of smooth muscle cells into chondrocytes in atherosclerotic arteries in situ: implications for diffuse intimal calcification. J Pathol. 2005;205(5):641-650.

181. Bostrom KI, Yao J, Guihard PJ, Blazquez-Medela AM, Yao Y. Endothelial-mesenchymal transition in atherosclerotic lesion calcification. Atherosclerosis. 2016;253:124-127.

182. Schulick AH, Taylor AJ, Zuo W, et al. Overexpression of transforming growth factor beta1 in arterial endothelium causes hyperplasia, apoptosis, and cartilaginous metaplasia. Proceedings of the National Academy of Sciences of the United States of America. 1998;95(12):6983-6988.

183. Speer MY, Li X, Hiremath PG, Giachelli CM. Runx2/Cbfa1, but not loss of myocardin, is required for smooth muscle cell lineage reprogramming toward osteochondrogenesis. J Cell Biochem. 2010;110(4):935-947.

184. Xu Z, Ji G, Shen J, Wang X, Zhou J, Li L. SOX9 and myocardin counteract each other in regulating vascular smooth muscle cell differentiation. Biochemical and biophysical research communications. 2012;422(2):285-290.

185. Chen D, Zhao M, Mundy GR. Bone morphogenetic proteins. Growth Factors. 2004;22(4):233-241.

186. Chen G, Deng C, Li YP. TGF-beta and BMP signaling in osteoblast differentiation and bone formation. Int $J$ Biol Sci. 2012;8(2):272-288.

187. Worssam MD, Jørgensen HF. Mechanisms of vascular smooth muscle cell investment and phenotypic diversification in vascular diseases. Biochem Soc Trans. 2021.

188. Bakhshian Nik A, Hutcheson JD, Aikawa E. Extracellular Vesicles As Mediators of Cardiovascular Calcification. Front Cardiovasc Med. 2017;4:78.

189. Doria A, Gatto M, Punzi L. Autophagy in human health and disease. N Engl J Med. 2013;368(19):1845.

190. Dai XY, Zhao MM, Cai Y, et al. Phosphate-induced autophagy counteracts vascular calcification by reducing matrix vesicle release. Kidney international. 2013;83(6):1042-1051.

191. Deng XS, Meng X, Venardos N, et al. Autophagy negatively regulates pro-osteogenic activity in human aortic valve interstitial cells. J Surg Res. 2017;218:285-291. 
192. Carracedo M, Persson O, Saliba-Gustafsson P, et al. Upregulated Autophagy in Calcific Aortic Valve Stenosis Confers Protection of Valvular Interstitial Cells. Int J Mol Sci. 2019;20(6).

193. Murphy WA, Nedden Dz D, Gostner P, Knapp R, Recheis W, Seidler H. The iceman: discovery and imaging. Radiology. 2003;226(3):614-629.

194. Ruffer MA, Rietti A. On osseous lesions in ancient Egyptians. The Journal of Pathology and Bacteriology. 1911;16(1):439-465.

195. Burke AP, Weber DK, Kolodgie FD, Farb A, Taylor AJ, Virmani R. Pathophysiology of calcium deposition in coronary arteries. Herz. 2001;26(4):239-244.

196. Nikolaou K, Flohr T, Knez A, et al. Advances in cardiac CT imaging: 64-slice scanner. Int J Cardiovasc Imaging. 2004;20(6):535-540.

197. McEvoy JW, Blaha MJ, Defilippis AP, et al. Coronary artery calcium progression: an important clinical measurement? A review of published reports. J Am Coll Cardiol. 2010;56(20):1613-1622.

198. Hutcheson JD, Goettsch C, Bertazzo S, et al. Genesis and growth of extracellular-vesicle-derived microcalcification in atherosclerotic plaques. Nat Mater. 2016;15(3):335-343.

199. Cardoso L, Kelly-Arnold A, Maldonado N, Laudier D, Weinbaum S. Effect of tissue properties, shape and orientation of microcalcifications on vulnerable cap stability using different hyperelastic constitutive models. J Biomech. 2014;47(4):870-877.

200. Virmani R, Burke AP, Kolodgie FD, Farb A. Pathology of the thin-cap fibroatheroma: a type of vulnerable plaque. $J$ Interv Cardiol. 2003;16(3):267-272.

201. Kwee RM. Systematic review on the association between calcification in carotid plaques and clinical ischemic symptoms. Journal of vascular surgery. 2010;51(4):1015-1025.

202. Davaine JM, Quillard T, Brion R, et al. Osteoprotegerin, Pericytes and Bone-Like Vascular Calcification Are Associated with Carotid Plaque Stability. In: PLoS One. Vol 9.2014.

203. Huang H, Virmani R, Younis H, Burke AP, Kamm RD, Lee RT. The impact of calcification on the biomechanical stability of atherosclerotic plaques. Circulation. 2001;103(8):1051-1056.

204. Li ZY, Howarth S, Tang T, Graves M, J UK-I, Gillard JH. Does calcium deposition play a role in the stability of atheroma? Location may be the key. Cerebrovasc Dis. 2007;24(5):452-459.

205. Shaalan WE, Cheng H, Gewertz B, et al. Degree of carotid plaque calcification in relation to symptomatic outcome and plaque inflammation. Journal of vascular surgery. 2004;40(2):262-269.

206. Imoto K, Hiro T, Fujii T, et al. Longitudinal structural determinants of atherosclerotic plaque vulnerability: a computational analysis of stress distribution using vessel models and three-dimensional intravascular ultrasound imaging. J Am Coll Cardiol. 2005;46(8):1507-1515.

207. Hoshino T, Chow LA, Hsu JJ, et al. Mechanical stress analysis of a rigid inclusion in distensible material: a model of atherosclerotic calcification and plaque vulnerability. Am J Physiol Heart Circ Physiol. 2009;297(2):H802-810.

208. Criqui MH, Denenberg JO, Ix JH, et al. Calcium density of coronary artery plaque and risk of incident cardiovascular events. JAMA. 2014;311(3):271-278.

209. Reynolds JL, Joannides AJ, Skepper JN, et al. Human vascular smooth muscle cells undergo vesicle-mediated calcification in response to changes in extracellular calcium and phosphate concentrations: a potential mechanism for accelerated vascular calcification in ESRD. Journal of the American Society of Nephrology : JASN. 2004;15(11):2857-2867.

210. Johnson RC, Leopold JA, Loscalzo J. Vascular calcification: pathobiological mechanisms and clinical implications. Circ Res. 2006;99(10):1044-1059.

211. Raggi P, Genest J, Giles JT, et al. Role of inflammation in the pathogenesis of atherosclerosis and therapeutic interventions. Atherosclerosis. 2018;276:98-108.

212. Perrotta I, Perri E. Ultrastructural, Elemental and Mineralogical Analysis of Vascular Calcification in Atherosclerosis. Microsc Microanal. 2017;23(5):1030-1039.

213. Kelly-Arnold A, Maldonado N, Laudier D, Aikawa E, Cardoso L, Weinbaum S. Revised microcalcification hypothesis for fibrous cap rupture in human coronary arteries. Proceedings of the National Academy of Sciences of the United States of America. 2013;110(26):10741-10746.

214. Lin ME, Chen TM, Wallingford MC, et al. Runx2 Deletion in Smooth muscle Cells Inhibits Vascular Osteochondrogenesis and Calcification but not Atherosclerotic Lesion Formation. Cardiovascular research. 2016.

215. Hosaka N, Mizobuchi M, Ogata H, et al. Elastin degradation accelerates phosphate-induced mineralization of vascular smooth muscle cells. Calcif Tissue Int. 2009;85(6):523-529.

216. Alexopoulos N, Raggi P. Calcification in atherosclerosis. Nat Rev Cardiol. 2009;6(11):681-688.

217. Doherty TM, Fitzpatrick LA, Inoue D, et al. Molecular, endocrine, and genetic mechanisms of arterial calcification. Endocr Rev. 2004;25(4):629-672.

218. Aikawa E, Nahrendorf M, Figueiredo JL, et al. Osteogenesis associates with inflammation in early-stage atherosclerosis evaluated by molecular imaging in vivo. Circulation. 2007;116(24):2841-2850.

219. Hunt JL, Fairman R, Mitchell ME, et al. Bone formation in carotid plaques: a clinicopathological study. Stroke. 2002;33(5):1214-1219.

220. Taylor J, Butcher M, Zeadin M, Politano A, Shaughnessy SG. Oxidized low-density lipoprotein promotes osteoblast differentiation in primary cultures of vascular smooth muscle cells by up-regulating Osterix expression in an Msx2-dependent manner. J Cell Biochem. 2011;112(2):581-588.

221. Kapustin AN, Shanahan CM. Osteocalcin: a novel vascular metabolic and osteoinductive factor? Arterioscler Thromb Vasc Biol. 2011;31(10):2169-2171.

222. Bobryshev YV, Orekhov AN, Sobenin I, Chistiakov DA. Role of bone-type tissue-nonspecific alkaline phosphatase and PHOSPO1 in vascular calcification. Curr Pharm Des. 2014;20(37):5821-5828.

223. Chinetti-Gbaguidi G, Daoudi M, Rosa M, et al. Human Alternative Macrophages Populate Calcified Areas of Atherosclerotic Lesions and Display Impaired RANKL-Induced Osteoclastic Bone Resorption Activity. Circ Res. 2017;121(1):19-30.

224. Fukumoto S, Martin TJ. Bone as an endocrine organ. Trends in endocrinology and metabolism: TEM. 2009;20(5):230-236.

225. Gutierrez O, Isakova T, Rhee E, et al. Fibroblast growth factor-23 mitigates hyperphosphatemia but accentuates calcitriol deficiency in chronic kidney disease. Journal of the American Society of Nephrology : JASN. 2005;16(7):2205-2215.

226. Farrow EG, White KE. Recent advances in renal phosphate handling. Nat Rev Nephrol. 2010;6(4):207-217.

227. Hu MC, Shi M, Zhang J, et al. Klotho deficiency causes vascular calcification in chronic kidney disease. Journal of the American Society of Nephrology : JASN. 2011;22(1):124-136.

228. Saito Y, Yamagishi T, Nakamura T, et al. Klotho protein protects against endothelial dysfunction. Biochemical and biophysical research communications. 1998;248(2):324-329.

229. Jono S, Peinado C, Giachelli CM. Phosphorylation of osteopontin is required for inhibition of vascular smooth muscle cell calcification. The Journal of biological chemistry. 2000;275(26):20197-20203.

230. Paloian NJ, Leaf EM, Giachelli CM. Osteopontin protects against high phosphate-induced nephrocalcinosis and vascular calcification. Kidney international. 2016;89(5):1027-1036. 
231. Scatena M, Liaw L, Giachelli CM. Osteopontin: a multifunctional molecule regulating chronic inflammation and vascular disease. Arterioscler Thromb Vasc Biol. 2007;27(11):2302-2309.

232. A1-Aly Z, Shao JS, Lai CF, et al. Aortic Msx2-Wnt calcification cascade is regulated by TNF-alpha-dependent signals in diabetic Ldlr-/- mice. Arterioscler Thromb Vasc Biol. 2007;27(12):2589-2596.

233. Son BK, Akishita M, Iijima K, et al. Adiponectin antagonizes stimulatory effect of tumor necrosis factor-alpha on vascular smooth muscle cell calcification: regulation of growth arrest-specific gene 6-mediated survival pathway by adenosine 5'monophosphate-activated protein kinase. Endocrinology. 2008;149(4):1646-1653.

234. Idelevich A, Rais Y, Monsonego-Ornan E. Bone Gla protein increases HIF-1alpha-dependent glucose metabolism and induces cartilage and vascular calcification. Arterioscler Thromb Vasc Biol. 2011;31(9):e55-71.

235. Tsiridis E, Upadhyay N, Giannoudis P. Molecular aspects of fracture healing: which are the important molecules? Injury. 2007;38 Suppl 1:S11-25.

236. Einhorn TA, Majeska RJ, Rush EB, Levine PM, Horowitz MC. The expression of cytokine activity by fracture callus. $J$ Bone Miner Res. 1995;10(8):1272-1281.

237. Gerstenfeld LC, Cho TJ, Kon T, et al. Impaired fracture healing in the absence of TNF-alpha signaling: the role of TNF-alpha in endochondral cartilage resorption. J Bone Miner Res. 2003;18(9):1584-1592.

238. Wright HL, McCarthy HS, Middleton J, Marshall MJ. RANK, RANKL and osteoprotegerin in bone biology and disease. Curr Rev Musculoskelet Med. 2009;2(1):56-64.

239. Ramji DP, Davies TS. Cytokines in atherosclerosis: Key players in all stages of disease and promising therapeutic targets. In: Cytokine Growth Factor Rev. Vol 26.2015:673-685.

240. McKellar GE, McCarey DW, Sattar N, McInnes IB. Role for TNF in atherosclerosis? Lessons from autoimmune disease. Nat Rev Cardiol. 2009;6(6):410-417.

241. Di Bartolo BA, Cartland SP, Harith HH, Bobryshev YV, Schoppet M, Kavurma MM. TRAIL-deficiency accelerates vascular calcification in atherosclerosis via modulation of RANKL. PloS one. 2013;8(9):e74211.

242. Mackie EJ, Ahmed YA, Tatarczuch L, Chen KS, Mirams M. Endochondral ossification: how cartilage is converted into bone in the developing skeleton. Int J Biochem Cell Biol. 2008;40(1):46-62.

243. Goldring MB, Tsuchimochi K, Ijiri K. The control of chondrogenesis. J Cell Biochem. 2006;97(1):33-44.

244. Arnold MA, Kim Y, Czubryt MP, et al. MEF2C transcription factor controls chondrocyte hypertrophy and bone development. Dev Cell. 2007;12(3):377-389.

245. Nakashima K, Zhou X, Kunkel G, et al. The novel zinc finger-containing transcription factor osterix is required for osteoblast differentiation and bone formation. Cell. 2002;108(1):17-29.

246. Oh JH, Park SY, de Crombrugghe B, Kim JE. Chondrocyte-specific ablation of Osterix leads to impaired endochondral ossification. Biochemical and biophysical research communications. 2012;418(4):634-640.

247. Lian JB, Stein GS, Javed A, et al. Networks and hubs for the transcriptional control of osteoblastogenesis. Rev Endocr Metab Disord. 2006;7(1-2):1-16.

248. Goldring SR, Goldring MB. Eating bone or adding it: the Wnt pathway decides. In: Nat Med. Vol 13. United States2007:133134.

249. Mansson-Broberg A, Rodin S, Bulatovic I, et al. Wnt/beta-Catenin Stimulation and Laminins Support Cardiovascular Cell Progenitor Expansion from Human Fetal Cardiac Mesenchymal Stromal Cells. Stem Cell Reports. 2016;6(4):607-617.

250. Bartoli-Leonard F, Wilkinson FL, Langford-Smith AWW, Alexander MY, Weston R. The Interplay of SIRT1 and Wnt Signaling in Vascular Calcification. Front Cardiovasc Med. 2018;5.

251. Albanese I, Khan K, Barratt B, Al-Kindi H, Schwertani A. Atherosclerotic Calcification: Wnt Is the Hint. In: J Am Heart Assoc. Vol 7.2018.

252. Prisell PT, Edwall D, Lindblad JB, Levinovitz A, Norstedt G. Expression of insulin-like growth factors during bone induction in rat. Calcif Tissue Int. 1993;53(3):201-205.

253. Beneit N, Martin-Ventura JL, Rubio-Longas C, et al. Potential role of insulin receptor isoforms and IGF receptors in plaque instability of human and experimental atherosclerosis. Cardiovasc Diabetol. 2018;17(1):31.

254. Razuvaev A, Henderson B, Girnita L, et al. The cyclolignan picropodophyllin attenuates intimal hyperplasia after rat carotid balloon injury by blocking insulin-like growth factor-1 receptor signaling. Journal of vascular surgery. 2007;46(1):108-115.

255. Ahmed YA, Tatarczuch L, Pagel CN, Davies HM, Mirams M, Mackie EJ. Hypertrophy and physiological death of equine chondrocytes in vitro. Equine Vet J. 2007;39(6):546-552.

256. Chang X, Zhang B, Lihua L, Feng Z. T3 inhibits the calcification of vascular smooth muscle cells and the potential mechanism. Am J Transl Res. 2016;8(11):4694-4704.

257. Derwall M, Malhotra R, Lai CS, et al. Inhibition of bone morphogenetic protein signaling reduces vascular calcification and atherosclerosis. Arterioscler Thromb Vasc Biol. 2012;32(3):613-622.

258. Yonemitsu R, Tokunaga T, Shukunami C, et al. Fibroblast Growth Factor 2 Enhances Tendon-to-Bone Healing in a Rat Rotator Cuff Repair of Chronic Tears. Am J Sports Med. 2019;47(7):1701-1712.

259. Che J, Okigaki M, Takahashi T, et al. Endothelial FGF receptor signaling accelerates atherosclerosis. Am J Physiol Heart Circ Physiol. 2011;300(1):H154-161.

260. Chen PY, Simons M. FGF-TGF $\beta$ dialogues, endothelial cell to mesenchymal transition, and atherosclerosis. Curr Opin Lipidol. 2018;29(5):397-403.

261. Lynch P, Lee TC, Fallavollita JA, Canty JM, Jr., Suzuki G. Intracoronary administration of AdvFGF-5 (fibroblast growth factor5) ameliorates left ventricular dysfunction and prevents myocyte loss in swine with developing collaterals and ischemic cardiomyopathy. Circulation. 2007;116(11 Suppl):I71-76.

262. Iozzo RV, Schaefer L. Proteoglycan form and function: A comprehensive nomenclature of proteoglycans. Matrix Biol. 2015;42:11-55.

263. Douaiher J, Succar J, Lancerotto L, et al. Development of mast cells and importance of their tryptase and chymase serine proteases in inflammation and wound healing. Adv Immunol. 2014;122:211-252.

264. Bernfield M, Götte M, Park PW, et al. Functions of cell surface heparan sulfate proteoglycans. Annu Rev Biochem. 1999;68:729777.

265. Choi Y, Chung H, Jung H, Couchman JR, Oh ES. Syndecans as cell surface receptors: Unique structure equates with functional diversity. Matrix Biol. 2011;30(2):93-99.

266. Christianson HC, Belting M. Heparan sulfate proteoglycan as a cell-surface endocytosis receptor. Matrix Biol. 2014;35:51-55.

267. Malmström A, Bartolini B, Thelin MA, Pacheco B, Maccarana M. Iduronic acid in chondroitin/dermatan sulfate: biosynthesis and biological function. The journal of histochemistry and cytochemistry : official journal of the Histochemistry Society. 2012;60(12):916-925.

268. Andersson-Sjöland A, Hallgren O, Rolandsson S, et al. Versican in inflammation and tissue remodeling: the impact on lung disorders. Glycobiology. 2015;25(3):243-251.

269. Chang YT, Chan CK, Eriksson I, et al. Versican accumulates in vascular lesions in pulmonary arterial hypertension. Pulm Circ. 2016;6(3):347-359. 
270. Fuki IV, Kuhn KM, Lomazov IR, et al. The syndecan family of proteoglycans. Novel receptors mediating internalization of atherogenic lipoproteins in vitro. J Clin Invest. 1997;100(6):1611-1622.

271. Koyama N, Kinsella MG, Wight TN, Hedin U, Clowes AW. Heparan sulfate proteoglycans mediate a potent inhibitory signal for migration of vascular smooth muscle cells. Circ Res. 1998;83(3):305-313.

272. Teng YH, Aquino RS, Park PW. Molecular functions of syndecan-1 in disease. Matrix Biol. 2012;31(1):3-16.

273. Westergren-Thorsson G, Sime P, Jordana M, Gauldie J, Särnstrand B, Malmström A. Lung fibroblast clones from normal and fibrotic subjects differ in hyaluronan and decorin production and rate of proliferation. Int J Biochem Cell Biol. 2004;36(8):15731584 .

274. Lord MS, Chuang CY, Melrose J, Davies MJ, Iozzo RV, Whitelock JM. The role of vascular-derived perlecan in modulating cell adhesion, proliferation and growth factor signaling. Matrix Biol. 2014;35:112-122.

275. Yamashita Y, Nakada S, Yoshihara T, et al. Perlecan, a heparan sulfate proteoglycan, regulates systemic metabolism with dynamic changes in adipose tissue and skeletal muscle. Scientific reports. 2018;8(1):7766.

276. Baker AB, Ettenson DS, Jonas M, Nugent MA, Iozzo RV, Edelman ER. Endothelial cells provide feedback control for vascular remodeling through a mechanosensitive autocrine TGF-beta signaling pathway. Circ Res. 2008;103(3):289-297.

277. Wilusz RE, Defrate LE, Guilak F. A biomechanical role for perlecan in the pericellular matrix of articular cartilage. Matrix Biol. 2012;31(6):320-327.

278. Kim SM, Huh JW, Kim EY, et al. Endothelial dysfunction induces atherosclerosis: increased aggrecan expression promotes apoptosis in vascular smooth muscle cells. BMB Rep. 2019;52(2):145-150.

279. Kiani C, Chen L, Wu YJ, Yee AJ, Yang BB. Structure and function of aggrecan. Cell Res. 2002;12(1):19-32.

280. Hayes AJ, Melrose J. Aggrecan, the Primary Weight-Bearing Cartilage Proteoglycan, Has Context-Dependent, Cell-Directive Properties in Embryonic Development and Neurogenesis: Aggrecan Glycan Side Chain Modifications Convey Interactive Biodiversity. Biomolecules. 2020;10(9).

281. Tabas I, Williams KJ, Borén J. Subendothelial lipoprotein retention as the initiating process in atherosclerosis: update and therapeutic implications. Circulation. 2007;116(16):1832-1844.

282. Ali L, Flowers SA, Jin C, Bennet EP, Ekwall AK, Karlsson NG. The O-glycomap of lubricin, a novel mucin responsible for joint lubrication, identified by site-specific glycopeptide analysis. Mol Cell Proteomics. 2014;13(12):3396-3409.

283. Abubacker S, Dorosz SG, Ponjevic D, Jay GD, Matyas JR, Schmidt TA. Full-Length Recombinant Human Proteoglycan 4 Interacts with Hyaluronan to Provide Cartilage Boundary Lubrication. Ann Biomed Eng. 2016;44(4):1128-1137.

284. Majd SE, Kuijer R, Kowitsch A, Groth T, Schmidt TA, Sharma PK. Both hyaluronan and collagen type II keep proteoglycan 4 (lubricin) at the cartilage surface in a condition that provides low friction during boundary lubrication. Langmuir. 2014;30(48):14566-14572.

285. Ikegawa S, Sano M, Koshizuka Y, Nakamura Y. Isolation, characterization and mapping of the mouse and human PRG4 (proteoglycan 4) genes. Cytogenet Cell Genet. 2000;90(3-4):291-297.

286. Flannery CR, Hughes CE, Schumacher BL, et al. Articular cartilage superficial zone protein (SZP) is homologous to megakaryocyte stimulating factor precursor and Is a multifunctional proteoglycan with potential growth-promoting, cytoprotective, and lubricating properties in cartilage metabolism. Biochemical and biophysical research communications. 1999;254(3):535-541.

287. Jay GD, Tantravahi U, Britt DE, Barrach HJ, Cha CJ. Homology of lubricin and superficial zone protein (SZP): products of megakaryocyte stimulating factor (MSF) gene expression by human synovial fibroblasts and articular chondrocytes localized to chromosome 1q25. J Orthop Res. 2001;19(4):677-687.

288. Al-Sharif A, Jamal M, Zhang LX, et al. Lubricin/Proteoglycan 4 Binding to CD44 Receptor: A Mechanism of the Suppression of Proinflammatory Cytokine-Induced Synoviocyte Proliferation by Lubricin. Arthritis Rheumatol. 2015;67(6):1503-1513.

289. Alquraini A, Garguilo S, D'Souza G, et al. The interaction of lubricin/proteoglycan 4 (PRG4) with toll-like receptors 2 and 4: an anti-inflammatory role of PRG4 in synovial fluid. Arthritis Res Ther. 2015;17:353.

290. Elsaid KA, Zhang L, Shaman Z, Patel C, Schmidt TA, Jay GD. The impact of early intra-articular administration of interleukin-1 receptor antagonist on lubricin metabolism and cartilage degeneration in an anterior cruciate ligament transection model. Osteoarthritis and cartilage. 2015;23(1):114-121.

291. Iqbal SM, Leonard C, Regmi SC, et al. Lubricin/Proteoglycan 4 binds to and regulates the activity of Toll-Like Receptors In Vitro. Scientific reports. 2016;6:18910.

292. Qadri M, Jay GD, Zhang LX, et al. Recombinant human proteoglycan-4 reduces phagocytosis of urate crystals and downstream nuclear factor kappa B and inflammasome activation and production of cytokines and chemokines in human and murine macrophages. Arthritis Res Ther. 2018;20(1):192.

293. Qadri M, Jay GD, Zhang LX, Richendrfer H, Schmidt TA, Elsaid KA. Proteoglycan-4 regulates fibroblast to myofibroblast transition and expression of fibrotic genes in the synovium. Arthritis Res Ther. 2020;22(1):113.

294. Qadri M, Jay GD, Zhang LX, Schmidt TA, Totonchy J, Elsaid KA. Proteoglycan-4 is an essential regulator of synovial macrophage polarization and inflammatory macrophage joint infiltration. Arthritis Res Ther. 2021;23(1):241.

295. Sun Y, Berger EJ, Zhao C, An KN, Amadio PC, Jay G. Mapping lubricin in canine musculoskeletal tissues. Connect Tissue Res. 2006;47(4):215-221.

296. Rees SG, Davies JR, Tudor D, et al. Immunolocalisation and expression of proteoglycan 4 (cartilage superficial zone proteoglycan) in tendon. Matrix Biol. 2002;21(7):593-602.

297. Jin C, Ekwall AK, Bylund J, et al. Human synovial lubricin expresses sialyl Lewis $\mathrm{x}$ determinant and has L-selectin ligand activity. The Journal of biological chemistry. 2012;287(43):35922-35933.

298. Cui Z, Xu C, Li X, Song J, Yu B. Treatment with recombinant lubricin attenuates osteoarthritis by positive feedback loop between articular cartilage and subchondral bone in ovariectomized rats. Bone. 2015;74:37-47.

299. Naylor AR, Rothwell PM, Bell PR. Overview of the principal results and secondary analyses from the European and North American randomised trials of endarterectomy for symptomatic carotid stenosis. European journal of vascular and endovascular surgery : the official journal of the European Society for Vascular Surgery. 2003;26(2):115-129.

300. Virmani R, Kolodgie FD, Burke AP, Farb A, Schwartz SM. Lessons from sudden coronary death: a comprehensive morphological classification scheme for atherosclerotic lesions. Arterioscler Thromb Vasc Biol. 2000;20(5):1262-1275.

301. Fang Q, Boas DA. Tetrahedral mesh generation from volumetric binary and grayscale images. IEEE International Symposium on Biomedical Imaging: From Nano to Macro; 2009.

302. Heiland VM, Forsell C, Roy J, Hedin U, Gasser TC. Identification of carotid plaque tissue properties using an experimentalnumerical approach. J Mech Behav Biomed Mater. 2013;27:226-238.

303. Ishibashi S, Brown MS, Goldstein JL, Gerard RD, Hammer RE, Herz J. Hypercholesterolemia in low density lipoprotein receptor knockout mice and its reversal by adenovirus-mediated gene delivery. J Clin Invest. 1993;92(2):883-893.

304. Zhang SH, Reddick RL, Piedrahita JA, Maeda N. Spontaneous hypercholesterolemia and arterial lesions in mice lacking apolipoprotein E. Science. 1992;258(5081):468-471.

305. Getz GS, Reardon CA. Do the Apoe-/- and Ldlr-/- Mice Yield the Same Insight on Atherogenesis? Arterioscler Thromb Vasc Biol. 2016;36(9):1734-1741. 
306. Coleman R, Hayek T, Keidar S, Aviram M. A mouse model for human atherosclerosis: long-term histopathological study of lesion development in the aortic arch of apolipoprotein E-deficient (E0) mice. Acta Histochem. 2006;108(6):415-424

307. Herring BP, Hoggatt AM, Burlak C, Offermanns S. Previously differentiated medial vascular smooth muscle cells contribute to neointima formation following vascular injury. Vascular cell. 2014;6:21.

308. Eken SM, Jin H, Chernogubova E, et al. MicroRNA-210 Enhances Fibrous Cap Stability in Advanced Atherosclerotic Lesions. Circ Res. 2017;120(4):633-644.

309. Lindner V, Fingerle J, Reidy MA. Mouse model of arterial injury. Circ Res. 1993;73(5):792-796.

310. Luo G, Ducy P, McKee MD, et al. Spontaneous calcification of arteries and cartilage in mice lacking matrix GLA protein. Nature. 1997;386(6620):78-81.

311. Moe SM. Vascular calcification: the three-hit model. Journal of the American Society of Nephrology : JASN. 2009;20(6):11621164.

312. Kaesler N, Verhulst A, De Maré A, et al. Sclerostin deficiency modifies the development of CKD-MBD in mice. Bone. 2018;107:115-123.

313. Aikawa E, Aikawa M, Libby P, et al. Arterial and aortic valve calcification abolished by elastolytic cathepsin S deficiency in chronic renal disease. Circulation. 2009;119(13):1785-1794.

314. Suda T, Takahashi F, Takahashi N. Bone effects of vitamin D - Discrepancies between in vivo and in vitro studies. Archives of biochemistry and biophysics. 2012;523(1):22-29.

315. Razzaque MS. The dualistic role of vitamin D in vascular calcifications. Kidney international. 2011;79(7):708-714.

316. Schurgers LJ, Joosen IA, Laufer EM, et al. Vitamin K-antagonists accelerate atherosclerotic calcification and induce a vulnerable plaque phenotype. PloS one. 2012;7(8):e43229.

317. Cloyd KL, El-Hamamsy I, Boonrungsiman S, et al. Characterization of porcine aortic valvular interstitial cell 'calcified' nodules. PloS one. 2012;7(10):e48154.

318. Shioi A, Nishizawa Y, Jono S, Koyama H, Hosoi M, Morii H. Beta-glycerophosphate accelerates calcification in cultured bovine vascular smooth muscle cells. Arterioscler Thromb Vasc Biol. 1995;15(11):2003-2009.

319. Giachelli CM. Vascular calcification: in vitro evidence for the role of inorganic phosphate. Journal of the American Society of Nephrology : JASN. 2003;14(9 Suppl 4):S300-304.

320. Villa-Bellosta R, Millan A, Sorribas V. Role of calcium-phosphate deposition in vascular smooth muscle cell calcification. Am $J$ Physiol Cell Physiol. 2011;300(1):C210-220.

321. Cahalane RM, Barrett HE, O'Brien JM, Kavanagh EG, Moloney MA, Walsh MT. Relating the mechanical properties of atherosclerotic calcification to radiographic density: A nanoindentation approach. Acta Biomater. 2018;80:228-236.

322. Lehoux S, Castier Y, Tedgui A. Molecular mechanisms of the vascular responses to haemodynamic forces. Journal of internal medicine. 2006;259(4):381-392.

323. O'Rourke M. Mechanical principles in arterial disease. Hypertension. 1995;26(1):2-9.

324. Su BY, Shontz KM, Flavahan NA, Nowicki PT. The effect of phenotype on mechanical stretch-induced vascular smooth muscle cell apoptosis. J Vasc Res. 2006;43(3):229-237.

325. Mantella LE, Quan A, Verma S. Variability in vascular smooth muscle cell stretch-induced responses in 2D culture. Vascular cell. 2015;7:7.

326. MOVAT HZ. Demonstration of all connective tissue elements in a single section; pentachrome stains. AMA Arch Pathol. 1955;60(3):289-295

327. Peeters W, Moll FL, Vink A, et al. Collagenase matrix metalloproteinase- 8 expressed in atherosclerotic carotid plaques is associated with systemic cardiovascular outcome. Eur Heart J. 2011;32(18):2314-2325.

328. Zernecke A, Weber C. Chemokines in atherosclerosis: proceedings resumed. Arterioscler Thromb Vasc Biol. 2014;34(4):742750 .

329. Asciutto G, Dias NV, Edsfeldt A, et al. Low elastin content of carotid plaques is associated with increased risk of ipsilateral stroke. PloS one. 2015;10(3):e0121086.

330. Yang X, Chen L, Xu X, Li C, Huang C, Deng CX. TGF-beta/Smad3 signals repress chondrocyte hypertrophic differentiation and are required for maintaining articular cartilage. J Cell Biol. 2001;153(1):35-46.

331. Cheng P, Wirka RC, Kim JB, et al. Smad3 Regulates Smooth Muscle Cell Fate and Governs Adverse Remodeling and Calcification of Atherosclerotic Plaque2020, bioRxiv.

332. Bi W, Deng JM, Zhang Z, Behringer RR, de Crombrugghe B. Sox9 is required for cartilage formation. Nat Genet. 1999;22(1):85-89.

333. Lin ME, Chen T, Leaf EM, Speer MY, Giachelli CM. Runx2 Expression in Smooth Muscle Cells Is Required for Arterial Medial Calcification in Mice. The American journal of pathology. 2015;185(7):1958-1969.

334. Nahon JE, Hoekstra M, Havik SR, et al. Proteoglycan 4 regulates macrophage function without altering atherosclerotic lesion formation in a murine bone marrow-specific deletion model. Atherosclerosis. 2018;274:120-127.

335. Chavez RD, Coricor G, Perez J, Seo HS, Serra R. SOX9 protein is stabilized by TGF-beta and regulates PAPSS2 mRNA expression in chondrocytes. Osteoarthritis and cartilage. 2017;25(2):332-340.

336. Milewicz DM, Trybus KM, Guo DC, et al. Altered Smooth Muscle Cell Force Generation as a Driver of Thoracic Aortic Aneurysms and Dissections. Arterioscler Thromb Vasc Biol. 2017;37(1):26-34.

337. WHO. World Health Organization, Global Health Estimates Summary Tables: Projection of Deaths by Cause, Age \& Sex. https://www.who.int/data/gho/data/themes/mortality-and-global-health-estimates/ghe-leading-causes-of-death. Accessed 2021, 2021.

338. EHN. European Heart Network, European Cardiovascular Disease Statistics 2017. https://ehnheart.org/cvd-statistics.html. Accessed 2021.

339. Rhee DK, Marcelino J, Al-Mayouf S, et al. Consequences of disease-causing mutations on lubricin protein synthesis, secretion, and post-translational processing. The Journal of biological chemistry. 2005;280(35):31325-31332.

340. Kuhn TC, Knobel J, Burkert-Rettenmaier S, et al. Secretome Analysis of Cardiomyocytes Identifies PCSK6 (Proprotein Convertase Subtilisin/Kexin Type 6) as a Novel Player in Cardiac Remodeling After Myocardial Infarction. Circulation. 2020;141(20):1628-1644.

341. Perisic L, Hedin E, Razuvaev A, et al. Profiling of atherosclerotic lesions by gene and tissue microarrays reveals PCSK6 as a novel protease in unstable carotid atherosclerosis. Arterioscler Thromb Vasc Biol. 2013;33(10):2432-2443.

342. Rykaczewska U, Suur BE, Röhl S, et al. PCSK6 Is a Key Protease in the Control of Smooth Muscle Cell Function in Vascular Remodeling. Circ Res. 2020;126(5):571-585. 



\section{CURRICULUM VITAE}

\section{About the author:}

Till Seime was born on January $30^{\text {th }}, 1989$ in Saalfeld (Saale), Germany. He grew up in Jena, Germany, where he completed his secondary education at the Carl-Zeiss-Gymnasium, a high school specialized on natural sciences, following his childhood dream to become a researcher. After an internship at the Max-Planck-Institute of Biogeochemistry, he moved to Innsbruck, Austria, to study Engineering-, Environmental- \& Biotechnology at the Management Center Innsbruck (MCI), with a focus on the utilization of algae for molecular farming. Till completed his Bachelor's degree including an exchange semester at the Indian Institute of Technology in Madras

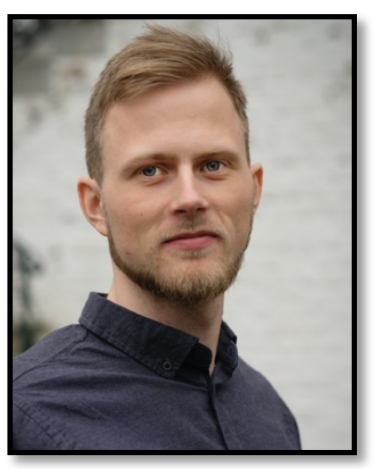
(IITM), Chennai, India, in 2012 and proceeded at MCI with the Master's program in biotechnology. Instead of a career plan in pharmaceutical industry, he decided to focus on medical and regenerative research and completed his master's degree 2014 at the Orthopedic Research and Biotechnology Unit, Children's Hospital Westmead, Sydney, Australia, specializing in bone regeneration and fracture repair under the supervision of Assoc. Prof. Aaron Schindeler. Thereafter, he returned to Innsbruck to work for two years as a biomedical scientist in molecular oncology at the Daniel Swarovski Research Laboratory, Department of Visceral-, Transplantation- and Thoracic Surgery, supervised by Prof. Jakob Troppmair. In 2017, he was accepted for PhD studies at Karolinska Institutet, Stockholm, Sweden, as part of the EU Horizon 2020 International Network for Training on Risks of Vascular Intimal Calcification and roads to Regression of Cardiovascular Disease (INTRICARE) Marie-Curie program. His research has been focused on the role of smooth muscle cells in calcification of atherosclerotic plaques utilizing human bio-banks, primary human cell cultures, rodent in vivo models and in silico analysis. The $\mathrm{PhD}$ project was performed under the supervision of Prof. Ulf Hedin and Assoc. Prof. Ljubica Perisic Matic at Karolinska Institutet, Department of Molecular Medicine and Surgery, Division of Vascular Surgery as well as Prof. Leon J. Schurgers and Prof. Chris Reutelingsperger at Maastricht University, Department of Biochemistry, Cardiovascular Research Institute Maastricht, The Netherlands. The scientific output of this double degree project between Karolinska Institutet and Maastricht University is summarized in the presented thesis entitled "The role of smooth muscle cells in calcification of atherosclerotic plaques".

\section{Publications:}

Seime T, Akbulut AC, Liljeqvist ML, Siika A, Jin H, Winski G, van Gorp RH, Karlöf E, Lengquist M, Buckler AJ, Kronqvist M, Waring OJ, Lindeman JHN, Biessen EAL, Maegdefessel L, Razuvaev A, Schurgers LJ, Hedin U, Matic L. Proteoglycan 4 Modulates Osteogenic Smooth Muscle Cell Differentiation during Vascular Remodeling and Intimal Calcification. Cells. 2021 May 21;10(6):1276.

Röhl S, Suur BE, Lengquist M, Seime T, Caidahl K, Hedin U, Arner A, Matic L, Razuvaev A. Lack of PCSK6 Increases Flow-Mediated Outward Arterial Remodeling in Mice. Cells. 2020 Apr 18;9(4):1009.

Artiach $G^{*}$, Carracedo $M^{*}$, Seime T, Plunde O, Laguna-Fernandez A, Matic L, FrancoCereceda A, Bäck M. Proteoglycan 4 is Increased in Human Calcified Aortic Valves and Enhances Valvular Interstitial Cell Calcification. Cells. 2020 Mar 11;9(3):684. (*equal contribution) 
Röhl S*, Rykaczewska U*, Seime T*, Suur BE, Diez MG, Gådin JR, Gainullina A, Sergushichev AA, Wirka R, Lengquist M, Kronqvist M, Bergman O, Odeberg J, Lindeman JHN, Quertermous T, Hamsten A, Eriksson P, Hedin U, Razuvaev A, Matic LP. Transcriptomic profiling of experimental arterial injury reveals new mechanisms and temporal dynamics in vascular healing response. JVS Vasc Sci. 2020 Feb 7;1:13-27. (*equal contribution)

Karlöf E, Seime T, Dias N, Lengquist M, Witasp A, Almqvist H, Kronqvist M, Gådin JR, Odeberg J, Maegdefessel L, Stenvinkel P, Matic LP, Hedin U. Correlation of computed tomography with carotid plaque transcriptomes associates calcification with lesionstabilization. Atherosclerosis. 2019 Sep;288:175-185.

Hatzl S, Geiger O, Kuepper MK, Caraffini V, Seime T, Furlan T, Nussbaumer E, Wieser R, Pichler M, Scheideler M, Nowek K, Jongen-Lavrencic M, Quehenberger F, Wölfler A, Troppmair J, Sill H, Zebisch A. Increased Expression of miR-23a Mediates a Loss of Expression in the RAF Kinase Inhibitor Protein RKIP. Cancer Res. 2016 Jun 15;76(12):364454. doi: 10.1158/0008-5472.CAN-15-3049. Epub 2016 Apr 15.

Seime T, Kolind M, Mikulec K, Summers MA, Cantrill L, Little DG, Schindeler A. Inducible cell labeling and lineage tracking during fracture repair. Dev Growth Differ. 2015 Jan;57(1):1023. doi: 10.1111/dgd.12184. Epub 2014 Nov 11.

\section{Other manuscripts:}

Seime T, van Wanrooji M, Karlöf E, Johansson S, Matic L, Gasser TC, Hedin U. Biomechanical assessment of macro-calcification in human carotid atherosclerosis and its impact on smooth muscle cell phenotype. Manuscript

Skenteris NT, Seime T, Witasp A, Karlöf E, Wasilewski G, Heuschkel M, Jaminon A, Oduor L, Dzhanaev R, Kronqvist M, Lengquist M, Peeters F, Söderberg M, Hultgren R, Roy J, Maegdefessel L, Arnardottir H, Bengtsson E, Goncalves I, Quertermous T, Goettsch C, Stenvinkel P, Schurgers L, Matic L. Osteomodulin attenuates smooth muscle cell osteogenic transition in vascular calcification. Clin Transl Med. In Revision

Zhou Z, Collado A, Sun C, Tratsiakovich Y, Mahdi A, Winter H, Chernogubova E, Seime T, Narayanan S, Jiao T, Jin H, Alvarsson M, Zheng X, Yang J, Hedin U, Catrina SB, Maegdefessel L, Pernow J. Downregulation of Erythrocyte miR-210 Induces Endothelial Dysfunction in Type 2 Diabetes. Diabetes. In Revision

\section{Presentations at international scientific conferences:}

"Biomechanical assessment of carotid intimal macro-calcification and its impact on smooth muscle cell phenotype" (Poster, Virtual) European Atherosclerosis Society Congress (EAS), Helsinki, Finland, May $30^{\text {th }}-$ June $2^{\text {nd }}, 2021$

"Proteoglycan 4 modulates osteogenic smooth muscle cell differentiation during vascular remodeling and intimal calcification" (Oral, Virtual) European Society for Vascular Surgery Translational Meeting (ESVS), Krakow, Poland, September $29^{\text {th }}-$ October $2^{\text {nd }}, 2020$

"Proteoglycan 4 is a key factor in chondrogenic smooth muscle cell differentiation during vascular remodeling \& intimal calcification" (Poster, Virtual) International Vascular Biology Meeting (IVBM), Seoul, South Korea, September $9^{\text {th }}-12^{\text {th }}, 2020$

"Proteoglycan 4 is implicated in osteo-chondrogenic smooth muscle cell differentiation during vascular remodeling and intimal calcification" (Poster) Atherosclerosis, Thrombosis and Vascular Biology Meeting (ATVB), Boston, USA, May $14^{\text {th }}-16^{\text {th }} 2019$ 
"Proteoglycan 4 is implicated in osteo-chondrogenic smooth muscle cell differentiation during vascular remodeling and intimal calcification" (Oral) Vascular Research Initiatives Conference (VRIC), Boston, USA, May 13 ${ }^{\text {th }}, 2019$

"Macro-calcification associates to lesion-stabilization in advanced carotid plaques" (Poster) International Vascular Biology Meeting (IVBM), Helsinki, Finland, June $3^{\text {rd }}-7^{\text {th }}, 2018$

\section{Grants:}

Svenska Sällskapet för Medicinsk Forskning (SSMF) travel grant, 2020: "Investigation of Proteoglycan 4 as a mediator of inflammation and micro-calcification in atherosclerosis"

Hjärt-Lungfonden (HLF) travel grant, 2019: "Proteoglycan 4 is implicated in osteochondrogenic smooth muscle cell differentiation during vascular remodeling and intimal calcification"

Karolinska Institutet (KI) travel grant, 2018: "Proteoglycan 4 is associated to calcification in advanced atherosclerotic plaques"

Hjärt-Lungfonden (HLF) travel grant, 2018: "Macro-calcification associates to lesionstabilization in advanced carotid plaques" 